PRISCILA PAIVA PORTERO

\begin{abstract}
AVALIAÇÃO INSTRUMENTAL DA CORRESPONDÊNCIA DE COR DE RESINAS COMPOSTAS EM FUNÇÃO DE ESCALA DE REFERÊNCIA, TONALIDADE, COMPOSIÇÃO E ESPESSURA
\end{abstract}


UNESP - UNIVERSIDADE ESTADUAL PAULISTA

FACULDADE DE ODONTOLOGIA DE ARARAQUARA

PRISCILA PAIVA PORTERO

\title{
AVALIAÇÃO INSTRUMENTAL DA CORRESPONDÊNCIA DE COR DE RESINAS COMPOSTAS EM FUNÇÃO DE ESCALA DE REFERÊNCIA, TONALIDADE, COMPOSIÇÃO E ESPESSURA
}

\begin{abstract}
Tese apresentada ao Programa de PósGraduação em Ciências Odontológicas Área de Dentística Restauradora, da Faculdade de Odontologia de Araraquara da Universidade Estadual Paulista, para obtenção do título de Doutor em Dentística Restauradora.

Orientador: Prof. Dr. Osmir Batista de Oliveira Júnior
\end{abstract}




\section{Portero, Priscila Paiva}

Avaliação instrumental da correspondência de cor de resinas compostas em função de escala de referência, tonalidade, composição e espessura / Priscila Paiva Portero . - Araraquara: [s.n.], 2009.

137 f. ; $30 \mathrm{~cm}$.

Tese (Doutorado) - Universidade Estadual Paulista, Faculdade de Odontologia

Orientador : Prof. Dr. Osmir Batista de Oliveira Júnior

\section{Cor 2. Dente 3. Espectrofotômetros 4. Resinas compostas} I. Título

Ficha catalográfica elaborada pela Bibliotecária Marley C. Chiusoli Montagnoli, CRB-8/5646 Serviço Técnico de Biblioteca e Documentação da Faculdade de Odontologia de Araraquara / UNESP 
PRISCILA PAIVA PORTERO

\title{
AVALIAÇÃO DA CORRESPONDÊNCIA DE COR DE RESINAS COMPOSTAS EM FUNÇÃO DE ESCALA DE REFERÊNCIA, TONALIDADE, COMPOSIÇÃO E ESPESSURA
}

\author{
Comissão Julgadora
}

TESE PARA OBTENÇÃO DO GRAU DE DOUTOR

\author{
Presidente e Orientador: Prof. Dr. Osmir Batista de Oliveira Júnior \\ 2 Examinador: Prof. Dr. Edson Alves Campos \\ 3 Examinador: Prof. Dra. Silvio José Mauro \\ 4 Examinador: Profa. Dra. Ângela Scarparo Caldo-Teixeira \\ 5 Examinador: Profa. Dra. Osnara Maria Mongruel Gomes
}

Araraquara, 26 de março de 2010. 


\title{
Dados Curriculares
}

\author{
Nascimento \\ 18 de agosto de 1979 \\ Filiação \\ Leopoldino Portero Cardoso \\ Célia Guiomar Paiva Portero \\ Naturalidade \\ Birigui - SP \\ $1997 / 2000$ \\ Curso de Graduação em Odontologia na Faculdade \\ Odontologia da Fundação Educacional de Barretos - FEB, Barretos \\ $-\mathrm{SP}$
}

$2001 / 2002$

Curso de Especialização em Dentística Restauradora, na Faculdade de Odontologia de Araçatuba - Universidade Estadual Paulista Júlio de Mesquita Filho, Araçatuba - SP.

$2002 / 2003$

Curso de Aperfeiçoamento em Dentística e suas relações com procedimentos gengivais, na Faculdade de Odontologia de Araçatuba - Universidade Estadual Paulista Júlio de Mesquita Filho, Araçatuba - SP.

$2003 / 2003$

Curso de Aperfeiçoamento em Periodontia no Núcleo de Educação Continuada em Odontologia - NEC, Araçatuba - SP.

$2004 / 2006$

Curso de Pós Graduação em Clínica Integrada, nível Mestrado, na Faculdade de Odontologia de Ponta Grossa - Universidade Estadual de Ponta Grossa, Ponta Grossa - PR.

$2006 / 2006$

Curso de Aperfeiçoamento em Reabilitação oral associada a implantes I, na Faculdade de Odontologia de Araraquara Universidade Estadual Paulista Júlio de Mesquita Filho, Araraquara $-\mathrm{SP}$.

$2006 / 2007$

Curso de Aperfeiçoamento em Reabilitação oral associada a implantes II, na Faculdade de Odontologia de Araraquara Universidade Estadual Paulista Júlio de Mesquita Filho, Araraquara $-\mathrm{SP}$.

$2006 / 2009$

Curso de Pós Graduação em Dentística Restauradora, nível Doutorado, na Faculdade de Odontologia de Araraquara Universidade Estadual Paulista Júlio de Mesquita Filho, Araraquara $-\mathrm{SP}$.

$2007 / 2008$

Curso de Aperfeiçoamento em Reabilitação oral associada a implantes, na Faculdade de Odontologia de Araraquara Universidade Estadual Paulista Júlio de Mesquita Filho, Araraquara $-\mathrm{SP}$.

Professora Assistente da disciplina de Dentística Restauradora da Faculdade de Odontologia da Universidade Federal Fluminense / Pólo de Nova Friburgo (FOUF/NF). 


\section{Dedico Este Trabalho}




\section{DEDICATÓRIA}

Dedico

a Deus, porque sempre me amparou em todos os momentos da minha vida: "É certo que, no bom sentido, a confiança nas próprias forças tornanos capazes de realizar coisas que não podemos fazer, quando duvidamos de nós mesmos..." "A fé robusta confere a perseverança, a energia e os recursos necessários para a vitória sobre os obstáculos, tanto nas pequenas quanto nas grandes coisas".

(Emmanuel)

Aos meus pais Leopoldino e Célia, por sempre fazerem tudo por mim, muitas vezes tornando possível o "impossível" para que meus sonhos pudessem se concretizar, pelo apoio incondicional, por sempre estarem ao meu lado e por serem um exemplo de retidão de caráter, esforço e força de vontade. Amo vocês e muito obrigada por tudo! Essa vitória é de vocês!

"Deus criou os pais porque não poderia estar em todos os lugares ao mesmo tempo!"

(Autor desconhecido)

À minha irmã Camila, pela convivência e pelos anos compartilhados.

Ao meu cunhado Marco Aurélio, pelas palavras de alento, pela amizade e ajuda em todos os momentos. Obrigada por tudo!

À minha avó Corina, pelo amor, carinho conselhos e pelas incansáveis orações para que tudo desse certo e para que eu voltasse logo e com saúde para casa. 
Agradecimentos 


\section{AGRADECIMENTOS}

Ao Prof. Dr. Osmir Batista de Oliveira Júnior pela amizade, pela convivência, pela orientação, pelo incentivo a esta pesquisa, pelos conhecimentos transmitidos e por acreditar e apoiar a realização deste trabalho.

À Simone Xavier Silva Costa pela amizade, companhia e incentivo em todos os momentos, não tenho palavras para expressar a gratidão por você. "O afeto é como a luz do meio-dia, não necessita da presença do outro para manifestar-se, a separação também é ilusória, pois tudo está unido no universo: nossos espíritos estarão sempre juntos" (Isabel Allende). Foi uma bênção tê-la conhecido e fazer parte da sua vida nestes quatro anos!

À Carol Chaves pela amizade sincera, pelo apoio, pelo incentivo, pelos conselhos e por sempre ter uma palavra de carinho e consolo nos momentos difíceis. Agradeço também por todos os momentos compartilhados, por abrir as portas de seu lar e pela ajuda na correção dos artigos. Muito obrigada por tudo amiga! Você está guardada em meu coração!

Ao Alexandre Bier e à Anne Buss Becker pela amizade, companhia, pela alegria, auto-astral e pelos maravilhosos momentos em que passamos juntos, que estarão sempre em minha memória e em meu coração.

Aos companheiros de doutorado: Benícia Carolina Ribeiro, Desirée Rossato, Milko Cortez, Renato Queiroz, Simone Xavier Silva 
Costa e Ubiracy Gaião saibam que guardo cada um de vocês em meu coração.

À Angela Scarparo Caldo Teixeira (Ló) pelo carinho, disposição, confiança, pela amizade, pelo apoio e pela grande ajuda prestada para a finalização desta etapa. Não tenho palavras para dizerIhe o quanto sou grata!

Ao Fernando Florez pela ajuda nos experimentos no laboratório da Universidade Federal de São Carlos (UFSCar) e pelos momentos compartilhados.

À Juliana Boaventura pela amizade, pela convivência e pela disposição em todos os momentos.

Ao João Paulo Lima (JP) pela alegria, pela disposição em ajudar e pelos momentos compartilhados.

Ao Darlon Martins, Adriano Augusto, Martin Kreidler, Luís Rafael Calixto, William, Matheus Bandéca, Gislaine e Ângela Amaral pelos bons momentos e pela amizade.

À Universidade Estadual Paulista Júlio de Mesquita Filho Câmpus Araraquara, na pessoa do Ilmo. Reitor Herman Jacobus Cornelis Voorwald e vice-reitor Dr. Julio Cezar Durigan, pela oportunidade de estudar nesta instituição.

Ao diretor desta Faculdade Prof. Dr. José Cláudio Martins Segalla pela oportunidade de estudar nesta instituição, pela simpatia e prestatividade sempre demonstradas. 
À Coordenação de Aperfeiçoamento de Nível Superior (CAPES) do Ministério da Educação e Cultura, pelo apoio financeiro para a realização deste Doutorado.

Aos professores do Programa de Pós-Graduação da área de Dentística Restauradora desta Instituição: José Roberto Cury Saad, Leonor de Castro Monteiro Loffredo, Marcelo Ferrarezzi de Andrade, Maria Salete Machado Candido (In Memorian), Osmir Batista de Oliveira Júnior e Sizenando de Toledo Porto Neto, pelos ensinamentos e pela convivência.

A todos os professores do Programa de Pós-Graduação pelos conhecimentos transmitidos.

Aos funcionários da clínica nas pessoas de Marinho, Dona Cida (loira) e Dona Cida (morena) pela amizade e pela prestatividade, e apoio em todos os meus momentos de sufoco.

Ao Vanderlei, ao Marquinho, à Creuza, à Martinha e à Mara, pela prestatividade, amizade e pelo incentivo.

À Ivolclar Vivadent, na pessoa de Camila Madruga pela doação de alguns dos materiais utilizados nesta pesquisa.

Aos funcionários da biblioteca, em especial à Ceres, Marley e Maria Helena pela prestatividade, sempre com cordialidade, no atendimento e esclarecimento das dúvidas. 
Ao Prof. Dr. Romeu Magnani pelo auxílio na análise dos resultados desta pesquisa e pela disposição e compreensão a mim dispensadas.

Ao Prof. Dr. Vanderlei Salvador Bagnato pela orientação nos experimentos realizados na Universidade Federal de São Carlos (UFSCar).

A todos os amigos e alunos da Faculdade de Odontologia de Araraquara - UNESP.

A todos que indiretamente contribuíram para o desenvolvimento deste trabalho.

MUITO OBRIGADA! 


\section{NÃ O IMPORTA O QUE \\ FIZERAM DE NÓS. \\ IMPORTA, ISTO SIM, O QUE \\ FIZEMOS DO QUE FOI FEITO \\ DE NÓS!}

Wil I ia n Sha keSpeare 
Sumário 


\section{SUMÁRIO}

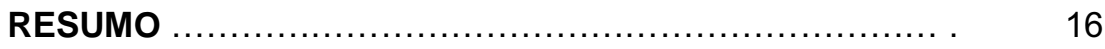

ABSTRACT

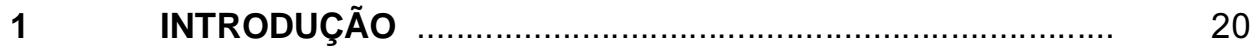

2 REVISÃO DA LITERATURA .............................................. 28

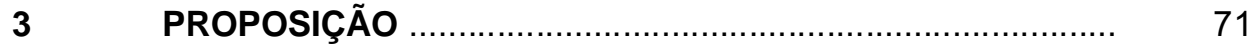

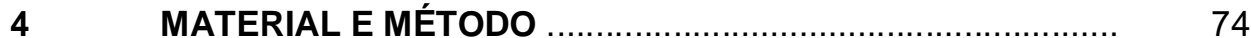

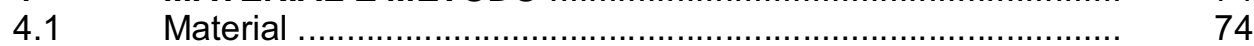

4.1.1 Escalas de referência de cor............................................ $\quad 74$

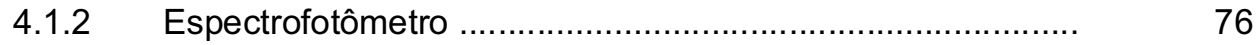

4.1.3 Resinas compostas ......................................................

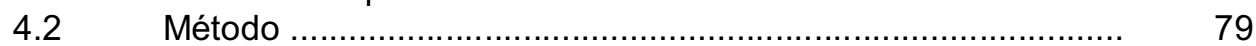

4.2.1 Determinação da correspondência de cor .............................. 79

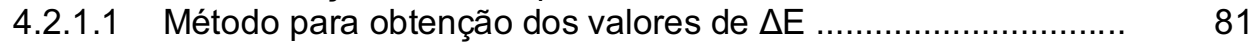

4.2.3 Critérios de correspondência de cor ............................ 84

4.3 Experimento 1 - Correspondência de cor entre as tonalidades de diferentes marcas comerciais de escalas de referência de cor segundo o espectrofotômetro Vita Easyshade ${ }^{\circledR}$.

4.4 Experimento 2 - Correspondência de cor entre resinas compostas e escalas de referência de cor em função de tonalidade, composição e espessura ..................................... $\quad 85$

$4.5 \quad$ Análise Estatística ......................................................... 91

$5 \quad$ RESULTADO …................................................................. 93

5.1 Experimento 1 - Correspondência de cor entre as tonalidades de diferentes marcas comerciais de escalas de referência de cor segundo o espectrofotômetro Vita Easyshade ${ }^{\circledR}$

5.2 Experimento 2 - Correspondência de cor entre resinas compostas e escalas de referência de cor em função de: tonalidade, composição e espessura 
Resumo 
Portero PP. Avaliação instrumental da correspondência de cor de resinas compostas em função de escala de referência, tonalidade, composição e espessura [Tese de doutorado]. Araraquara: Faculdade de Odontologia da UNESP; 2010.

\section{RESUMO}

Este estudo avaliou por meio do espectrofotômetro de reflectância Vita Easyshade ${ }^{\circledR}$ a correspondência de cor entre 3 escalas de referência [Vita Lumin Vacuum (Vita Classical), Vitapan 3D-Master e Chromascop] Experimento 1, e a correspondência de cor de 2 resinas compostas (4 Seasons ${ }^{\circledR}$ e Filtek $^{T M}$ Supreme XT), nas tonalidades A2E e B2E, em relação a essas 3 escalas de referência por diferirem em sua composição - Experimento 2. Foram confeccionados 5 corpos-de-prova com dimensões de $8 \mathrm{~mm}$ de diâmetro e 10 diferentes espessuras $(0,2$ a 2,0 $\mathrm{mm}$ ) fotoativados pelo aparelho LED Ultrablue $\left(440 \mathrm{~mW} / \mathrm{cm}^{2}\right)$. Em cada amostra foram realizadas 3 mensurações de cor e os valores de diferença de tonalidade $(\Delta \mathrm{E})$ obtidos, analisados por regressão quadrática. Os resultados do experimento 1 demonstraram que: houve pouca correspondência de cor entre as tonalidades das 3 escalas avaliadas; no experimento 2, a resina composta nano-aglomerada (Filtek ${ }^{\mathrm{TM}}$ Supreme XT) apresentou maior correspondência de cor com as 3 escalas de referência analisadas, quando comparada à resina 4 Seasons ${ }^{\circledR}$; não houve correspondência de cor entre as resinas compostas avaliadas; as espessuras de resinas compostas que apresentaram maior correspondência de cor com todas as escalas estudadas foram: 1,0; 1,2; 1,$4 ; 1,6 ; 1,8$ e $2,0 \mathrm{~mm}$. Porém, estes corpos-de-prova apresentaram correspondência com a cor de referência (A2E e B2E) e também com outras diferentes tonalidades, demonstrando baixa relação direta entre a cor da escala e a do material restaurador. Concluiu-se de acordo com os resultados que: 1) As escalas de cor Vita Classical, Vitapan 3D-Master e Chromascop não apresentaram correspondência entre suas tonalidades, demonstrando apenas semelhança variada entre si; 2) Composição e propriedades ópticas interferem na correspondência de cor entre as resinas compostas 4 Seasons $^{\circledR}$ e Filtek $^{T M}$ Supreme $X T$; 3) A resina nano-aglomerada Filtek $^{\mathrm{TM}}$ Supreme $\mathrm{XT}$ apresentou maior correspondência de cor com as tonalidades A2E e B2E adotadas como referência para avaliação; 4) As espessuras de 1,2; 1,4 e 1,6 apresentaram maior correspondência de cor com a tonalidade A2E da escala de referência Vita Classical para ambos os materiais testados; 5) Nenhuma das espessuras dos corpos-de-prova da resina híbrida 4 Seasons ${ }^{\circledR}$ na tonalidade B2E apresentou correspondência com a escala Vita Classical; 6) O método empregado $(\Delta E)$ demonstrou limitações para determinação da correspondência de cor em odontologia.

Palavras-chave: Cor; dente; espectrofotômetros; resinas compostas. 
A6stract 
Portero PP. Instrumental evaluation of the correspondence of color of composite resins in function of shade guide, shade, composition and thickness [Tese de doutorado]. Araraquara: Faculdade de Odontologia da UNESP; 2010.

\begin{abstract}
This study evaluated by the spectrophotometer Vita Easyshade ${ }^{\circledR} \mathrm{Nita}$, the color correspondence among three shade guides [Vita Lumin Vacuum (Vita Classical), Vitapan 3D-Master/Vita e Chromascop/Ivoclar Vivadent] experiment 1 , and the color correspondence of two composite resins (4 Seasons ${ }^{\circledR}$ and Filtek ${ }^{\mathrm{TM}}$ Supreme XT) in the colors A2E and B2E with these three shade guides, for they differ in its composition - experiment 2 . Five specimens were made with $8.0 \mathrm{~mm}$ in diameter and 10 different thickness $(0.2$ to $2.0 \mathrm{~mm})$ and light polymerized by LED Ultrablue $\left(440 \mathrm{~mW} / \mathrm{cm}^{2}\right)$. The color of specimens were measured 3 times and the values of color difference $(\Delta \mathrm{E})$ were obtained, analyzed by analysis of quadratic regression. The results of experiment 1 demonstrated that: there were a little color correspondence among three shade guides; in the experiment 2 , the composite resin (Filtek ${ }^{\mathrm{TM}}$ Supreme $\mathrm{XT}$ ) presented higher color correspondence in 3 shade guides than the composite resin 4 Seasons ${ }^{\circledR}$, there wasn't color matching between the composite resins analysed; the composite resin thickness that presented larger color correspondence with all shade guides evaluated were: $1.0 ; 1.2 ; 1.4 ; 1.6 ; 1.8$ e $2.0 \mathrm{~mm}$. However, these specimens presented correspondence with the reference color (A2E and B2E) and also with other different shades, showing low direct relationship among the color of the shade guides and of the restoring material. It could be concluded that: 1) The shade guides Vita Classical, Vitapan 3D-Master e Chromascop did'nt presented correspondence among its shades, just demonstrating likeness varied to each other; 2) Composition and optical properties ópticas interfere in the color correspondence between composite resins 4 Seasons $^{\circledR}$ e Filtek ${ }^{\mathrm{TM}}$ Supreme XT; 3) The composite resin nanoclusters Filtek ${ }^{\mathrm{TM}}$ Supreme XT presented larger color correspondence with the shades A2E e B2E adopted as reference for evaluation; 4) The thicknessess of 1.2; 1.4 and 1.6 presented larger correspondence with the shade A2E of the shade guide for both tested materials; 5 ) None of the thickness of specimens of the hybrid composite resin 4 Seasons ${ }^{\circledR}$ in the shade B2E presented correspondence with the Vita Classical shade guide; 6) The method employee $(\Delta \mathrm{E})$ demonstrated limitations for determination of the color correspondence in dentistry.
\end{abstract}

Keywords: Color; resins; spectrophotometers; tooth. 
Introdução 


\section{INTRODUÇÃO}

Em virtude da busca pela estética têm-se observado uma maior demanda por restaurações adesivas ${ }^{2,27,64,76}$, consequentemente nota-se um constante desenvolvimento de materiais restauradores estéticos que se assemelhem à cor dos dentes naturais.

O objetivo de uma restauração estética é reproduzir, parcial ou totalmente, o dente natural alcançando uma aceitação morfológica, óptica e biológica com a utilização de materiais restauradores que, inerentemente, tem características distintas da estrutura dental ${ }^{67}$. No entanto, apesar das técnicas restauradoras/laboratoriais e do preparo meticuloso auxiliarem na execução da forma da restauração, a seleção da cor, devido a sua subjetividade e à variações de interpretação, continua sendo um dos principais problemas estéticos enfrentados pelo cirurgiãodentista $^{67}$. Esse fato é relevante do ponto de vista clínico, uma vez que uma correta correspondência de cor entre a restauração e o dente natural, associada secundariamente à superfície, forma e translucidez, determinará o grau de satisfação e aprovação do paciente ${ }^{68}$.

O elemento dentário tem sua cor determinada por fatores extrínsecos e intrínsecos ${ }^{37,81}$. Os fatores extrínsecos relacionam-se à deposição de pigmentos provenientes dos alimentos sobre a película adquirida ou esmalte ${ }^{15,82}$. E os fatores intrínsecos estão relacionados às propriedades do esmalte e da dentina na dispersão e reflexão da luz, sendo a cor do dente fortemente influenciada por essas propriedades ${ }^{38}$. 
O processo de seleção da cor é influenciado por muitos fatores, dentre os quais pode-se destacar: o policromatismo dental, bem como a subjetividade na seleção da cor realizada pelo operador ${ }^{37}$. Adicionalmente, a fadiga, a idade e o estado emocional do clínico, condições de iluminação do ambiente e metamerismo, tornam ainda mais complexo o processo de seleção da cor. Desta forma, torna-se difícil a obtenção de uma correspondência perfeita entre a restauração e o dente natural $^{6,32,83}$.

Clinicamente, existem dois métodos para se avaliar a cor dos dentes: o visual e o instrumental. A seleção visual é realizada por meio de escalas de referências, que se baseiam nas amostras de cores encontradas mais frequentemente na dentição humana. Por outro lado, a seleção de cor instrumental é realizada por meio de colorímetros, espectrofotômetros, espectroradiômetros, analisadores de imagens ou uma combinação destes equipamentos. Destes, os tipos mais comuns são os colorímetros e os espectrofotômetros, os quais calculam a cor do dente a partir da mensuração da quantidade e da composição espectral da luz absorvida, transmitida ou refletida na superfície dental ${ }^{46}$.

Os espectrofotômetros estimam a cor por mensurar a intensidade da luz absorvida, transmitida ou refletida em todos os comprimentos de onda visíveis após interação com um objeto, enquanto que os colorímetros mensuram a intensidade da luz refletida filtrada por filtros vermelho, verde e azul. As diferenças entre os dois equipamentos no 
modo intra-oral de seleção da cor estão na maneira como eles interpretam a luz absorvida, transmitida ou refletida, influenciando diretamente as funções de mensuração dos equipamentos, e indiretamente, suas funções de seleção de cores ${ }^{46}$.

A função de seleção de cores desses equipamentos é baseada na extrapolação dos valores de mensuração dentre os valores mais significativos para o clínico, tais como as referências de cores dos sistemas de escalas ${ }^{30,44}$. É possível que haja uma inconsistência entre equipamentos na mensuração dos parâmetros de cor ou seleção dos dentes em um sistema de cores que resultarão em dificuldades no uso de equipamentos intercambiáveis, assim como, na comunicação da cor entre os clínicos e técnicos, se tais equipamentos forem diferentes. As diferenças entre mensurações realizadas por diferentes equipamentos afetam a precisão da seleção instrumental. Verifica-se que a concordância entre-instrumentos é relativamente fraca em comparação com a confiabilidade de mensurações realizadas em um mesmo instrumento ${ }^{22}$.

Dentre estes dois métodos descritos, a seleção de cor baseada nas escalas de referências (visual) é a mais empregada pelos clínicos. Estas escalas de cores apresentam limitações como incapacidade para reproduzir exatamente as cores dos dentes naturais, em função dos materiais com que as mesmas são confeccionadas (cerâmica, resina acrílica) serem diferentes do material restaurador; discrepâncias 
existentes nas cores disponibilizadas por diferentes fabricantes; os dentes das escalas apresentam espessuras que não condizem com a realidade clínica; falta de padronização dos vários lotes das escalas de referência do mesmo fabricante; presença de diferentes curvas de reflexão e texturas de superfície dos dentes das escalas em relação ao dente natural; a distribuição desigual e a incapacidade de se obter uma totalidade de cores para representar as cores dos dentes naturais. No entanto, sua utilização ainda é o método mais empregado e preferido pelos clínicos $9,24,29,57,70,75$.

A partir das limitações do método visual para seleção de cor, foram desenvolvidos equipamentos eletrônicos que possuem um potencial para selecionar a cor de forma mais precisa e confiável ${ }^{61-62}$, por não sofrerem influências como iluminação e variabilidade do operador. Os equipamentos para seleção de cores normalmente expressam os resultados por meio do sistema $\mathrm{CIE} \mathrm{L}^{*} \mathrm{a}^{*} \mathrm{~b}^{*}(\mathrm{CIE}, 2004)^{11}$, ou dos sistemas de escalas de cores convencionais. O sistema CIE L*a*b* é um modelo de cor padrão usado para descrever todas as cores visíveis, usando três coordenadas básicas $\left(L^{*}, a^{*} e b^{*}\right)$. Onde $L^{*}$ representa a luminosidade da cor, $a^{*}$ representa as cores verde ( $a^{*}$ negativo) a vermelho ( $a^{*}$ positivo) e $b^{*}$ representa as cores azul ( $b^{*}$ negativo) a amarelo ( $b^{*}$ positivo). Dentre estes equipamentos podem ser citados: Vita Easyshade ${ }^{\circledR}$ (Vita), ShadeScan (Cynovad), ShadeEye NCC (Shofu). 
Além das questões anteriormente abordadas na busca por cores correspondentes através do processo de seleção da cor, seja pelo método visual ou instrumental, existem outros fatores a serem considerados, tais como: a espessura da estrutura dental perdida a ser reconstituída, o tipo de resina composta a ser empregada, o substrato dental sobre o qual a resina será inserida, bem como as estruturas adjacentes os quais interferirão nos resultados finais ${ }^{56}$.

As propriedades ópticas dos dentes são influenciadas por sua configuração externa. A dimensão do dente, a forma e a textura da superfície geralmente refletem uma luz padrão que influencia na cor total. Sabe-se que a quantidade de luz absorvida e refletida depende da espessura e translucidez da dentina e do esmalte, e é evidente que a espessura da dentina e do esmalte afeta a cor dental ${ }^{23}$. A mesma situação é verificada para os materiais restauradores, uma vez que, de acordo com a extensão da estrutura dental perdida, será necessário reconstituir estes incrementos e eles interferirão na absorção, dispersão e reflexão da luz incidida ${ }^{73}$.

Os materiais restauradores estéticos foram desenvolvidos, tendo como um dos principais objetivos mimetizar as propriedades ópticas dos tecidos dentais, não somente no que se refere à cor, como também seu grau de translucidez, opacidade, fluorescência, opalescência, etc ${ }^{25}$.

Está disponível no mercado odontológico uma grande variedade de resinas compostas, classificadas em diferentes categorias, as quais 
apresentam diferentes propriedades. Dentre as categorias de resinas compostas disponíveis estão as resinas híbridas e as nano-aglomeradas.

As resinas híbridas apresentam tamanho médio de partículas de carga entre $0,6 \mu \mathrm{m}$ e $1,0 \mu \mathrm{m}$ e o conteúdo de carga entre 75 a $80 \%$ em peso. Estas resinas agregam propriedades como resistência mecânica e estética ${ }^{1}$

Mais recentemente surgiram no mercado odontológico as resinas nano-aglomeradas, com partículas de carga que apresentam variação média de tamanho de 0,1-1000 nanômetros, enquanto o tamanho médio das partículas de carga mantém-se em torno de 8-30 $\mu \mathrm{m}$ em compósitos híbridos e 0,7-3,6 $\mu \mathrm{m}$ em compósitos microhíbridos. Estes materiais apresentam características como translucidez, excelente polimento e retenção de polimento similar à resina microparticulada, enquanto mantém as propriedades físicas e de resistência ao desgaste similar às resinas híbridas ${ }^{55}$.

Com relação ainda as resinas compostas, características tais como: a composição, o tamanho, a quantidade e a distribuição das partículas de carga podem afetar a cor final do material, pois determinam suas propriedades ópticas. O tamanho e a quantidade das partículas de carga influenciam na reprodução da cor devido ao índice de refração entre as partículas e a matriz resinosa ${ }^{43}$. Para o entendimento da cor é fundamental o conhecimento de algumas propriedades da luz. Sendo assim, quando a luz atinge um objeto translúcido como o dente ou o 
material estético, ela pode sofrer absorção ou dispersão, e a resultante dessa interação luz/objeto desempenha um papel importante na cor e na translucidez deste material ${ }^{43}$.

Considerando todas as limitações no tocante à correspondência de cor entre as escalas de referência e resinas compostas, além da complexidade de se reconstituir opticamente o dente natural, há a necessidade do desenvolvimento de estudos que tenham como objetivo facilitar a etapa de seleção da cor, tornando esta correspondente à da estrutura dental.

Sendo assim, este estudo teve como objetivo avaliar, por meio de um espectrofotômetro, a correspondência de cor entre diferentes escalas de referência e a correspondência de cor de diferentes tonalidades, composições e espessuras de resinas compostas com essas escalas de referência. 
Revisão da Literatura 


\section{REVISÃO DA LITERATURA}

Ruyter et al. ${ }^{69}$, em 1987, avaliaram a estabilidade de cor de 3 resinas compostas fotoativadas para a confecção de coroas totais. Foram confeccionados 3 corpos-de-prova (cps) de cada material. Destes, $3 \mathrm{cps}$ foram armazenados em água destilada a $37^{\circ} \mathrm{C}$ e expostos a uma fonte de luz de xenônio. Os outros $3 \mathrm{cps}$ foram armazenados em água destilada a $37^{\circ} \mathrm{C}$, porém em ambiente escuro. As coordenadas da cor $\left(L^{*}, a^{*} e b^{*}\right)$ foram mensuradas por meio de um espectrofotômetro. Verificaram que houve alteração de cor perceptível para aqueles cps que foram expostos à luz de xenônio quando comparados àqueles que foram armazenados em ambiente escuro.

Johnston, $\mathrm{Kao}^{36}$, em 1989, realizaram uma análise sobre a percepção da seleção de cor realizada pela média do critério visual estabelecido pelo Serviço de Saúde Pública dos Estados Unidos (USPHS) e pela média da escala da faixa visual. Para este estudo foram avaliadas facetas de resina composta em comparação com dentes naturais. Foi utilizado um colorímetro que utilizava o sistema de cor CIELAB para calcular as diferenças de cor para a faixa visual. Os resultados demonstraram uma correlação estatisticamente significativa entre os dois sistemas de avaliação e entre as diferenças de cor obtidas. Verificaram também que a média da diferença de cor CIELAB das faixas julgadas pela USPHS foi de 3,7 unidades de $\triangle \mathrm{E}$. Os autores concluíram que as diferenças na cor encontradas entre estes dois métodos se devem 
a fatores como translucidez e aos efeitos decorrentes de estímulos visuais externos. Concluíram também, que a escala de faixa visual não ofereceu vantagens em relação ao critério amplamente definido pela USPHS.

Douglas $^{18}$, em 1997, avaliou a repetibilidade de um colorímetro fotoelétrico tristímulo (Minolta CR-321) posicionado intra-oralmente nos incisivos centrais superiores esquerdos de 7 indivíduos. Os coeficientes da correlação intra-grupo e repetibilidade das diferenças de cor foram determinados através de mensurações de cores repetidas feitas pelo mesmo examinador em 3 dias diferentes. A repetibilidade interexaminador foi testada pela comparação das mensurações CIELAB do mesmo dente feitas por 2 diferentes examinadores, ambos usando um posicionador. Um alto coeficiente de correlação intraclasse foi demonstrado para a repetibilidade intra e interexaminadores. A repetibilidade das diferenças de cor foi de 0,34 unidades de $\Delta \mathrm{E}$ para a avaliação intra-examinador, enquanto a repetibilidade interexaminador para as diferenças de cor foi de 0,13 a 0,61 unidades de $\Delta \mathrm{E}$ para os 2 pares de examinadores. Foi concluído que o colorímetro equipado com um posicionador feito sob encomenda apresentou uma precisão aceitável para mensuração intra-oral de alterações longitudinais na cor dos dentes.

Paravina et al. $^{60}$, em 1997, revisaram a literatura sobre os problemas na padronização da seleção de cor e o procedimento de reprodução da cor na odontologia, afirmando que a seleção de cores é muito mais complexa do que pode parecer e que a análise final sobre a 
cor do dente deveria ser feita por um cirurgião-dentista e poderia eventualmente consultar um protético. Segundo estes autores, os cirurgiões-dentistas deveriam ser educados sobre a ciência básica da cor, e os dentistas, protéticos e estudantes de odontologia deveriam passar por alguns testes visuais em relação à cor. Afirmam ainda, que a variabilidade dos fatores que influenciam os procedimentos de seleção da cor deve ser minimizada, havendo a necessidade de novas e melhores escalas de referência de cores lógica e cientificamente arranjadas de forma a abranger a completa extensão de cores dos dentes naturais. Para os autores, as escalas deveriam ser feitas da mesma maneira que as restaurações metalocerâmicas, com liga metálica e camada de porcelana opaca. E afirmam que enquanto forem usadas as escalas de cores e materiais de diferentes fabricantes, diminui-se a possibilidade de selecionar cores de forma apropriada. A comunicação com o laboratório deveria também, segundo eles, ser melhorada, enviando-se informações mais precisas e mais objetivas ao protético, e ainda, seria essencial que os protéticos seguissem rigorosamente as instruções dos fabricantes relativas à tecnologia de trabalho e às instruções dos cirurgiões-dentistas em relação à seleção da cor.

Douglas, Brewer ${ }^{19}$, em 1998, estudaram a correlação entre as diferenças de cor de coroas metalocerâmicas avaliadas visual e instrumentalmente. Foram selecionados pares de indivíduos para distinguir as alterações de cor que foram perceptíveis ou imperceptíveis 
clinicamente. Os indivíduos tentaram discernir as diferenças entre pares de cores e indicaram a aceitabilidade clínica de diferentes cores entre 2 coroas metalocerâmicas. Os resultados indicaram que a correlação entre a avaliação de cor visual e instrumental das diferenças de cor nestes pares de coroas não apresentou concordância em todas as dimensões do espaço de cor. Os resultados indicaram também que o limite de aceitabilidade para as diferenças de cor foi de 1,1 unidades de $\Delta \mathrm{E}$ para coroas com tonalidades mais avermelhadas e de 2,1 unidades de $\Delta E$ para coroas com tonalidades mais amareladas. Verificaram ainda, que o limite de perceptibilidade foi significativamente menor do que o limite de aceitabilidade. Concluíram nesta investigação que o limite de aceitabilidade foi dependente da cor avaliada e que os observadores foram mais críticos quando observaram coroas cuja tonalidade era mais avermelhada.

A avaliação e a comparação da habilidade de um novo colorímetro computadorizado com o teste visual de uma amostra para seleção de dentes da escala de cor de cerâmica foi realizada por Okubo et al. ${ }^{58}$, em 1998. Foram utilizados 31 observadores, com visão normal em relação à cor, aos quais foi permitido um tempo ilimitado para seleção de um grupo de dentes da escala de cores Vita Lumin Vacuum (Vita Zahnfabrik, Germany) que correspondessem aos dentes de uma segunda escala de cores Vita Lumin Vacuum. O mesmo teste foi aplicado para 14 dos observadores, vários meses depois, para determinar a variabilidade intra- 
observadores. O colorímetro computadorizado Colortron II (Light Source Computer Images, Inc., San Francisco, Calif.) equipado com um posicionador guia foi utilizado para mensurar o terço médio de cada dente da escala. Foram realizadas leituras de uma das escalas, que foram comparadas com as leituras da outra escala por meio do programa "match tool" presente no software do computador, este programa empregava as mensurações CIELAB e os valores $\Delta \mathrm{E}$. O número médio de correspondência pelo colorímetro e a correspondência correta do teste visual foram comparados pelo teste t-pareado. Os resultados demonstraram que o instrumento Colortron II selecionou corretamente 8 das 16 cores da escala ( $50 \%$ de acerto), enquanto que a seleção de cor visual realizada pelos observadores selecionou 7,7 das 16 cores da escala (acerto de 48\%) (desvio-padrão de 2,7). O colorímetro demonstrou $100 \%$ de repetibilidade e o teste visual demonstrou favorável repetibilidade (coeficiente de correlação $r=0,60$ ). Foi concluída nesta pesquisa, que a determinação da cor pelo método visual foi inconsistente em comparação ao método instrumental. A precisão do novo colorímetro para a seleção das cores dos dentes da escala de porcelana foi melhor do que o método visual.

Hasegawa et al. ${ }^{29}$, em 2000, estudaram as informações da cor e a translucidez entre os dentes naturais para todos os grupos de idades (13 a 84 anos) e tentou esclarecer a diferença de cor e a translucidez entre os dentes naturais e a escala de cores Vita Lumin Vacuum. Foram avaliados 
incisivos centrais hígidos de 87 indivíduos (42 homens e 45 mulheres, com idades entre 13 a 84 anos) e 16 escalas de cores Vita Lumin Vacuum por meio do espectroradiômetro PR-650 SpectraColorimeter (Photo Research 9330, Chatsworth, Calif.). A cor e a translucidez de 5 áreas, cada uma de $1,0 \mathrm{~mm}$ de diâmetro, nas superfícies dentais foram mensuradas para $L^{*}, a^{*} e b^{*}$, usando um computador regulado de acordo com os espaços de cor CIELAB. Os autores concluíram que os indivíduos mais velhos apresentaram uma cor mais amarelada e mais escurecida no centro do terço médio dos dentes naturais. Ambas as cores avermelhada e amarelada dos dentes naturais tenderam a aumentar da incisal para cervical, enquanto que a translucidez diminuiu. A escala de cores Vita Lumin Vacuum não foi distribuída de modo a abranger as coordenadas de cor e a translucidez dos dentes naturais.

Russel et al. ${ }^{68}, 2000$, quantificaram as alterações de cor ocorridas e o tempo de retorno à coloração normal de dentes que foram isolados com borracha para isolamento absoluto. Para tanto, mensuraram por meio de um espectrofotômetro a cor dos incisivos centrais superiores direito de sete indivíduos antes e após a colocação da borracha para isolamento absoluto, e nos outros sete indivíduos foram realizadas moldagens antes e após este procedimento. Os resultados demonstraram que houve alterações estatisticamente significativas nos valores de $L^{*}, a^{*}$ e b* após a colocação do isolamento absoluto e nos valores de $L^{*}$ após a realização da moldagem. Concluíram que os dentes tornaram-se mais brilhantes e 
com a coloração menos saturada após a colocação do isolamento absoluto e mais brilhantes após a realização da moldagem; verificaram também que, os valores voltaram ao normal após 30 minutos da remoção da borracha para isolamento absoluto.

Sproull $^{77}$, em 2001, explorou a natureza da cor e sua correta terminologia e afirmou que é possível arranjar a cor de uma maneira em que o enigma tridimensional seja compreensível. Afirmou ainda, que uma vez que as dimensões da cor (matiz, valor e croma) se tornassem termos familiares, os cirurgiões-dentistas conheceriam a linguagem da cor e as ferramentas necessárias para diminuir os problemas de seleção da cor e a realizariam de uma maneira lógica.

As alterações de cor e a translucidez de resinas compostas híbrida e microparticulada após exposição à luz com e sem armazenagem em água foram determinadas por Buchala et al. $^{7}$ (2002). Uma resina composta híbrida (Tetric) e uma microparticulada (Silux Plus) foram submetidas à uma luz artificial que simulava a luz do dia, com e sem armazenagem em água. Os valores tristímulos Yxy foram determinados colorimetricamente sobre um fundo branco e preto. As diferenças do valor inicial (baseline) foram calculadas como $\Delta \mathrm{E}_{\mathrm{ab}}{ }^{*}$ para mais de 1 mês. Após 1 mês, $\Delta \mathrm{L}^{*}, \Delta \mathrm{a}^{*}, \Delta \mathrm{b}^{*}$, e a proporção de contraste $\Delta \mathrm{C}$ foram calculadas. Os dados foram analisados com ANOVA de 2 critérios $(p<0,05) . \mathrm{O} \Delta \mathrm{E}_{\mathrm{ab}}{ }^{*}$ aumentou com o tempo para os materiais armazenados secos e úmidos. A armazenagem em água por 1 mês resultou em $\Delta \mathrm{E}_{\mathrm{ab}}{ }^{*}$ e $\Delta \mathrm{C}$ 
significativamente maior mas menor $\Delta \mathrm{b}^{*}$ que os armazenados a seco. $\mathrm{O}$ $\Delta \mathrm{a}^{*}$ foi significativamente maior para Tetric comparada com a Silux Plus. Ambos os materiais demonstraram valores de $\Delta L^{*}$ negativos sob ambas as condições de armazenagem, sem diferenças significantivas entre os materiais ou condições de armazenagem. Os resultados sugeriram que os materiais restauradores sofreram alterações mensuráveis devido exposição à luz do dia e que o aumento dessas alterações ocorreu sob a influência da armazenagem em água.

A confiabilidade de um colorímetro odontológico e a correlação da cor registrada pelo colorímetro com a cor selecionada por clínicos experientes foi estudada por Tung et al. ${ }^{78}$ (2002). Na primeira parte deste estudo, 2 examinadores (A e B) realizaram 2 mensurações por meio do colorímetro Shade Eye (Dental Chroma Meter) dos incisivos centrais superiores direito de 11 indivíduos. Os examinadores desconheciam seus próprios dados e aqueles dos outros investigadores. As mensurações foram repetidas 3 semanas depois, com o mesmo protocolo. Na segunda parte deste estudo, 2 clínicos experientes (examinadores D e E) selecionaram uma cor da escala Vita Lumin Clássica para os incisivos centrais superiores direito dos mesmos 11 indivíduos. Os clínicos também desconheciam cada uma das outras seleções de cores e as mensurações do colorímetro. A confiabilidade das análises dos resultados para cada um dos testes combinados para cor, valor e matiz foram todos $>0,94$. Os valores de confiabilidade $\alpha$ interexaminadores foram $>0,9$ para cor e valor 
e 0,64 a 0,74 para matiz. O interexaminador a representou o valor alcançado por cada uma das 4 mensurações. Os valores de confiabilidade $\alpha$ interexaminadores para cor, valor e matiz foram: 0,99, 0,95, e 0,96 para o examinador A e 0,99, 0,93, e 0,97 para o examinador $\mathrm{B}$, respectivamente. $\mathrm{Na}$ segunda parte do estudo, o colorímetro "concordou com ele mesmo" $82 \%$ das vezes, enquanto que os clínicos concordaram um com o outro em $73 \%$ das vezes. As seleções feitas pelo colorímetro e pelos clínicos equivaleram de $55 \%$ a $64 \%$ das vezes. De acordo com os resultados, os autores concluíram que o colorímetro é um método confiável para a seleção de cores dos dentes naturais.

Segundo Dancy et al. $^{16}$, em 2003, o uso de análises fotocolorimétricas na seleção de cor pode servir como uma alternativa à seleção de cor visual. Afirmaram ainda, que não houve diferença significativa nos resultados de seleção de cor quando esta foi realizada por especialistas experientes ou com o colorímetro.

A influência quantitativa da espessura da camada de porcelana na cor final das restaurações de cerâmica foi determinada por Dozic' et al. ${ }^{21}$ (2003). Foram confeccionados $5 \mathrm{cps}$ em forma de discos, com espessuras de aproximadamente: $0,25,0,50,0,75$ e $1,0 \mathrm{~mm}$, que consistiam de um disco para simular um coping de 0,70 mm (Syntoceram) e discos de porcelana para simular a camada de revestimento de porcelana opaca (OP) e / ou translúcida (TP) (Sintagon Plus), com os discos OP sempre posicionados entre os discos de coping e os discos TP. Os valores 
CIELAB foram determinados por meio do espectrofotômetro Color-Eye 7000A (GretagMacbeth, New Windsor, NY) para as tonalidades da escala Vita A1, A2 e A3. Água destilada foi usada para conseguir contato entre as camadas. Para se avaliar a influência do fundo na cor final, foram usados fundos brancos e fundos pretos. Foram determinadas as diferenças de cor $(\Delta \mathrm{E})$ entre as camadas dos cps. A correlação entre a espessura e os valores de $L^{*}, a^{*} e b^{*}$ foi calculada pela análise de correlação de Spearman. Os resultados indicaram que pequenas alterações na proporção da espessura OP / TP podem influenciar perceptivelmente a cor final das camadas dos $\operatorname{cps}(\Delta \mathrm{E}>1)$. A vermelhidão $a^{*}$ e o amarelado $b^{*}$ aumentou com a espessura da OP para todas as tonalidades. A vermelhidão $a^{*}(p<0,01$ para todas as tonalidades) foi correlacionada mais fortemente com a espessura do que o amarelado $b^{*}$ $(p<0,01$ para $A 1$ e $A 3 ; p<0,05$ para $A 2)$. A luminosidade $\left(L^{*}\right)$ foi dependente da tonalidade. A correlação ( $r$ ) entre as espessuras de OP / TP e $L^{*}$ foi de $0,975(p<0,01)$ para a tonalidade $A 1,0,700$ (sem significância estatística) para a tonalidade A2, e $0,900 \quad(p<0,05)$ para a tonalidade A3. Os autores concluíram que pequenas alterações na espessura e na tonalidade das camadas de porcelanas translúcida e opaca podem influenciar na cor final dos cps simulando camadas de porcelana.

Hammad ${ }^{28}$, em 2003, avaliou os efeitos de 2 escalas de referência (Vita Lumin Vacuum e Vitapan 3D-Master) na repetibilidade intra- 
observadores, os quais eram protesistas e clínicos gerais. Dez protesistas e 10 clínicos gerais (homens de 35-45 anos) com uma experiência clínica média de 14 anos participaram deste estudo. Cada clínico utilizou as escalas de cores Vita Lumin Vacuum e Vitapan 3D-Master para determinar as cores de caninos superiores direito de 20 pacientes seguindo o protocolo padrão. Foram feitos códigos de identificação para impedir que houvesse uma memória para a cor. Todos os dentes foram polidos antes de cada seleção de cor, e o processo de seleção foi padronizado para os procedimentos sob iluminação controlada. As seleções de cores foram aleatoriamente repetidas após 1 mês, pelos mesmos clínicos, no mesmo grupo de pacientes, de acordo com o mesmo protocolo de seleção de cores. A análise de variância e o teste T para comparação individual entre as médias foram realizadas $(p<0,05)$. O autor concluiu, que os protesistas demonstraram uma repetibilidade superior intra-observadores na seleção de cores, especialmente quando a escala Vita Lumin Vacuum foi usada.

A seleção da cor de restaurações metalocerâmicas com a dentição natural adjacente e realizada de acordo com os dados de uma seleção de cor visual ou de um novo sistema espectrofotométrico foi estudada por Paul et al. ${ }^{63}$ (2004). Amostras de uma escala de referência Vita Classical foram mensuradas com o espectrofotômetro para determinar os parâmetros de cor no $\operatorname{CIE~} L^{*} a^{*} b^{*}$, e 3 clínicos independentes selecionaram a melhor opção de cor para um incisivo central esquerdo ou 
direito que necessitava ser restaurado em 10 pacientes. Os 10 incisivos foram então mensurados usando o espectrofotômetro de reflectância. Os autores concluíram que a análise de cor espectrofotométrica e a comunicação entre observadores podem ser usadas eficientemente para a confecção de restaurações metalocerâmicas.

A precisão da reprodução das gradações de cor para restaurações cerâmicas usando uma técnica de seleção de cor por computador (CCM) ou espectrofotômetros, foi avaliada por Ishikawa-Nagai et $a{ }^{33} \cdot(2005)$. As tonalidades de 10 referências de cor $(1 \mathrm{M}-1,2 \mathrm{~L}-1,5,2 \mathrm{R}-1,5,3 \mathrm{~L}-1,5,3 \mathrm{M}-2$, 3R-2,5, 3M-3, 4L-2,5, 4M-2 e 5M-2) da escala Vitapan 3D-Master foram mensuradas em 4 áreas da coroa destas referências de cor (da área cervical até a incisal) usando o espectrofotômetro MSC-2000 (Olympus, Tokyo, Japan). Foram confeccionados $30 \mathrm{cps}$ de cerâmica com a forma do dente ( 3 cps para cada uma das 10 referências), de acordo com as prescrições calculadas usando um programa CCM. As cores dos cps de cerâmica selecionadas por CCM e as referências de cores foram comparadas em 10 áreas - de cervical a incisal (cada mensuração possuía 1,0 mm de altura e $3,0 \mathrm{~mm}$ de largura). Os valores de $\Delta \mathrm{E}, \Delta \mathrm{L}^{*}$, $\Delta \mathrm{a}^{*}$ e $\Delta \mathrm{b}^{*}$ foram calculados. Os valores de diferença de cor $(\Delta \mathrm{E})$ foram analisados pela ANOVA $(p<0,0001)$. Três protesistas avaliaram os cps CCM por meio de técnicas de percepção. Diferenças significativas na média dos valores de $\Delta E$ entre as referências de cores $(p<0,0001)$, áreas $(p<0,0001)$, e os efeitos entre a interação áreas/referências de cor 
$(p<0,0001)$ foram analisadas. Foi concluído que a técnica CCM testada neste estudo utilizando as 4 mensurações nas referências de cor poderiam reproduzir a gradação da cor do dente da área incisal até a área pré-cervical com resultados clinicamente aceitáveis.

Lee et al. $^{48}$, em 2005, avaliaram as diferenças na cor e as alterações de cor de resinas compostas sobre 2 tipos de fundos. Foram confeccionados 20 cps para cada uma das 5 resinas compostas: Charisma - Heraues / kulzer (tonalidade A2), Pyramid - Bisco (tonalidade A2), Synerg compact - Coltene (tonalidades A2 e B2), Vitalescence Ultradent (tonalidade A2), Z100 - 3M / ESPE (tonalidade A2), medindo 12 $\mathrm{mm}$ de diâmetro e $2 \mathrm{~mm}$ de espessura, que foram divididos em grupos: cps que foram fotoativados e cps que não foram fotoativados, antes e após o polimento com lixas de papel das seguintes granulações: 600, 1000,1500 . As mensurações foram realizadas de acordo com o espaço de cor CIELAB relativo ao iluminante D65 sobre um fundo branco (WB; reflectância $=91,57 \%$ ) e um fundo "aprisionador" de luz (LT; reflectância de $0,01 \%$ ) por meio do espectrofotômetro CM - A124 (Minolta, Osaka, Japan). As diferenças de $\operatorname{cor}\left(\Delta \mathrm{E}^{*}{ }_{\mathrm{ab}}\right)$ em função dos fundos e das condições dos cps sobre cada um desses fundos foram calculadas. Os valores de $\Delta \mathrm{E}^{*}{ }_{\text {ab }}$ pelos mesmos cps em função do fundo foram de 2,38 a 11,60. Os valores de $\Delta \mathrm{E}^{*}$ ab pelas condições dos cps variaram de acordo com o fundo, e as $\Delta E^{*}{ }_{\text {ab }}$ entre os cps polidos/fotoativados sobre WB foram significativamente mais elevados do que aqueles sobre LT $(p<0,05)$. 
fundo influenciou diferentemente nas 3 coordenadas de cor nos valores de $\mathrm{CIEL}^{*}, a^{*}$ e $b^{*}$ dependendo do material e das condições dos cps. Concluíram que 1) o fundo influenciou significativamente nas coordenadas de cor e na diferença de cor pelas condições dos cps; 2) que como a luz "aprisionada" pode eliminar a influência das variações do fundo, a mensuração da cor sobre uma luz aprisionada pode ser a cor real do material.

A correlação entre a mensuração da cor realizada em três escalas de referência do mesmo fabricante, obtida por análise espectrofotométrica e digital foi pesquisada por Cal et al. ${ }^{8}(2006)$. Sessenta cores de 3 escalas de referência foram analisadas para determinação dos valores de $L^{*} a^{*} b^{*}$ com um espectrofotômetro (Spectraflash 600 PLUS). As mesmas cores foram também digitalizadas com uma câmera digital (Olympus Camedia C-2500-L), e os mesmos parâmetros de cor foram determinados na imagem digital com o software. Foram realizadas 3 mensurações para cada cor com ambos os métodos. As diferenças estatísticas entre os resultados dos dois métodos foram determinadas usando ANOVA $(\alpha=0,05)$. Foi observado que os valores de $a^{*} e b^{*}$ obtidos pelo método digital foram correlacionados com aqueles do espectrofotômetro. A análise espectrofotométrica não revelou nenhuma diferença entre as mensurações de $L^{*}$ das cores das 3 escalas de referência $(p>0,05)$, mas diferenças significantivas foram observadas entre os valores de $L^{*}$ das cores com o método da análise digital $(p=0,000)$. Para os valores de $\mathrm{a}^{*} \mathrm{e}$ 
$b^{*}$, ambos os métodos revelaram diferenças significantes entre as cores $(p<0,05)$. Foi concluído que os resultados obtidos pelo método digital foram correlacionados com aqueles do espectrofotômetro, especialmente para os valores de $a^{*} e b^{*}$.

Klemetti et al. ${ }^{44}$, em 2006, testaram a variabilidade entre observadores na seleção de cor para restaurações de porcelana, utilizando 3 diferentes escalas de referência: Vita Lumin Vacuum, Vitapan 3D-Master e Procera. Dezenove cirurgiões-dentistas recém-formados atuaram como observadores e os resultados foram comparados com aqueles obtidos do colorímetro digital Shade Eye (Shofu, Japan). Com relação à repetibilidade, nenhuma diferença significantiva foi encontrada entre as 3 escalas de referência, embora a repetibilidade tenha sido relativamente baixa (33 - 43\%), em concordância com os resultados colorimétricos que foram também baixos $(8-34 \%)$. Concluíram que a seleção de cor demonstrou alta variabilidade entre os observadores e que o colorímetro digital é uma ferramenta educacional útil no ensino e padronização da seleção de cores.

Park et al. ${ }^{61}$, em 2006, determinaram a distribuição de cor em 2 escalas de referência (Vita Lumin Vaccum e Chromascop) na luminosidade $\left(\mathrm{CIEL}^{*}\right)$, tonalidade $\left(C^{*}{ }_{a b}\right)$ e ângulo do matiz $\left(h^{\circ}\right)$ relativos aos iluminantes padrão $D_{65}$, A, e F2. As cores das 2 escalas $(n=36)$ foram mensuradas, e os valores para as distribuições para $\operatorname{CIE~} \mathrm{L}^{*}, C^{*}{ }_{\text {ab }}$ e $h^{\circ}$ comparados. As diferenças de cor das referências de cor das escalas 
variando os iluminantes foram calculadas. Foi determinada a distribuição dos valores de $\mathrm{CIEL}^{*}$ e $C^{*}{ }_{\mathrm{ab}}$ de cada referência de cor comparada com o mais baixo valor de cada referência ou com o mais baixo valor de croma. Os dados para valor, croma e ângulo do matiz para cada escala foram analisados com ANOVA de 2 critérios com os fatores das designações das cores e o tipo de iluminante $(\alpha=0,05)$. Os valores de $\mathrm{CIEL}^{*}, C^{*}$ ab e $h^{\circ}$ foram influenciados pela designação da cor e pelo tipo de iluminante para ambas as escalas de referência. A diferença de cor ocasionada pela variação do iluminante foi influenciada pela designação da cor e pelo par de iluminante comparado. A ordem das médias das diferenças de cor das 16 referências de cores da escala Vita Lumin Vacuum pelos pares de iluminantes comparados foi a seguinte: $\Delta \mathrm{E}^{*}{ }_{\mathrm{ab}}(\mathrm{D} 65 / \mathrm{F} 2)=1,63<\Delta \mathrm{E}^{*}{ }_{\mathrm{ab}}$ $(\mathrm{D} 65 / \mathrm{A})=2,22<\Delta \mathrm{E}^{*}{ }_{\mathrm{ab}}(\mathrm{A} / \mathrm{F} 2)=2,46(p<0,05) . \mathrm{A}$ ordem das médias das diferenças de cor das 20 referências de cores da escala Chromascop foi a seguinte: $\Delta \mathrm{E}^{*}{ }_{\mathrm{ab}}(\mathrm{D} 65 / \mathrm{F} 2)=2,45<\Delta \mathrm{E}^{*}{ }_{\mathrm{ab}}(\mathrm{D} 65 / \mathrm{A})=2,71<\Delta \mathrm{E}^{*}{ }_{\mathrm{ab}}(\mathrm{A} / \mathrm{F} 2)$ $=3,14(p<0,05)$. As distribuições dos valores e dos cromas em ambas as escalas foram arbitrárias. Os autores concluíram que a distribuição de cor das 2 escalas variaram de acordo com o iluminante e a extensão da diferença de cor para as referências de cor pelo iluminante foi de 0,80 a 4,82, o qual seria clinicamente inaceitável $\left(\Delta E^{*}{ }_{a b}>3,7\right)$ e que a distribuição de cor das 2 escalas pelo valor e croma não foi lógica.

O efeito da espessura do coping e do revestimento de porcelana nos parâmetros de cor de 2 sistemas de cerâmica pura foi estudado por 
Shokry et al. ${ }^{74}(2006)$. Corpos-de-prova em forma de discos de $16,0 \mathrm{~mm}$ de diâmetro com espessuras de coping / camada $(\mathrm{mm})$ de 0,8 / 0,2 (baseline); $0,8 / 0,7 ; 0,8 / 1,2 ; 1,0 / 0,5 ; 1,3 / 0,2$ e $1,8 / 0,2$ foram confeccionados de cerâmica reforçada com leucita (IPS Empress, tonalidade B2) e espessura ( $\mathrm{mm}$ ) de 0,5 / 0,5 (baseline); 0,5 / 1,0;0,5 / 1,$5 ; 0,8 / 0,7 ; 1,0 / 0,5$ e 1,5 / 0,5 foram confeccionados de cerâmica spinell infiltrada com vidro (In - Ceram Spinell, tonalidade A2). Os parâmetros de cor $L^{*} a^{*} e b^{*}$ do espaço de cor CIELAB foram mensurados contra um fundo cinza neutro por meio do colorímetro tristímulo Model CR-300, Minolta, Ramsey, NJ), e a diferença de cor ( $\Delta E)$ entre os grupos foi calculada. A análise de variância foi usada para determinar o efeito da espessura do coping e do revestimento sobre os parâmetros de cor dos materiais $(\alpha=0,05)$. Os resultados demonstraram que ao aumentar a espessura total dos cps, diminuía-se os valores de $L^{*}(p<0,001)$ e aumentava-se os valores de $\mathrm{a}^{*}(p<0,001)$, de $\mathrm{b}^{*}(p<0,001)$ e de $\Delta \mathrm{E}^{*}$ $(p=0,0236)$. Para a cerâmica reforçada com leucita, a espessura do coping, do revestimento e sua interação exibiram influências significativas nos valores médios de $a^{*}$ e $b^{*}(p<0,0028)$ mas não nos valores médios de $L^{*}$. Para a cerâmica spinell, a espessura do coping e do revestimento exibiu influência significativa sobre os valores médios de $L^{*} e b^{*}$ $(p<0,0272)$, mas não nos valores de $a^{*}$; a interação demonstrou influência significativa sobre $b^{*}(p=0,0003)$, mas não sobre $L^{*}$ e $a^{*}$. Foi concluído que a aparência dos cps de cerâmica é fortemente influenciada não 
apenas pela espessura do coping e do revestimento, mas também por sua interação.

Sidhu et al. ${ }^{72}$, em 2006, avaliaram as alterações de cor e de translucidez ocasionadas pela fotoativação das resinas compostas: Charisma (Heraeus / Kulzer), Solare (GC), Filtek Supreme (3M / ESPE) nas tonalidades A2 e A2 opaca. Os parâmetros de $\operatorname{CIELAB}\left(L^{*}, a^{*}\right.$ e b*) dos cps $(n=10)$ em forma de discos medindo $8,0 \mathrm{~mm}$ de diâmetro e 2,0 $\mathrm{mm}$ de espessura foram avaliados sobre os fundos preto, branco e do próprio material, antes e após a fotoativação, para avaliar as alterações de cor e translucidez (pelas médias dos cálculos de $\Delta \mathrm{E}^{*}$ e parâmetros de translucidez, respectivamente). As resinas compostas Solare e Filtek Supreme mostraram significativamente menores alterações de cores durante a fotoativação do que a Charisma; entretanto, os valores de $\Delta \mathrm{E}^{*}$ de todas as resinas / cores foram ainda clinicamente inaceitáveis $\left(\Delta \mathrm{E}^{*}>\right.$ 3,3). Considerando as alterações de translucidez durante a fotaotivação, as tonalidades A2 e A2 opaca da resina Charisma mostraram um aumento estatisticamente significante, embora nenhuma diferença tenha sido observada para as outras resinas. Foi concluído que as resinas Solare e Filtek ${ }^{\mathrm{TM}}$ Supreme tenderam a apresentar menos alterações na translucidez e na cor durante a fotoativação comparadas à resina Charisma, apesar disso, as alterações na cor durante a fotoativação estavam ainda num limite de alteração de cor inaceitável; sendo também 
necessário que a seleção de cor das resinas compostas seja realizada após a sua fotoativação.

Douglas et al. $^{20}$, em 2007, determinaram a tolerância à aceitabilidade e perceptibilidade válida para a correspondência de cor no cenário clínico atual usando instrumentação espectroradiométrica. Foi confeccionada uma prótese para teste que possuía 10 dentes superiores e permitia uma troca do incisivo central superior esquerdo. $O$ espectroradiômetro PR 705 (Photo Research Inc, Chatsworth, Calif) foi usado para determinar as coordenadas de cor CIELAB e as diferenças de cor $(\Delta \mathrm{E})$ entre o incisivo central superior direito e o esquerdo que era intercambiável. O incisivo central superior esquerdo apresentou variação de 1 unidade de $\Delta \mathrm{E}$ (visualmente imperceptível) a 10 unidades de $\Delta \mathrm{E}$ (visualmente perceptível). A prótese testada com cada um dos dentes intercambiáveis (tonalidades: P67, B3, A3, A2, B4, P59, C3, C4, B1) foi avaliada por 28 cirurgiões-dentistas (4 mulheres e 24 homens). Para cada dente intercambiado, era perguntado aos dentistas se eles poderiam ver a diferença entre os incisivos centrais e se a resposta fosse afirmativa, essa diferença seria considerada aceitável. De acordo com os resultados, a diferença de cor que $50 \%$ dos observadores poderiam perceber foi 2,6 unidades de $\Delta \mathrm{E}$ (perceptibilidade) e a diferença de cor que $50 \%$ dos cirurgiões-dentistas refariam a restauração devido a não correspondência de cor (clinicamente inaceitável) seria de 5,5 unidades de $\Delta \mathrm{E}$. Concluíram que a tolerância para a perceptibilidade foi significativamente mais baixa 
do que a tolerância para a aceitabilidade para correspondência de cor entre os 2 dentes da prótese.

O efeito da espessura da porcelana para esmalte na cor, e a capacidade de uma escala de referência prescrever o croma, foi avaliado por Jarad et al. ${ }^{34}$ (2007). Foram utilizadas 3 tonalidades (3M1, 3M2 e 3M3) da escala Vitapan 3D-Master. Foram confeccionados 5 cps em forma de disco, que consistiam de 3 camadas (dentina opaca, dentina e esmalte) com espessuras de 0,6, 0,8 e 0,6 mm, respectivamente. A cor de cada cp foi avaliada usando o espectrofotômetro Monolight (Macam Photometrics/Scotland), os cps de porcelana para esmalte foram reduzidos para $0,3 \mathrm{~mm}$ após a primeira mensuração e em seguida remensurados. Os resultados indicaram que ao reduzir a espessura dos cps de porcelana aumentou-se significativamente os valores de $L^{*}(p<0,05), b^{*}$, o croma e o matiz $(p<0,001)$. Para as 3 tonalidades estudadas (3M1, 3M2 e 3M3) os valores de $L^{*}$ não foram significativamente diferentes $(p=0,05)$ e o croma aumentou para $3 M 1$ que possuía o mais baixo valor de croma e aumentou também para 3M3 que possuía o mais alto valor de croma, o que estava de acordo com as especificações do fabricante da escala. Embora as mudanças estatisticamente significativas para o matiz tenham sido pequenas (menor que $3^{\circ}$ ), as diferenças no croma entre as 3 tonalidades $3 \mathrm{M} 1,3 \mathrm{M} 2$ e $3 \mathrm{M} 3$ foram maiores para as camadas de esmalte mais delgadas do que para as mais espessas. Uma alteração na espessura de esmalte de 0,6 para 
$0,3 \mathrm{~mm}$ resultou em uma variação de 3 unidades no valor de $L^{*}$ e para o croma e para o matiz uma variação de $4^{\circ}$. Verificou-se que uma alteração na espessura da porcelana para esmalte teria um maior efeito para as tonalidades com cromas mais altos do que para aquelas com cromas mais baixos. Concluíram que as escalas de referência possuem capacidade para prescreverem o croma, mas essa capacidade dependerá da espessura da camada de esmalte empregado.

Karamouzos et al. $^{39}$, em 2007, avaliaram a precisão de um espectrofotômetro de reflectância durante avaliação longitudinal da cor do dente in vivo. Os dados do espectrofotômetro de 5 áreas circulares padronizadas na superfície vestibular de 6 dentes (4 superiores e 2 inferiores) de 27 estudantes de odontologia, foram realizadas 3 mensurações $(n=3)$ em 3 dias distintos $\left(1^{\circ}, 3^{\circ}\right.$ e $30^{\circ}$ dia). As diferenças de cores totais foram calculadas de acordo com a equação $\Delta \mathrm{E}=\left[\left(\Delta \mathrm{L}^{*}\right)^{2}+\right.$ $\left.\left(\Delta \mathrm{a}^{*}\right)^{2}+\left(\Delta \mathrm{b}^{*}\right)^{2}\right]^{1 / 2}$. Foi observado que todas as mensurações das áreas dentais registradas pelo mesmo observador $\left(\Delta \mathrm{E}_{\text {intra }}\right)$ demonstraram menores alterações de cor durante os 3 diferentes intervalos de tempo $(\Delta \mathrm{E}=1)$. Os menores valores de $\Delta \mathrm{E}$ foram registrados para os incisivos centrais superiores, enquanto que os incisivos centrais inferiores e os primeiros pré-molares superiores revelaram as diferenças de cores mais significativas $(0,68 \pm 0,21$ e $0,70 \pm 0,25$ unidades de $\Delta \mathrm{E}$, respectivamente). A porção central do terço médio de cada superfície vestibular do dente exibiu os registros mais precisos. Com respeito à 
repetibilidade interexaminadores $\left(\Delta \mathrm{E}_{\text {inter }}\right)$, as áreas mesial e distal de todos os dentes mensurados apresentaram as maiores diferenças de cor estatisticamente significantivas $(0,48 \pm 0,15$ e 0,50 $\pm 0,17$ unidades de $\Delta \mathrm{E}$, respectivamente). Concluíram que o espectrofotômetro testado produziu uma mensuração precisa da cor dos dentes in vivo.

Kim et al. ${ }^{41}$, em 2007, avaliaram a confiabilidade e a precisão do instrumento odontológico de seleção de cor ShadeScan (Cynovad). A mensuração da cor foi feita em 3 escalas de referência (Vita Classical, Vitapan 3D-Master e Chromascop). As referências de cores foram selecionadas e colocadas no meio de uma matriz gengival (Shofu Gummy), com as designações das tonalidades registradas nos 2 lados das referências de cor. As mensurações foram feitas na área central do dente artificial dentro de uma caixa preta. Para avaliar a confiabilidade, cada referência de cor de cada uma das 3 escalas foi mensurads 10 vezes. Para avaliar a precisão, cada referência de cor das 30 escalas de referência (10 Vita Classical, 10 Vitapan 3D-Master e 10 Chromascop) foi mensurada 1 vez. De acordo com os resultados a confiabilidade do ShadeScan foi: Vita Classical $=95 \%$, Vitapan 3D-Master $=91,2 \%$ e Chromascop $=76,5 \%$ e sua precisão foi: Vita Classical $=65 \%$, Vitapan 3D-Master $=54,2 \%$ e Chromascop $=84,5 \%$. Este estudo in vitro demonstrou um grau variável de confiabilidade e precisão para o ShadeScan, dependendo do tipo de escala empregada. 
Lee $^{47}$, em 2007, determinou a influência das características de absorção e dispersão, incluindo a translucidez e opalescência nas coordenadas de cor $\operatorname{CIE}\left(L^{*}, a^{*}, e b^{*}\right)$ de resinas compostas. A distribuição espectral de 7 resinas compostas (14 tonalidades e $1 \mathrm{~mm}$ de espessura) foi mensurada nos modos de transmitância e reflectância. Foram confeccionados 3 cps para cada resina composta avaliada na tonalidade A2, as quais foram: Estelite (Tokuyama Dental Corp), Esthet $X$ (Dentsply Caulk), Filtek Supreme (3M / ESPE), Ice (SDI Inc), Palfique Estelite (Tokuyama Dental Corp), Tetric Ceram (Ivoclar Vivadent) e TPH Spectrum (Dentsply Caulk) com $38 \mathrm{~mm}$ de diâmetro e $1 \mathrm{~mm}$ de espessura. As características ópticas, incluindo o coeficiente de dispersão (S), coeficiente de absorção (K) e refletividade da luz (RI) foram calculadas através dos dados de reflectância espectral por meio da equação de Kubelka. Os parâmetros de opalescência (OP) foram calculados com as diferenças nas coordenadas de $\Delta b^{*}$ (amarelo-azul) e $\Delta \mathrm{a}^{*}$ (vermelho-verde) entre as cores refletidas e transmitidas. Os parâmetros de translucidez (TP) foram calculados para avaliar a translucidez. Uma correlação simples entre cada valor de CIEL*, a* e b* usando protocolos variados com parâmetros ópticos (S, K, RI, OP e TP) foi determinada, e uma análise de regressão múltipla foi usada para determinar as variáveis que influenciaram significativamente nas coordenadas de cor $(p<0,05)$. Os resultados indicaram que os valores de CIE L*, $a^{*}$ e b* foram influenciados pelos valores de S, K, RI, TP e OP. Os 
valores de $\mathrm{CIE} L^{*}, a^{*}$ e $b^{*}$ sem o fundo e aqueles no modo de transmissão foram altamente correlacionados com S. Os valores de OP e TP também foram influenciados pelos valores de CIE $L^{*}, a^{*} e b^{*}$. Os valores de CIE $L^{*}, a^{*} e b^{*}$ foram correlacionados com os valores de OP quando diferentes resinas compostas com a mesma tonalidade foram comparadas. Segundo esses autores, já que as características de dispersão e absorção influenciam na cor das resinas compostas, o tamanho e a fração de volume das partículas de carga deveriam ser controlados para se obter uma melhor reprodução da cor, considerandose os índices de refração das partículas de carga e da matriz resinosa.

Li, Wang ${ }^{49}$, em 2007, compararam a aplicabilidade de 2 métodos de seleção de cor: o método visual por meio da escala de referência Vintage Halo e o método instrumental por meio do colorímetro Shade Eye NCC. Foram avaliados 20 incisivos centrais superiores esquerdos de 20 voluntários (9 homens e 11 mulheres, com média de idade de 25,5 anos). Os critérios de inclusão no estudo foram: incisivos centrais superiores esquerdos hígidos presentes, sem qualquer relato de restauração no dente, sem história de terapia ortodôntica, sem história de clareamento, sem lesão de cárie presente e nenhuma giroversão excessiva do dente que pudesse interferir com a mensuração instrumental. Foram confeccionadas 2 coroas metalocerâmicas para cada modelo realizado após a moldagem dos dentes dos pacientes, com espessura de 0,3 $\pm 0,5$ $\mathrm{mm}$. As coordenadas de cor $\left(L^{*}, a^{*} e b^{*}\right)$ do terço médio de cada dente e 
da coroa metalocerâmica correspondente foram avaliadas por meio do espectrofotômetro PR - 650 Spectra Scan. A diferença de cor $(\Delta E)$ e as coordenadas da $\operatorname{cor}\left(\Delta \mathrm{L}^{*}, \Delta \mathrm{a}^{*}\right.$ e $\left.\Delta \mathrm{b}^{*}\right)$ entre os dentes $\mathrm{e}$ as coroas metalocerâmicas correspondentes foram calculadas. Foi encontrado que as diferenças de cor para ambos os grupos estavam dentro de um limite clinicamente inaceitável $(\Delta \mathrm{E}>2,75)$. Com relação ao $\Delta \mathrm{E}$ e as coordenadas das 3 cores, nenhuma diferença significativa foi encontrada, exceto para $a^{*}(p<0,01)$. O grau de dificuldade de seleção de cor foi analisado por meio da avaliação da seleção visual da cor. Dentre os casos classificados como de fácil seleção da cor, o método instrumental obteve os melhores resultados. Foi sugerido que a confiabilidade da seleção da cor pode ser obtida pelo colorímetro ou pelo método visual, entretanto, o colorímetro obteve melhores resultados e tornou mais fácil a seleção da cor.

A avaliação da transmitância das resinas compostas microhíbridas: Charisma F, Solitaire II, Intens e Tetric Ceram e das resinas compostas nanoparticuladas: Esthet-X e Filtek Supreme nas cores de dentina e translúcidas foi realizada por Masotti et al. ${ }^{53}$ (2007). Foram confeccionados $3 \mathrm{cps}$ de cada uma dessas tonalidades de resina composta com dimensões de $12 \mathrm{~mm}$ de diâmetro e $1 \mathrm{~mm}$ de espessura. Os cps foram fotoativados durante 10 segundos por meio do aparelho $\mathrm{XL}$ 1500 (3M Co./USA). Foram realizadas 3 mensurações para cada $\mathrm{cp}$ por meio do espectrofotômetro HP 8453 (Hewlet-Packard / USA). O espectro 
foi analisado pela média dos valores da transmitância nos intervalos de 20 nm no comprimento entre 400 e 700 nm (\%T) e a transmitância nos comprimentos de onda de 400, 560 e $700 \mathrm{~nm}(\mathrm{Td})$. Os resultados de acordo com o teste t-Student mostraram que a tonalidades de dentina da Charisma $\mathrm{F}$ apresentou mais alta \% T que a tonalidade translúcida. Para a Solitaire II, Intens, Tetric Ceram e Esthet-X a tonalidade translúcida apresentou mais alta porcentagem de $\mathrm{T}$ que a cor de dentina. Para a Filtek Supreme não houve diferença estatística entre as cores de dentina e as translúcidas. De acordo com a análise de variância (ANOVA) e teste de Tukey a Charisma F apresentou mais alta porcentagem de $\mathrm{T}$ e $\mathrm{Td}$ para as tonalidades de dentina e translúcidas, exceto para a tonalidade translúcida a $700 \mathrm{~nm}$, na qual a Esthet-X apresentou Td mais alto. Este estudo indicou que a transmitância não está diretamente relacionada com a cor da resina composta, já a composição da resina composta está diretamente relacionada à cor.

Vichi et al. ${ }^{81}, 2007$, avaliaram a influência da espessura da camada na cor final de combinações de resinas de diferentes opacidades e tonalidades em laboratório, simulando a técnica de estratificação de duas camadas. Seis cps em forma de discos de diferentes espessuras $(0,5$, $1,0,1,5,2,0,2,5,3,0)$ foram confeccionados com a resina composta Point4 (Kerr Co.), as tonalidades de dentina (base) selecionadas foram A1, A2, A3 e A4 e as translúcidas foram: T1, T2 e T3. Todas as 288 combinações de base + material translúcido foram mensuradas por meio 
do espectrofotômetro PSD1000 (Ocean Optics, FL, USA). Os resultados mostraram diferenças de até 5,1 unidades de $\Delta \mathrm{E}$ para as camadas de material de base com espessura de 0,5 a $3,0 \mathrm{~mm}$, essas diferenças aumentaram quando a espessura de material translúcido diminuiu. A cor translúcida também influenciou o aspecto final das amostras, enquanto que cada cor translúcida teve comportamento diferente dependendo de sua tonalidade e de sua espessura. Concluíram que a espessura da camada e a proporção das resinas translúcida e de dentina desempenham um papel significativo na percepção da cor em restaurações de múltiplas camadas.

Yuan et al. ${ }^{84}$, em 2007, definiram um espaço de cor baseado num sistema de cor tridimensional. Foi definido um espaço de cor, representativo da população do estado de Buffalo (Nova York), que foi comparado com o espaço de cor determinado pelo fabricante. Foram mensurados 933 incisivos centrais superiores (501 pacientes) por meio do espectrofotômetro Vita Easyshade ${ }^{\circledR}$. Para cada dente, os valores de $L^{*}, a^{*}$ e $b^{*}$, croma, matiz e a cor mais aproximada (Vitapan 3D-Master) foi registrada. Uma análise de regressão linear foi realizada para determinar o quanto os valores fornecidos pelos fabricantes predizem os valores reais para $L^{*}, a^{*} e b^{*}$. As diferenças de cor $(\Delta E)$ entre a população de Buffalo e a cor mais aproximada foram também calculadas. Um teste $\mathrm{T}$ de uma amostra foi usado para determinar se as diferenças de cor vistas nas amostras foram estatisticamente diferentes daquele limite 
perceptível, $\Delta \mathrm{E}^{*}=3,7(\alpha=0,05)$. Os resultados demonstraram que: 1$)$ todas 3 coordenadas dos dentes naturais da população de Buffalo apresentaram uma abrangência maior do que aquelas das escalas de referência; entretanto, a análise de regressão revelou uma relação significativamente positiva entre os valores de $L^{*}, a^{*}$, e b* dos 2 métodos $(p<0,001) ; 2)$ o teste $T$ revelou uma diferença de $\Delta \mathrm{E}$ significativa $\left(\Delta \mathrm{E}^{*}\right.$ médio $=6,15)$ no limite adotado como perceptível, o qual foi de $\Delta \mathrm{E}^{*}=3,7$ $(p<0,001)$. Concluíram que as diferenças de cor entre as coordenadas de cor da população de Buffalo e das escalas de referência foram normalmente acima do limite perceptível, mas dentro do limite de aceitabilidade. O espaço de cor dos dentes naturais da população de Buffalo foi mais amplo que o espaço de cor das escalas de referência.

A avaliação clínica quantitativa das propriedades ópticas dos incisivos foi realizada por Ardu et al. $^{3}$ (2008). Foram selecionados aleatoriamente 10 indivíduos na região de Veneza, com idade entre 18 e 33 anos. Esses indivíduos apresentavam os incisivos centrais superiores hígidos, sem malformações, colorações intrínsecas significativas, fissuras ou restaurações. Uma fotografia digital (FinePix S2 Pro, Fugifilm Switzerland, Dielsdorf, Switzerland) com lentes macro (105 mm, Nikon, Zurich, Switzerland) documentou a seleção de cor juntamente com a referência de cor da escala Vitapan 3D-Master (Vita, Bad Sackingen, Germany) com sua extremidade inferior alinhada com a extremidade inferior do incisivo central superior direito. Dois cirurgiões-dentistas 
calibrados escolheram independentemente as referências de cores e em caso de discordância, uma concordância era obtida por consenso entre os 2 operadores. Foi utilizado neste estudo o espectrofotômetro SpectroShade (Handy Dental Type 713000, Serial $n^{\circ}$ HDL0090, MHT, Arbizzano di Negar, Verona, Italy) que quantificou $L^{*}$ (luminosidade) $a^{*}$ (quantidade de verde-vermelho) e $b^{*}$ (quantidade de azul-amarelo) do esmalte e do complexo esmalte-dentina sobre fundo branco e preto. Baseados nesses dados in vivo, a opacidade (CR) e a opalescência (habilidade para refletir o comprimento de onda azul quando a luz branca atravessa perpendicularmente o objeto) foram também calculadas. Os valores médios de $L^{*}$ do complexo esmalte-dentina sobre fundo branco e preto foram respectivamente de: 79,6 e $75,4 \%$. Os valores médios de a* foram 2,5 sobre fundo preto e 0,8 sobre fundo branco. Os valores médios de $b^{*}$ foram 17,4 sobre fundo preto e 13,0 sobre fundo branco. O valor da opalescência foi de 4,8 . Os valores médios de $L^{*}$ do esmalte sobre fundo branco e preto foram de 79,0 e 64,2 , respectivamente. Os valores médios de $a^{*}$ foram de 2,1 sobre fundo preto e $-0,3$ sobre fundo branco. Os valores médios de $b^{*}$ foram 15,2 sobre fundo preto e 8,7 sobre fundo branco. O valor da opalescência foi de 7,4. Concluíram que a metodologia descrita quando aplicada sobre um grande grupo de indivíduos, pode servir como base para uma caracterização mais precisa das propriedades ópticas do esmalte e dentina naturais. 
Jarad et al. ${ }^{35}$, em 2008, investigaram se o clareamento realizado antes da cimentação de uma faceta de resina composta, afetaria na cor final da restauração e se esta seria afetada pela espessura ou pela cor da faceta. Vinte dentes bovinos foram coletados, seccionados e divididos em 2 grupos, um grupo que não foi submetido ao clareamento serviu como controle, enquanto o outro grupo foi composto por dentes em que foi realizado o clareamento. As mensurações de cor foram efetuadas utilizando o espectrofotômetro Easyshade ${ }^{\circledR}$. O grupo foi submetido ao clareamento externo com peróxido de hidrogênio a $38 \%$ e em seguida foi realizada a mensuração da cor. Cada um desses 2 grupos foram subdivididos em 4 subgrupos (resina composta híbrida TPH Spectrum ${ }^{\circledR}$ tonalidades A1 e A4 com 0,5 mm de espessura e 1,0 mm de espessura) nos quais uma camada de resina foi inserida e em seguida foi realizada a mensuração da cor. Houve diferença entre as tonalidades para as mesmas espessuras de resinas entre os 2 grupos avaliados. Para a resina com tonalidade $\mathrm{A} 4$ com espessura de $0,5 \mathrm{~mm}$, no grupo que foi submetido ao clareamento, foi encontrada uma diferença significativa na alteração de cor $(\Delta \mathrm{E})$ comparada apenas com a camada de resina. Para a resina com tonalidade $A 1$, no grupo que não foi submetido ao clareamento, houve uma diferença significativa no $\Delta \mathrm{E}$, produzida pela alteração na espessura da camada de resina. Os autores concluíram que o clareamento realizado previamente à confecção de uma faceta delgada $(0,5 \mathrm{~mm})$ de resina na tonalidade $\mathrm{A} 4$ produz uma diferença significativa 
na alteração de cor $(\Delta \mathrm{E})$. Quando o clareamento não foi realizado, a alteração na espessura da resina com tonalidade A1 produziu uma diferença de cor significativa; entretanto, quando o clareamento foi realizado não existiu diferença significativa.

Kim, Lee ${ }^{40}$, em 2008, avaliaram as alterações na cor e nas coordenadas de cor de uma resina composta indireta durante um ciclo de polimerização. A resina composta laboratorial belleGlass NG (Kerr Corp., Orange, CA, USA), em um total de 16 tonalidades, foi investigada. As cores foram divididas em 3 grupos: esmalte (EN), dentina opaca (OD) e translúcida (TL). Foram confeccionados $5 \mathrm{cps}$ medindo $12 \mathrm{~mm}$ de diâmetro e 1,0 mm de espessura para cada cor por meio de uma matriz de polietileno $(\mathrm{BC})$, polimerizados por meio do aparelho de luz polimerizadora Spectrum 800 (Dentsply/Caulk, Milford, DE, USA) (C1). A polimerização secundária foi realizada em uma câmara polimerizadora (C2). A cor foi mensurada nas tonalidades $\mathrm{C} 1$ e C2. As alterações na cor e nas coordenadas de cor foram calculadas pela ANOVA de 3 critérios. A alteração na cor devido à polimerização (C2 - BC) foi de 1,0 a 10,1 unidades de $\Delta \mathrm{E}^{*}$ ab. As alterações nas coordenadas de cor variaram de acordo com a tonalidade do grupo. Concluíram que as alterações na cor durante o ciclo de polimerização foram perceptíveis nas diversas cores de acordo com a tonalidade $\left(\Delta \mathrm{E}^{*}{ }_{\mathrm{ab}}>3,7\right)$; além disso, a prática clínica de seleção de cor deveria considerar essas alterações na cor. 
A influência da remoção da camada superficial das referências de cor na mensuração da cor por meio de um espectrofotômetro e de um espectroradiômetro foi estudada por Kim et al. ${ }^{43}$ (2008). A cor das referências de cores da escala Vitapan 3D-Master (Vita) foi mensurada antes e após a remoção da camada superficial das referências de cores por meio do espectrofotômetro (SP) Color-Eye 7000A (GretagMacbeth Instruments) e do espectroradiômetro (SR) PR 680 (Photo Research, Chatsworth, CA, USA). As correlações entre as superfícies originais (OR) das referências de cores e as que tiveram sua camada superficial removida $(\mathrm{RM})$ e entre as mensurações realizadas pelo espectrofotômetro e pelo espectroradiômetro foram determinadas $(\alpha=0,05)$. Baseados nos dados fornecidos pelo espectrofotômetro, a luminosidade, o croma e os valores de $\mathrm{ClEa}^{*}$ e b* após a remoção da camada superficial foram na maioria mais elevados que aqueles das referências de cores originais. Baseados nos dados fornecidos pelo espectroradiômetro, o croma e os valores de CIEa* e b* após a remoção da camada superficial foram na maioria mais elevados do que as referências de cores originais; entretanto, em relação à luminosidade, as alterações variaram em função da cor. O tipo de instrumento influenciou as alterações nos parâmetros de cor baseados no test T-pareado $(p<0,05)$. Os parâmetros de cor das referências OR e RM mostraram correlações baseadas nas mensurações por ambos os equipamentos SP e SR $(r=0,952-0,997$ e $p<0,01)$; entretanto, as diferenças de cor entre 
SP-RM e SR-OR foram da magnitude de $18,1-27,0$ unidades de $\Delta \mathrm{E}$ (média: $23,3 \pm 2,2$ ). Concluíram que quando a cor dos objetos com o formato de dente é mensurada com espectrofotômetro ou espectroradiômetro, os protocolos das mensurações deveriam ser especificados devido às diferenças de cor ocasionadas pela remoção da camada superficial e pelo equipamento de mensuração utilizado.

Lim et al. ${ }^{51}$, em 2008, estudaram a influência do tamanho e da quantidade das partículas de carga nos parâmetros de cor de resinas compostas experimentais. A cor de 11 resinas experimentais com 2 diferentes tamanhos de partículas (LG: 0,77 $\mu \mathrm{m}$ e SG: 0,50 $\mu \mathrm{m}$ ) em 10$70 \%$ em peso foi mensurada pelo espectrofotômetro Color - Eye 7000 A (GretagMacbeth Instruments Corp., New Windsor, NY, USA) que determinou as coordenadas de cor $\left(\operatorname{CIE~} L^{*}, a^{*}\right.$ e $\left.b^{*}\right)$, matiz e croma. Foram calculadas também as constantes ópticas incluindo o coeficiente de dispersão (S), coeficiente de absorção $(K)$ e a refletividade da luz (RI). Para determinar a influência da quantidade de partículas nos parâmetros ópticos, foi utilizada a correlação de Pearson $(p<0,05)$. Os resultados indicaram aumento no valor de $\mathrm{S}$ quando a quantidade de partículas aumentou. Os valores de $\mathrm{RI}$, geralmente, aumentaram quando a quantidade de partículas aumentou para o grupo LG e aumentou acima de $40 \%$ para o grupo SG. Os valores de $\mathrm{CIE} \mathrm{L}^{*}$ aumentaram quando a quantidade de partículas aumentou para ambos os grupos (LG e SG). Os valores de $\mathrm{CIE} \mathrm{L}^{*}$ foram mais elevados quando se correlacionou os 
valores de S e RI para ambos os grupos. Os autores concluíram que a luminosidade foi mais alta quando se correlacionou os valores da quantidade de partículas, os valores de S e de RI, mas o coeficiente de correlação entre a quantidade de partículas de carga foi moderada; além disso, a pigmentação simularia a cor dos dentes naturais, sendo outro fator a influenciar a cor das resinas compostas. Sendo assim, as propriedades ópticas das resinas compostas poderiam simular parcialmente àquelas dos dentes naturais pelo controle das partículas de carga.

Meireles et al. ${ }^{54}$, em 2008, avaliaram a validade e a confiabilidade da avaliação visual da cor do dente usando a escala Vita Classical (Vita Zahnfabrik, Bad Sackingen, Germany). Foram selecionados para o estudo 92 indivíduos, divididos em grupos, para comparar 2 formulações de peróxido de carbamida. Inicialmente, cada indivíduo tinha a cor de seus dentes anteriores superiores $(n=552)$ aferidas por meio do espectrofotômetro Vita Easyshade ${ }^{\circledR}$ (Vita - Zahnfabrik, Bad Sackingen, Germany). Em seguida, uma avaliação visual foi realizada por 2 examinadores calibrados usando a escala de referência. O espectrofotômetro foi usado como "padrão ouro" para calcular a sensibilidade e a especificidade da avaliação visual. Os autores concluíram que apesar da subjetividade, a avaliação visual da cor do dente usando a escala Vita Classical é um método válido, com adequada confiabilidade para diferenciar as cores claras das escuras. 
Com os propósitos de: 1) examinar as características de transmitância da luz de 2 resinas compostas com diferentes espessuras, 2) correlacionar a penetração da luz através das resinas compostas e das partículas de carga, e 3) determinar a profundidade de penetração da luz em função do comprimento de onda, Santos et al. ${ }^{70}$, em 2008, confeccionaram 3 cps com as resinas compostas Filtek ${ }^{\mathrm{TM}}$ Z-250 (3M/ ESPE), tonalidade A2 e Filtek ${ }^{T M}$ Supreme XT (3M/ESPE), tonalidade A2E com diferentes espessuras $(0,15,0,25,0,30,0,36,0,47$ e $0,75 \mathrm{~mm})$. A transmitância nos comprimentos de onda de 400, 450, 468, 500, 600, 700 e $800 \mathrm{~nm}$ foi mensurada usando o espectrofotômetro visível Ultra-Violeta HP 8452A (Palo Alto, Califórnia). De acordo com os resultados, diferenças significativas foram encontradas na dependência do comprimento de onda da transmitância entre os 2 materiais e entre os estágios das resinas compostas polimerizadas e não polimerizadas. Para os comprimentos de onda, a transmitância da luz da resina composta Filtek $^{T M}$ Supreme $\mathrm{XT}$ foi mais baixa do que para a Filtek ${ }^{\mathrm{TM}}$ Z-250. Para os comprimentos de onda mais elevados, entretanto, a Filtek ${ }^{\mathrm{TM}}$ Supreme XT apresentou mais alta transmitância da luz. Para ambas as resinas compostas, a profundidade de penetração da luz foi mais alta após a polimerização. No entanto, a resina Filtek ${ }^{\mathrm{TM}}$ Supreme XT demonstrou maior ganho na transmitância para a espessura de 0,15 mm. Foi concluído que as diferenças nas características de transmitância da luz podem afetar sua profundidade de polimerização. 
Silva et al. ${ }^{75}$, em 2008, avaliaram a efetividade clínica de um sistema espectrofotométrico de seleção de cor na reprodução da cor do dente. Foram confeccionadas 2 coroas metalocerâmicas para um incisivo central superior para 36 pacientes, usando 2 técnicas de seleção de cor: a primeira técnica foi a seleção visual convencional usando as escalas Vita Classical e Vitapan 3D-Master (Vita Zahnfabrik) e Chromascop (Ivoclar Vivadent, Schaan, Liechtenstein) e a segunda foi a seleção instrumental usando o espectrofotômetro Crystaleye (Olympus). Os valores de diferença de cor $(\Delta E)$ entre os dentes naturais contralaterais e cada uma das 2 coroas foram calculadas nas áreas cervical, medial e incisal. Os valores de $\Delta \mathrm{E}$ foram comparados usando o teste T-Student $(\alpha=0,05)$. Os resultados revelaram que os valores médios de $\Delta \mathrm{E}$ da seleção de cor das coroas com o espectrofotômetro foram significativamente mais baixos do que aqueles usando a técnica convencional $(p<0,01)$ e que as cores das coroas selecionadas convencionalmente apresentaram maior probabilidade de serem rejeitadas do que aquelas usando o espectrofotômetro $(p<0,001)$. Concluíram que as coroas confeccionadas usando o espectrofotômetro apresentaram uma seleção de cor significativamente melhor e um menor índice de rejeição quando comparadas às coroas confeccionadas com o método convencional.

Yu, Lee ${ }^{85}$, em 2008, avaliaram as propriedades ópticas tais como: cor, translucidez e fluorescência de resinas compostas fluidas 
comparadas com as cores universais correspondentes da mesma marca comercial. Foram investigadas 4 resinas compostas fluidas e universais: Esthelite Flow Quick e Esthelite Sigma / Tokuyama; Filtek Z350 Flowable e Filtek Z350 Universal / 3M ESPE; Unifil Flow e Gradia Direct / GC; Tetric Flow e Tetric Ceram / Ivoclar Vivadent, na tonalidade A2. A cor dos cps que possuíam $10 \mathrm{~mm}$ de diâmetro e $2 \mathrm{~mm}$ de espessura foi mensurada após a fotoativação, por meio do espectrofotômetro de reflectância Color - Eye 7000A / GretagMabeth, New Windsor, NY, USA) sobre os fundos branco, preto e correspondente à própria resina. As diferenças de cor $\left(\Delta \mathrm{E}^{*} \mathrm{ab}\right)$ entre cada combinação de resinas compostas foram determinadas. Foram também calculados o parâmetro de translucidez (TP) e a diferença de cor pela emissão de fluorescência $\left(\Delta \mathrm{E}^{*}{ }_{\mathrm{ab}}-\mathrm{FL}\right)$ dos materiais. As diferenças nas propriedades ópticas das resinas compostas fluidas e universais foram analisadas por meio de ANOVA de 1 critério. De acordo com os resultados a $\Delta E^{*}{ }_{a b}$ entre as resinas compostas fluidas e suas correspondentes universais foi de 1,0 a 6,0 unidades de $\Delta \mathrm{E}^{*}{ }_{\mathrm{ab}}$, que foi perceptível $\left(\Delta \mathrm{E}^{*}{ }_{\mathrm{ab}}>2,6\right)$ em 3 marcas. As resinas compostas fluidas revelaram menores valores de TP em 2 das 4 marcas. A $\Delta E^{*}$ ab entre as resinas compostas fluidas e suas correspondentes universais foi influenciada por sua diferença na translucidez. Todas as 4 resinas compostas universais mostraram picos de fluorescência e a $\Delta \mathrm{E}^{*}{ }_{\mathrm{ab}}-\mathrm{FL}$ foi de 0,3 a 2,3 unidades de $\Delta \mathrm{E}^{*}{ }_{\mathrm{ab}}$. Concluíram que as propriedades ópticas das resinas compostas fluidas e 
universais foram significativamente diferentes $(p<0,05)$ e que as diferenças na cor, translucidez e fluorescência entre essas resinas deveriam ser consideradas para uma seleção de cor clinicamente aceitável.

Com o propósito de investigar o efeito da composição da matriz resinosa na translucidez de resinas compostas experimentais Azzopard ${ }^{4}$ et al., em 2009, formularam e fotoativaram três tipos de matrizes resinosas sem carga (à base de TEGDMA, UDMA e BisGMA). Em seguida, formularam seis tipos de resinas compostas com mesma quantidade de carga (partículas de sílica), porém variando o tipo de monômero e o conteúdo de BisGMA. Foram confeccionados e fotoativados 3 discos (dimensões de $15,5 \mathrm{~mm}$ de diâmetro e $1 \mathrm{~mm}$ de espessura) de cada material testado. Os valores de transmitância total e difusa foram mensurados para cada $\mathrm{cp}$ por meio do espectrofotômetro PerkinElmer Lambda 2 que avaliava as diferenças de cor usando o sistema CIE Lab. A análise estatística realizada por meio de ANOVA, seguida pelo teste de Tukey não demonstrou diferenças estatisticamente significativa nos valores de transmitância entre as três resinas sem carga testadas. No entanto, com a adição das partículas de carga, as resinas compostas contendo BisGMA demonstraram valores de transmitância significativamente mais elevadas em comparação com as resinas compostas à base de UDMA e TEGDMA. A análise de regressão realizada revelou que houve uma correlação entre a quantidade de 
BisGMA da matriz resinosa e a translucidez total e difusa. Os autores concluíram que a quantidade de BisGMA adicionada à matriz resinosa da resina composta ocasiona um efeito significativo na translucidez das resinas compostas contendo partículas de sílica.

Della Bona et al. ${ }^{17}$, em 2009, avaliaram a concordância visual e instrumental na seleção da cor. A cor de um incisivo central superior direito (natural) (RUCl) foi selecionada por 3 populações distintas: observadores que não eram cirurgiões-dentistas (GP), estudantes de odontologia (DS) e cirurgiões-dentistas (DD). Todos os observadores $(n=600)$ usaram as escalas de cores Vitapan 3D-Master (3D) e Vita Classical (VC) em 2 condições de luminosidade: luz fria fluorescente branca (CWF) e luz natural do sol (NSL). A cor das escalas e dos dentes naturais foi identificada usando o espectrofotômetro intra-oral Vita Easyshade ${ }^{\circledR}$ para determinar a concordância da seleção da cor visual com a instrumental. A concordância percentual de cor visual-instrumental (PVIA) foi analisada estatisticamente considerando: a população observada, as escalas de cores e as condições de iluminação. Os resultados demonstraram uma concordância substancial intraexaminadores $(k=0,76)$. Os resultados indicaram que os GP com ou sem conhecimento odontológico nem experiência com escalas de referência, obtiveram uma PVIA significativamente mais elevada usando a escala VC do que a 3D. Os dentistas demonstraram o mais elevado PVIA (42\%) para ambas as condições de iluminação e escalas de cores. Os autores 
concluíram que uma concordância de cor visual-instrumental significativamente mais elevada foi demonstrada pelos cirurgiõesdentistas clinicamente experientes (DD), em detrimento das escalas e das condições de iluminação.

Kim, Lee ${ }^{42}$, em 2009, mensuraram a diferença de cor e das coordenadas de cor entre as mesmas tonalidades de resinas compostas de diferentes marcas e determinaram a influência da tonalidade na diferença de cor e nas coordenadas de cor entre elas. Foram investigadas 8 resinas compostas fotoativadas, com total de 32 tonalidades. A cor das amostras $(12 \mathrm{~mm}$ de diâmetro e $1 \mathrm{~mm}$ de espessura) foi mensurada por meio do espectrofotômetro Color-Eye $7000 \mathrm{~A}$ sobre um fundo branco. A diferença na cor $\left(\Delta \mathrm{E}_{a b}{ }^{*}\right)$ e nas coordenadas de cor, tais como CIEL* (luminosidade), a* (coordenada vermelho-verde), $b^{*}$ (coordenada amarelo-azul) entre cada par de resinas compostas da mesma cor foram calculadas e analisadas por análise de variância de 1 critério $(p<0,05)$. Foi concluído que, como a diferença de cor variou entre as resinas de mesma tonalidade e marcas comerciais diferentes de acordo com a cor, e como essa diferença foi perceptível em mais da metade dos pares de resinas comparadas $\left(\Delta \mathrm{E}_{\mathrm{ab}}{ }^{*}>3,7\right)$, as propriedades ópticas das resinas compostas deveriam ser consideradas durante a seleção destes materiais, em função da diferença apresentada de acordo com a tonalidade e marca comercial. 
Lagouvardos et al. $^{46}$, em 2009, avaliaram as diferenças na repetibilidade e na confiabilidade entre dois equipamentos: ShadeEye NCC (Shofu Dental) e Vita Easyshade ${ }^{\circledR}$ (Vita Zahnfabrik). Trinta e um dentes anteriores humanos extraídos foram mensurados 2 vezes com cada um dos equipamentos por um pesquisador experiente e calibrado. Os valores de $L^{*} a^{*}$ e a seleção de cores por meio dos sistemas de escalas de referência Vita Classical e Vitapan 3D-Master foram determinadas para todos os dentes. O teste T-pareado e o coeficiente de correlação intra-classe (ICCs) foram usados para analisar estatisticamente os dados $(\alpha=0,05)$. Os resultados mostraram que os valores de $L^{*} a^{*} b^{*}$ com Vita Easyshade ${ }^{\circledR}$ foram significativamente mais elevados do que aqueles mensurados com ShadeEye NCC, com uma diferença média de 10,01 unidades de $\Delta \mathrm{E}$. A repetibilidade ICCs do equipamento para mensuração da cor do dente alcançou de 0,693 a 0,929, com diferenças significativas entre os equipamentos apenas com respeito ao parâmetro de $L^{*}(p=0,042)$. O ICCs intra-equipamentos para a seleção da cor do dente alcançou de 0,714 a 0,894 , com diferenças significativas entre os equipamentos apenas em relação a escala Vita Classical $(p=0,042)$. Os ICCs de repetibilidade dos equipamentos para mensurar a cor do dente alcançou de 0,402 a 0,486, com diferenças significativas entre os parâmetros de $L^{*} a^{*} b^{*}$, enquanto a confiabilidade interequipamento alcançou de 0,189 a 0,430, com nenhuma diferença significativa entre as 2 escalas $(p>0,05)$. Concluíram que: todos os 
parâmetros foram mais altos com o equipamento Vita Easyshade ${ }^{\circledR}$; a repetibilidade do ShadeEye NCC foi maior do que para o Vita Easyshade $^{\circledR}$ para a escala Vita Classical; a confiabilidade interequipamento não foi diferente para os parâmetros de cor, mas a confiabilidade para a escala Vita Classical foi maior do que para Vitapan 3D-Master. 
Proposição 


\section{PROPOSIÇÃO}

Avaliar, por meio de metodologia instrumental, a correspondência entre tonalidades de diferentes escalas de cor e dessas com resinas compostas, a fim de testar as seguintes hipóteses:

1) Existe correspondência entre tonalidades de diferentes escalas de referência de cor;

2) Existe correspondência entre as tonalidades das resinas compostas;

3) A composição da resina composta não afeta a correspondência de cor entre as mesmas e nem com as escalas de referência;

4) A espessura do incremento de resina composta não afeta a correspondência de cor com as escalas de referência. 
Para tal, foram avaliados os seguintes fatores e níveis de variação:

1 Escalas referência de cor (3 níveis)

a. Vita Lumin Vacuum (Vita Classical)

b. Vitapan 3D-Master

c. Chromascop

2 Tonalidades (2 níveis)

a. Tonalidade A2E

b. Tonalidade B2E

3 Composição (2 níveis)

a. Híbrida (4 Seasons ${ }^{\circledR}$ )

b. Nano-aglomerada (Filtek ${ }^{\mathrm{TM}}$ Supreme XT)

4 Espessuras (10 níveis)
a. $\quad 0,2 \mathrm{~mm}$
b. $\quad 0,4 \mathrm{~mm}$
c. $\quad 0,6 \mathrm{~mm}$
d. $\quad 0,8 \mathrm{~mm}$
e. $1,0 \mathrm{~mm}$
f. $1,2 \mathrm{~mm}$
g. $1,4 \mathrm{~mm}$
h. $1,6 \mathrm{~mm}$
i. $\quad 1,8 \mathrm{~mm}$
j. $2,0 \mathrm{~mm}$ 


\section{Material e Método}




\section{MATERIAL E MÉTODO}

Em função do exposto, este estudo foi dividido em dois experimentos:

- Correspondência de cor entre tonalidades de diferentes escalas de referência;

- Correspondência de cor entre resinas compostas e escalas de referência em função da tonalidade, composição e espessura.

\subsection{Material}

\subsubsection{Escalas de referência de cor}

As escalas de cor utilizadas como referência foram: Vita Lumin Vacuum, (Vita Zahnfabrik, Germany), atualmente designada Vita Classical (FIGURA 1); Vitapan 3D-Master (Vita Zahnfabrik, Germany) (FIGURA 2) e Chromascop (Ivoclar Vivadent, Schaan, Liechtenstein) (FIGURA 3).

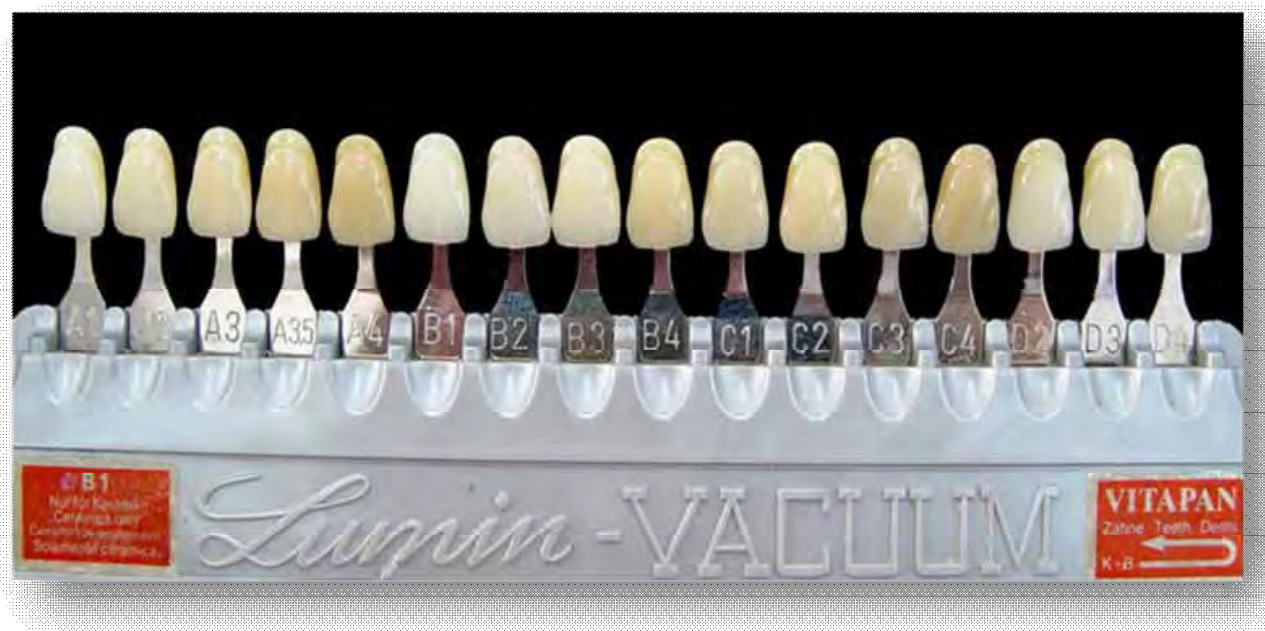

FIGURA 1 - Escala Vita Classical. 


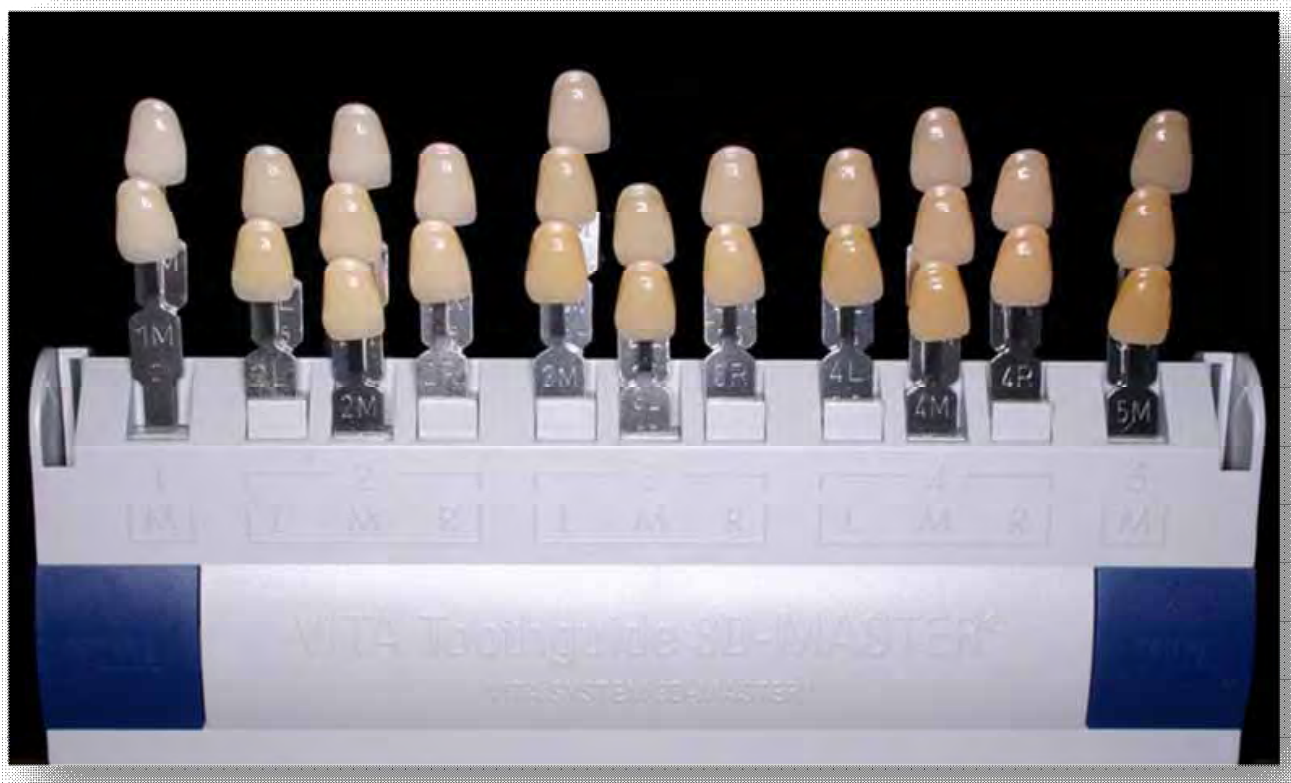

FIGURA 2 - Escala Vitapan 3D-Master.

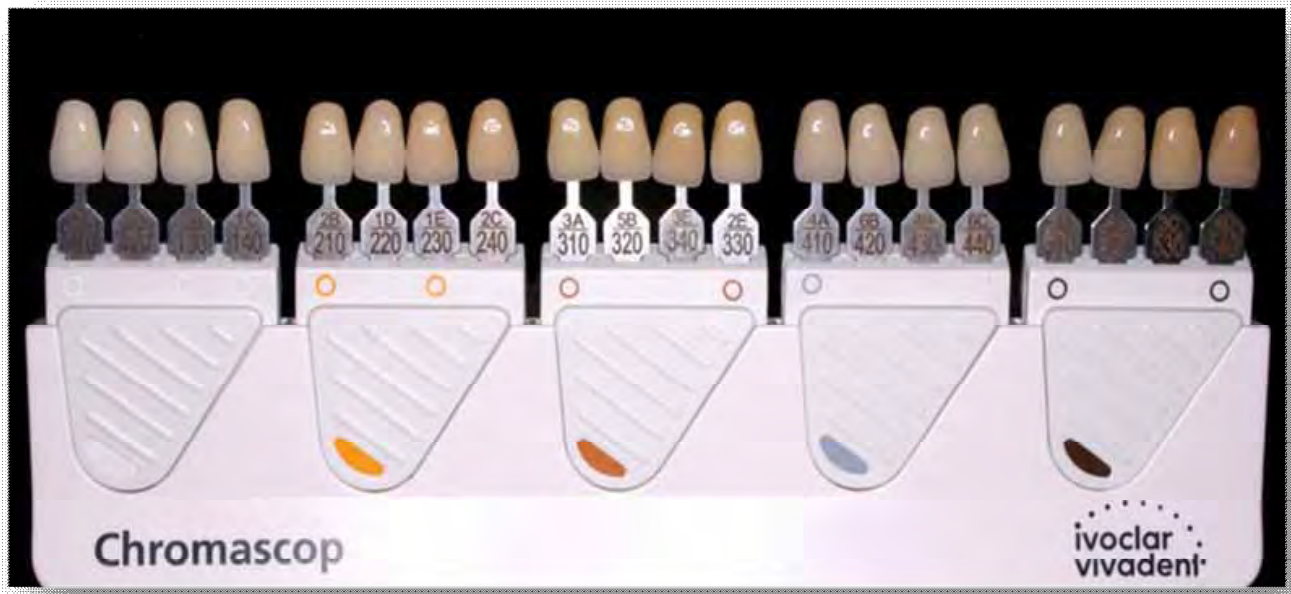

FIGURA 3 - Escala Chromascop. 
O Quadro 1 apresenta a forma de organização, siglas e descrição das escalas de referência utilizadas no estudo.

Quadro 1 - Forma de organização, siglas e descrição das escalas de cor utilizadas

\begin{tabular}{|c|c|c|c|c|}
\hline $\begin{array}{l}\text { ESCALA DE } \\
\text { REFERÊNCIA } \\
\text { DE COR }\end{array}$ & FABRICANTE & $\begin{array}{c}\text { FORMA DE } \\
\text { ORGANIZAÇÃO } \\
\text { DAS } \\
\text { TONALIDADES }\end{array}$ & SIGLAS & DESCRIÇÃO \\
\hline Vita Classical & Vita & Matiz & $\begin{array}{c}\text { A1, A2, A3, A3,5 e A4 } \\
\text { B1, B2, B3, B4 } \\
\text { C1, C2, C3, C4 } \\
\text { D2, D3,D4 }\end{array}$ & $\begin{array}{c}\text { Marrom } \\
\text { avermelhado } \\
\text { Amarelo } \\
\text { avermelhado } \\
\text { Cinza } \\
\text { Cinza } \\
\text { avermelhado }\end{array}$ \\
\hline $\begin{array}{l}\text { Vitapan 3D- } \\
\text { Master }\end{array}$ & Vita & $\begin{array}{l}\text { Luminosidade } \\
\text { (Valor) }\end{array}$ & $\begin{array}{c}1 \mathrm{M} 1 \text { e 1M2 } \\
2 \mathrm{~L} 1,5,2 \mathrm{~L} 2,5,2 \mathrm{M} 1,2 \mathrm{M} 2 \\
2 \mathrm{M} 3,2 \mathrm{R} 1,5,2 \mathrm{R} 2,5 \\
\text { 3L1,5, 3L2,5, 3M1, 3M2, } \\
\text { 3M3, 3R1,5, 3R2,5 } \\
\text { 4L1,5, 4L2,5, 4M1, 4M2, } \\
4 \mathrm{M} 3,4 \mathrm{R} 1,5,4 \mathrm{R} 2,5 \\
5 \mathrm{M} 1,5 \mathrm{M} 2 \text { e } 5 \mathrm{M} 3\end{array}$ & $\begin{array}{l}1 \\
2 \\
3 \\
4 \\
5\end{array}$ \\
\hline Chromascop & $\begin{array}{l}\text { Ivoclar I } \\
\text { Vivadent }\end{array}$ & Matiz & $\begin{array}{c}\text { 110/01, 120/1A, 130/2A e } \\
140 / 1 \mathrm{C} \\
\text { 210/2B, 220/2D, 230/1E } \\
\text { e 240/2C } \\
310 / 3 \mathrm{~A}, 320 / 5 \mathrm{~B}, 330 / 2 \mathrm{E} \\
\text { e } 340 / 3 \mathrm{E} \\
410 / 4 \mathrm{~A}, 420 / 6 \mathrm{~B}, 430 / 4 \mathrm{~B} \\
\text { e } 440 / 6 \mathrm{C} \\
510 / 6 \mathrm{D}, 520 / 4 \mathrm{C}, 530 / 3 \mathrm{C} \\
\text { e } 540 / 4 \mathrm{D}\end{array}$ & $\begin{array}{c}\text { Branco } \\
\text { Amarelo } \\
\text { Marrom } \\
\text { Cinza } \\
\text { Marrom Escuro }\end{array}$ \\
\hline
\end{tabular}

\subsubsection{Espectrofotômetro}

Para a obtenção dos valores de $\Delta \mathrm{E}$ das escalas de referência de cor e dos corpos-de-prova de resina composta foi utilizado um 
espectrofotômetro clínico específico para uso odontológico: Vita Easyshade $^{\circledR}$ (Vident, Brea, CA, USA) (FIGURA 4).

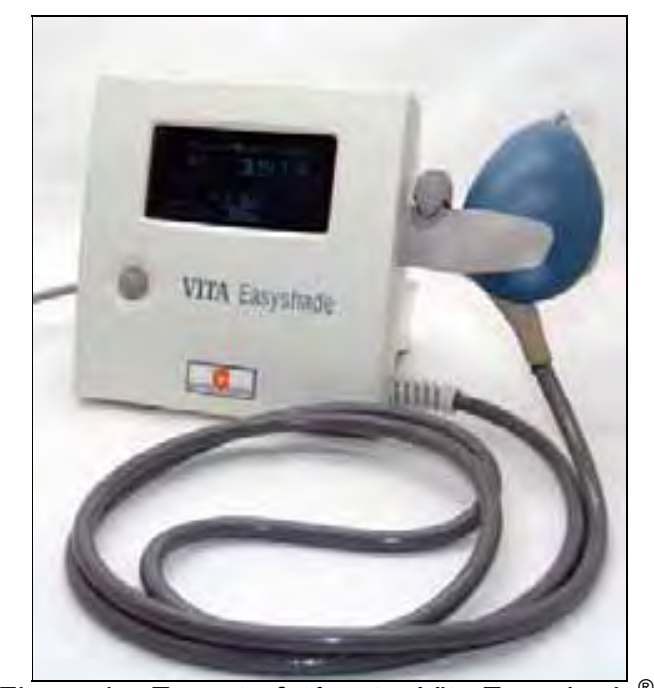

Figura 4 - Espectrofotômetro Vita Easyshade ${ }^{\circledR}$.

O Vita Easyshade ${ }^{\circledR}$ é um aparelho digital para seleção de cor. O Easyshade $^{\circledR}$ utiliza o iluminante D65-(6500 K) para a determinação das cores. Este iluminante é uma construção matemática que, em termos físicos não se traduz em forma de uma fonte de luz, mas que se assemelha à intensidade média da luz do dia no hemisfério norte. A amplitude de medição é de $5 \mathrm{~mm}$ de diâmetro. O Easyshade ${ }^{\circledR}$ utiliza um dispositivo de sonda patenteado que possibilita uma medição de cor sem a influência da luz direcionada, garantindo que a luz ofuscante refletida pela superfície do dente não infuencia a precisão da medição. O Easyshade $^{\circledR}$ abrange o espectro completo de luz visível entre $400 \mathrm{~nm}$ e 700nm. Com base neste espectro e utilizando as funções de ajustamento de cor do observador padrão e do espectro do iluminante, são calculadas as funções de cor $X Y Z$ e em seguida os valores $L^{*} a^{*} b^{*}$ e $L^{*} C^{*} h^{*}$. 
Alterando o espectro do iluminante podem ser calculados valores $L^{*} a^{*} b^{*} e$ $L^{*} C^{*} h^{*}$ para mostrar o efeito sobre a percepção da cor causado pela alteração da fonte de luz. Apresenta uma amplitude de temperatura de $0^{\circ} \mathrm{C}$ a $40^{\circ} \mathrm{C}$. O Easyshade ${ }^{\circledR}$ apresenta tabelas com 26 cores da Vitapan 3D-Master (e 3 cores de clareamento), as tabelas contém também 52 cores interpoladas (cores intermediárias) que, são obtidas através de uma mistura uniforme das massas 3D-Master correspondentes e tabelas com as 16 cores da Vita Classical. O Easyshade ${ }^{\circledR}$ mede dentes e restaurações até a cor 3D-Master (incluindo as interpoladas) mais aproximada.

\subsubsection{Resinas Compostas}

Das diferentes marcas comerciais disponíveis no mercado odontológico nacional, optou-se pela seleção da resina composta Filtek $^{\mathrm{TM}}$ Supreme XT (3M/ESPE) e 4 Seasons $^{\circledR}$ (Ivoclar/Vivadent) (FIGURAS 5 e 6, respectivamente) nas tonalidades A2E e B2E. Estas foram escolhidas por terem composições nitidamente diferentes conforme descrito no Quadro 2.

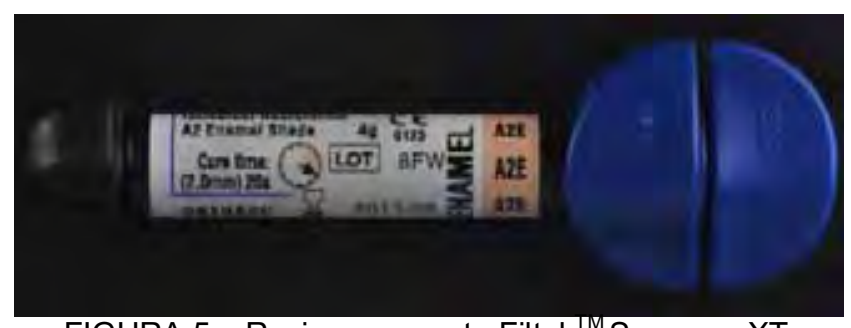

FIGURA 5 - Resina composta Filtek ${ }^{\mathrm{TW}}$ Supreme XT. 


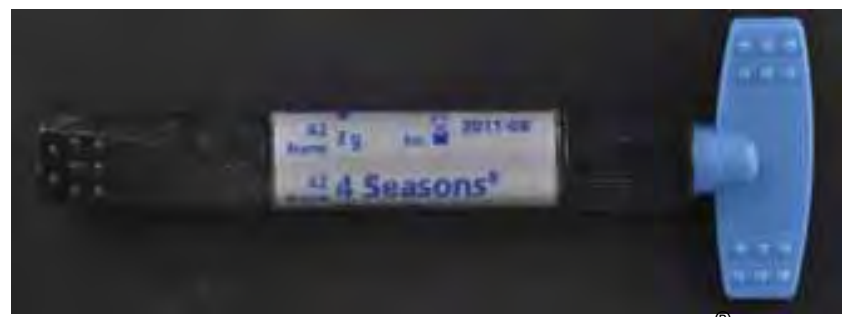

FIGURA 6 - Resina composta 4 Seasons ${ }^{\circledR}$.

Quadro 2 - Características das resinas compostas utilizadas

\begin{tabular}{|c|c|c|c|c|}
\hline $\begin{array}{c}\text { MARCAI } \\
\text { FABRICANTE }\end{array}$ & CLASSIFICAÇÃO & $\begin{array}{l}\text { TONALIDADE } \\
\text { (LOTE) }\end{array}$ & $\begin{array}{c}\text { FASE } \\
\text { ORGÂNICA }\end{array}$ & $\begin{array}{c}\text { FASE } \\
\text { INORGÂNICA }\end{array}$ \\
\hline $\begin{array}{c}\text { Filtek }^{\mathrm{TM}} \\
\text { Supreme XT } \\
\text { 3M / ESPE }\end{array}$ & $\begin{array}{l}\text { Nano- } \\
\text { aglomerada }\end{array}$ & $\begin{array}{c}\text { A2E } \\
\text { (3910A2E) } \\
\text { B2E } \\
\text { (3910B2E) }\end{array}$ & $\begin{array}{l}\text { Bis-GMA } \\
\text { UDMA } \\
\text { TEGDMA } \\
\text { Bis-EMA }\end{array}$ & $\begin{array}{c}\text { Zirconia } \\
\text { Sílica não aglomerada } \\
\text { Sílica aglomerada com } \\
\text { tamanho das } \\
\text { partículas entre } 0,04 \mathrm{e} \\
3 \mu \mathrm{m} \text { (tamanho } \\
\text { médio=0,6 } \mu \mathrm{m}) \text { e } 75- \\
77 \% \text { em peso }\end{array}$ \\
\hline $\begin{array}{c}4 \text { Seasons }^{\circledR} \\
\text { Ivoclar I } \\
\text { Vivadent }\end{array}$ & $\begin{array}{c}\text { Híbrida de } \\
\text { partículas finas }\end{array}$ & $\begin{array}{c}\text { A2E } \\
\text { (LO7764) } \\
\text { B2E } \\
\text { (LO7764) }\end{array}$ & $\begin{array}{c}\text { Bis-GMA } \\
\text { Dimetacrilato } \\
\text { de uretanto } \\
\text { Trietilenoglic } \\
\text { ol- } \\
\text { dimetacrilato }\end{array}$ & $\begin{array}{c}\text { Vidro de bário } \\
\text { Trifluoreto de itérbio } \\
\text { Vidro de fluorsilicato } \\
\text { de Ba-Al } \\
\text { Dióxido de silício } \\
\text { Óxidos mistos } \\
\text { esferoidais com } \\
\text { partículas de } \\
\text { tamanhos variados de } \\
0,6 \text { a } 1,4 \mu \mathrm{m}, 75 \mu \mathrm{m} \text { e } \\
\text { de } 5 \text { a } 20 \mathrm{~nm} \text { e } \\
\text { aproximadamente } \\
72,5 \% \text { em peso }\end{array}$ \\
\hline
\end{tabular}

\subsection{Método}

\subsubsection{Determinação da Correspondência de cor}

A avaliação quantitativa da correspondência de cor fundamentouse no critério recomendado pela Comissão Internacional em Iluminação (Commission Internationale de I'Eclairage - CIE $)^{11}$ segundo a qual, a 
correspondência/diferença de cores pode ser expressa matematicamente pelo valor de $\Delta \mathrm{E}^{6,10,11,14,46}$. Esse é obtido pela aplicação da fórmula proposta por Clarke $^{12}$ - Fórmula 1 , que utiliza os valores das 3 coordenadas espaciais do espaço de cores CIELab ${ }^{11}$.

Fórmula 1: Fórmula de Clarke para diferenças ou correspondências de cor

$$
\Delta \mathrm{E}=\sqrt{\left(L^{*}{ }_{1}-L_{2}^{*}\right)^{2}+\left(a^{*}{ }_{1}-a *_{2}\right)^{2}+\left(b^{*}{ }_{1}-b_{2}\right)^{2}}
$$

Nesse espaço de cores, $L^{*}$ representa a medida da luminosidade do objeto e é quantificada numa escala que varia de zero (preto) a cem (branco). Os valores de $a^{*}$ e $b^{*}$ são medidas da cromaticidade do objeto e expressam a variação das tonalidades verde-vermelho (eixo $a^{*}$ ) e azulamarelo (eixo b*) (FIGURA 7).

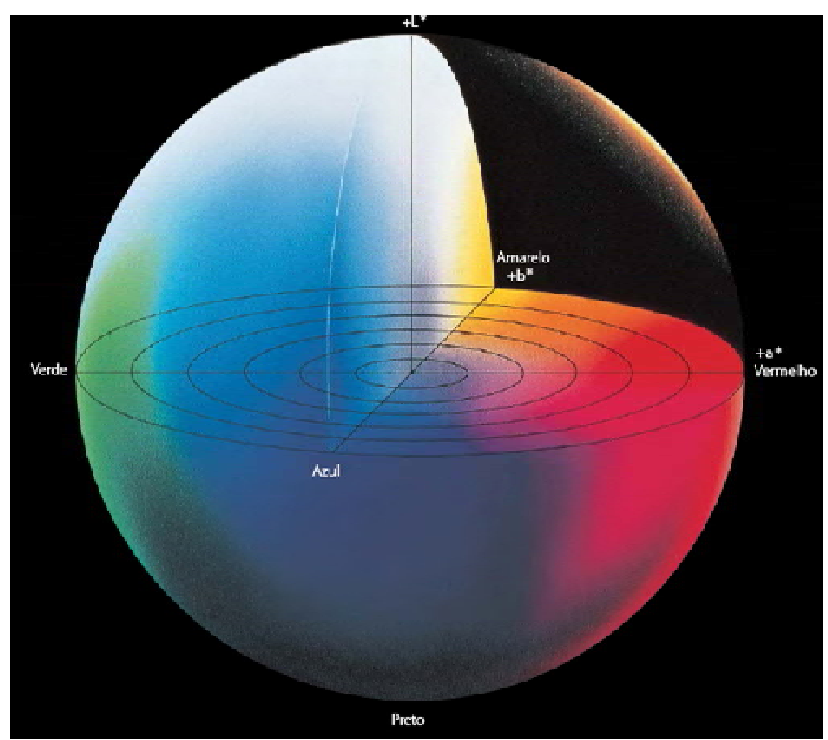

FIGURA 7 - Espaço de cor CIELab. 
Como já citado neste estudo, optou-se pela utilização do espectrofotômetro clínico Vita EasyShade ${ }^{\circledR}$, pois a partir dele obtém-se resultados mais próximos aos observados em situações clínicas e porque este aparelho fornece o resultado direto de $\Delta \mathrm{E}$ em sua tela (FIGURA 8).

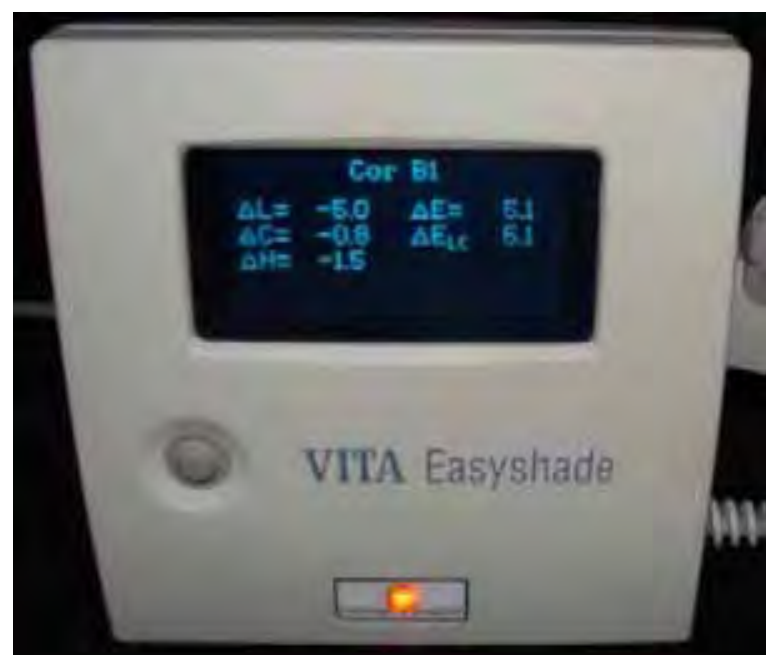

FIGURA 8 - Valor de $\Delta \mathrm{E}$ fornecido pelo equipamento.

\subsubsection{Método para obtenção dos valores de $\Delta \mathrm{E}$}

Para a avaliação da correspondência de cor tanto as tonalidades das escalas de referência como os corpos-de-prova de resina composta foram individualmente posicionadas sobre fundo branco padronizado ${ }^{48,66}$, ${ }^{80}$, constituído por bloco cerâmico de alumina $\left(L^{*}=79,85, a^{*}=3,98\right.$ e $b^{*}=-$ 3,48 ) medindo $1,5 \mathrm{~cm}$ de comprimento, $1,5 \mathrm{~cm}$ de largura e $0,5 \mathrm{~cm}$ de espessura.

A sonda de leitura do espectrofotômetro Vita EasyShade ${ }^{\circledR}$ foi fixada a uma haste metálica (FIGURA 9), a fim de que sua ponta ativa ficasse perpendicular e totalmente em contato com o terço médio da superfície 
vestibular da referência das escalas de cor e no centro dos corpos-deprova de resina, como sugerido por Okubo et al. ${ }^{58}$ (1998) (FIGURA 10).

RA 9 - Equipamento fixo a haste metálica. superfície

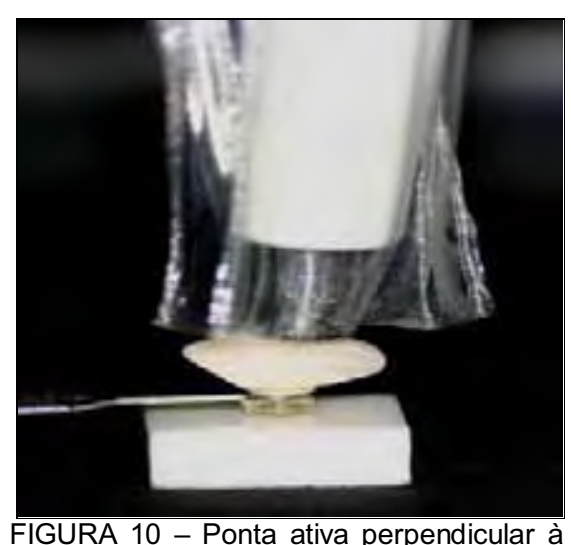

da referência de cor.

$\mathrm{Na}$ sequência, o protetor contra infecção foi adequadamente posicionado na sonda de leitura do espectrofotômetro e o aparelho foi ligado. Aguardava-se que a mensagem de término do aquecimento da lâmpada aparecesse na tela do aparelho.

A seguir, a calibração do aparelho foi realizada. Para tal, a sonda de leitura foi posicionada dentro da conexão de calibragem tomando-se o cuidado para que a mesma ficasse ligeiramente inclinada para frente, à direita ou à esquerda do aparelho, para que o protetor não interferisse na calibração e para que a sonda ficasse perpendicularmente posicionada em relação ao bloco de calibração. Este procedimento foi repetido até que a mensagem "calibração bem sucedida" aparecesse no display do aparelho. 
Essa rotina de calibração foi repetida todas as vezes que uma nova tonalidade/corpo-de-prova foi analisada. Foram realizados três (3) registros de cor para cada uma das amostras.

Assim, para a avaliação da correspondência entre tonalidades das escalas de referência (experimento 1) foram realizados 186 registros de cor (3 mensurações $X(16+20+26)$ tonalidades). Para a avaliação da correspondência dos corpos-de-prova de resina composta em função de espessuras e tonalidades foram realizados 600 registros (2 materiais $X 2$ tonalidades $X 10$ espessuras $X 5$ repetições $X 3$ mensurações).

Em função das características do espectrofotômetro, das recomendações do fabricante e dos resultados obtidos no estudo piloto, as leituras de correspondência de cor entre as escalas de referência foram obtidos no modo de leitura "dente individual" do espectrofotômetro Vita EasyShade ${ }^{\circledR}$, enquanto os registros dos corpos-de-prova de resina composta foram obtidos com a seleção "verificar restauração" (HTTP://www.vita-zahnfabrik.com) ${ }^{52}$ (FIGURA 11). 


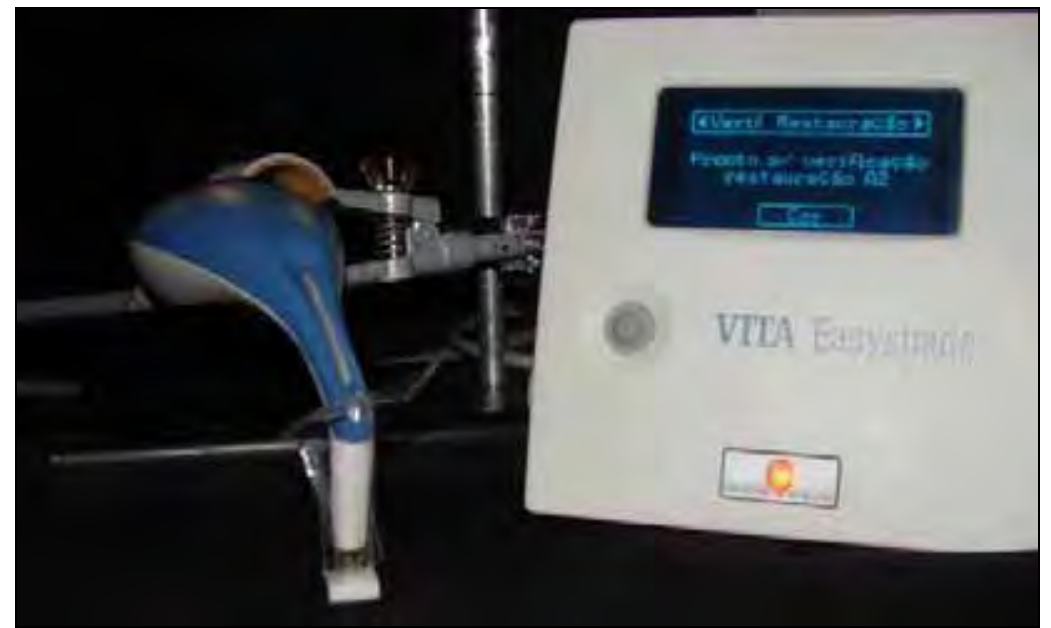

FIGURA 11- Espectrofotômetro acionado no modo "verificar restauração".

Os valores de $\Delta \mathrm{E}$ obtidos diretamente da tela do espectrofotômetro Vita Easyshade ${ }^{\circledR}$ foram transcritos para planilhas eletrônicas no Microsoft Excel para posterior tratamento estatístico.

\subsubsection{Critérios de Correspondência de cor}

A partir da literatura pertinente ${ }^{19,45,69}$ adotou-se como limite de tolerância para correspondência de cor o valor de $\Delta E \leq 3,7$ que, segundo o Serviço de Saúde Pública dos Estados Unidos (USPHS) representa o valor médio da acuidade da visão humana ${ }^{36}$.

Assim, valores de $\Delta \mathrm{E} \leq 3,7$ indicaram correspondência de cor entre as tonalidades analisadas, enquanto valores maiores determinaram diferenças visivelmente perceptíveis. 
4.3 Experimento 1 - Correspondência de cor entre as tonalidades de diferentes marcas comerciais de escalas de referência de cor segundo o espectrofotômetro Vita Easyshade ${ }^{\circledR}$

Nesse estudo, os valores de $\Delta \mathrm{E}$ de cada uma das tonalidades das três escalas de referência de cor utilizadas, foram obtidos conforme já descrito anteriormente.

A seguir, a diferença entre o $\Delta \mathrm{E}$ de cada uma das tonalidades da escala de referência Vita Classical e de todas as tonalidades das demais escalas foi determinada. Os resultados foram transcritos para matrizes de comparação: Vita Classical X Vita Classical, Vita Classical X Vitapan 3DMaster e Vita Classical X Chromascop.

A confirmação da correspondência de cor foi estabelecida para uma diferença de $\Delta \mathrm{E} \leq 3,7$.

\subsection{Experimento 2 - Correspondência de cor entre resinas compostas e escalas de referência em função de: tonalidade, composição e espessura}

Para este estudo, foram confeccionados corpos-de-prova de resina composta nas espessuras de 0,$2 ; 0,4 ; 0,6 ; 0,8 ; 1,0 ; 1,2 ; 1,4 ; 1,6 ; 1,8 ; 2,0$ mm (FIGURA 17).

Para tal, utilizou-se matriz metálica bipartida, que ao ser montada fornecia 10 cavidades cilíndricas de $8,0 \mathrm{~mm}$ de diâmetro, nas 10 profundidades pré-estabelecidas (FIGURA 12). 
Cada cavidade foi lubrificada internamente com haste flexível (COTONETES ${ }^{\circledR}$ Johnson\&Johnson do Brasil Ind. Com. Prod. para Saúde Ltda., Brasil) embebido em glicerina (RIOQUÍMICA Indústria Farmacêutica, São José do Rio Preto, Brasil) e preenchida com resina composta inserida em incremento único, com auxílio de espátula XTS Goldstein Flexi-Thin $n^{\circ} 3$ (Hu-Friedy). Sobre esta foi colocada tira de poliéster transparente (KG SORENSEN, Barueri, Brasil) (FIGURA 13) e, a seguir, foi posicionada placa de vidro (PRISMA Instrumentos Odontológicos, São Paulo, Brasil) de $20 \mathrm{~mm}$ de espessura, a qual foi pressionada por 1 minuto de encontro ao conjunto matriz/resina/tira de poliéster a fim permitir o extravasamento da resina em excesso, garantindo a uniformização das espessuras e a planificação da superfície dos corpos-de-prova (FIGURA 14). Após este período, a placa de vidro foi removida e cada corpo-de-prova foi fotoativado (FIGURA 15) por meio do aparelho de luz emitida por diodo (LED), Ultrablue (DMC Equipamentos, São Carlos, Brasil) (FIGURA 16) pelo tempo de 40 segundos, com potência de $440 \mathrm{mWcm}^{2}$ aferida por meio do radiômetro Demetron (Demetron Research Co. - Modelo 100, Danburry, USA).

A seguir, a matriz foi aberta e desmontada e os corpos-de-prova cuidadosamente deslocados a fim de evitar a fratura dos mesmos. Os excessos de resina composta presentes foram removidos com auxílio da espátula já citada. Os corpos-de-prova assim acabados foram individualmente armazenados em recipientes plásticos devidamente 
identificados, hermeticamente fechados e mantidos a seco em temperatura ambiente.

Os corpos-de-prova foram observados em lupa estereoscópica Zeiss (West Germany-mod.475200/9901) com 10X de aumento, a fim de selecionar somente os corpos-de-prova que não apresentavam imperfeições em sua superfície.

É importante destacar que durante a confecção dos corpos-deprova houve o descarte de cerca de $25 \%$ deles, o que ocorreu mais comumente com os corpos-de-prova de espessuras de 0,2 e 0,4 mm por serem mais delgados e frágeis que os demais. Sempre que isso ocorreu novos corpos-de-prova foram confeccionados.

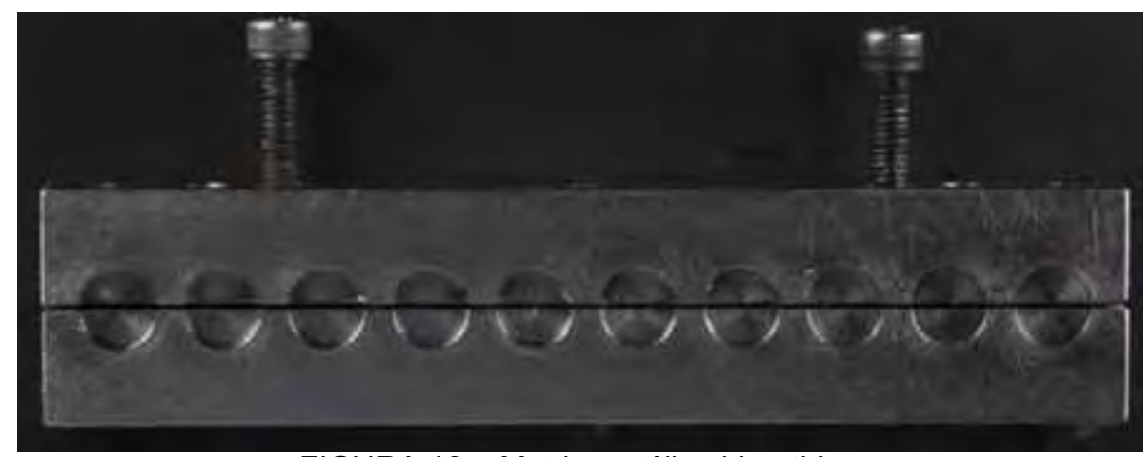

FIGURA 12 - Matriz metálica bipartida.

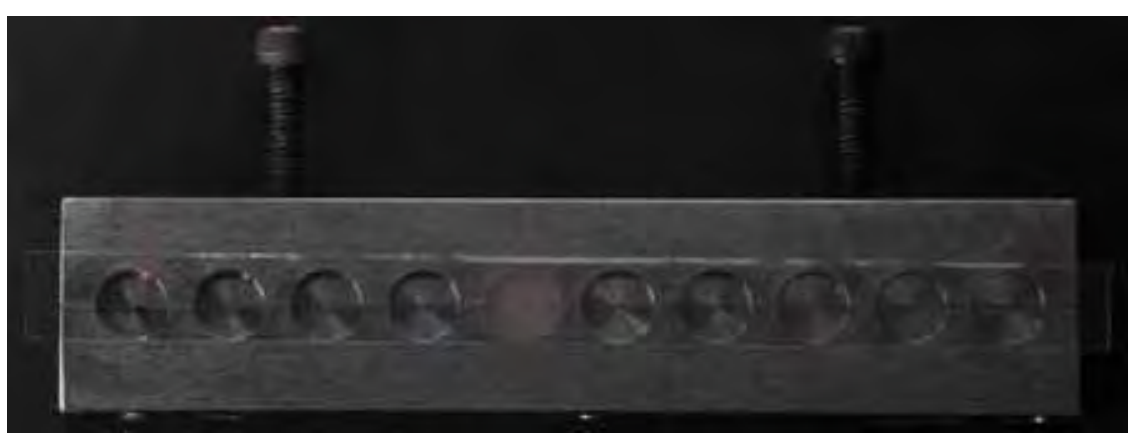

FIGURA 13 - Tira de poliéster sobre a resina. 


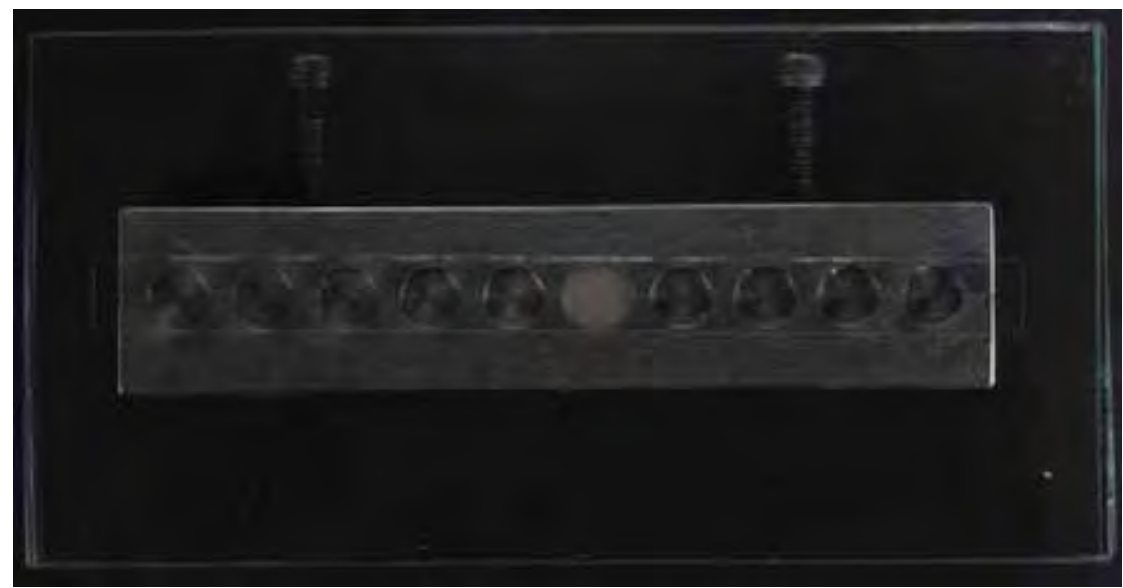

FIGURA 14 - Aplainamento da resina com placa de vidro.

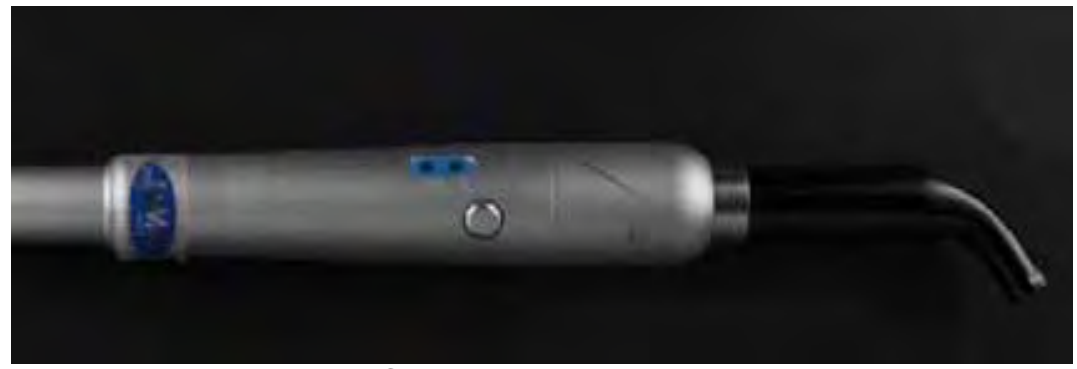

FIGURA 15 - LED Ultrablue.

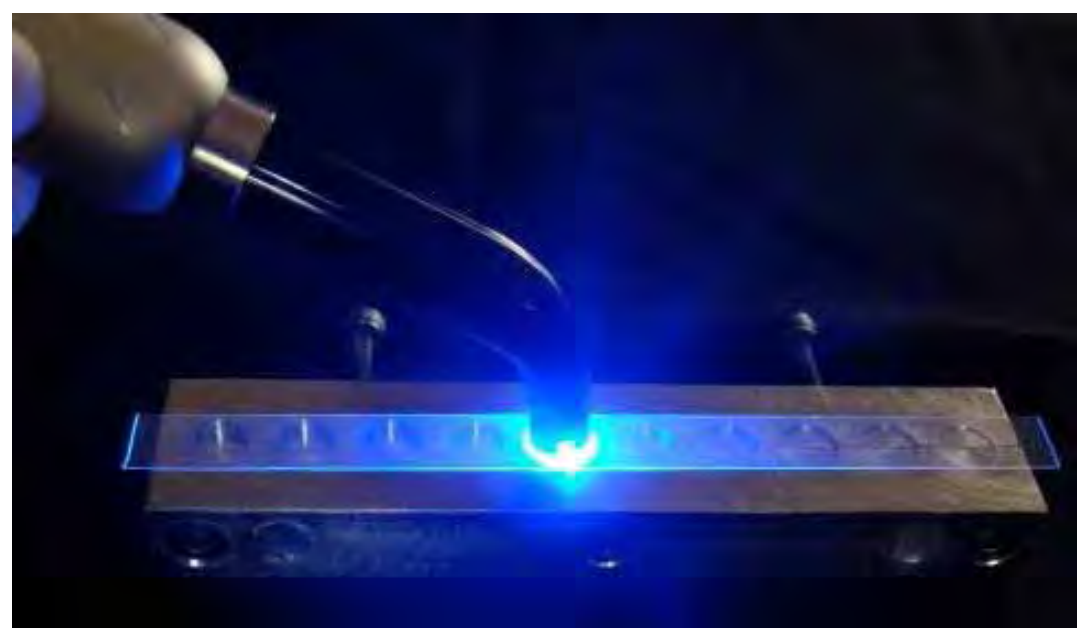

FIGURA 16 - Fotoativação dos corpos-de-prova. 


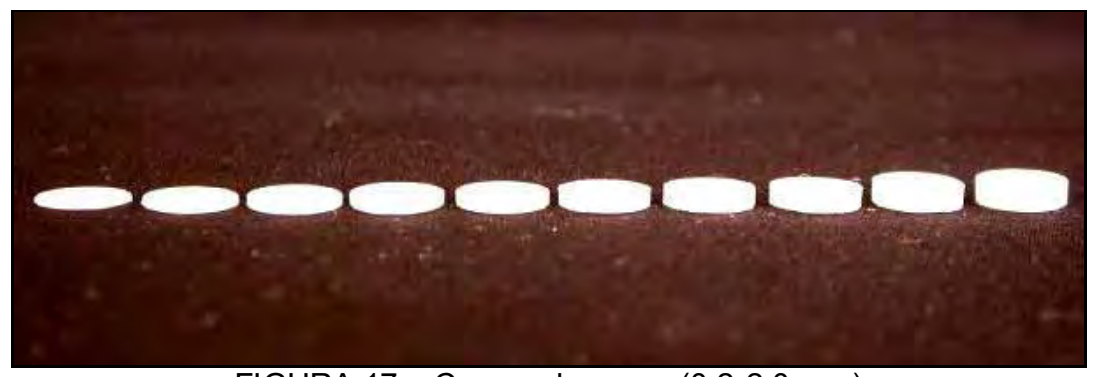

FIGURA 17 - Corpos-de-prova (0,2-2,0 mm).

Os corpos-de-prova assim obtidos, originaram os grupos experimentais descritos no Quadro 3.

Quadro 3 - Grupos experimentais do estudo

\begin{tabular}{|c|c|c|c|}
\hline MATERIAL (M) & TONALIDADE (T) & ESPESSURA (E) & GRUPO EXPERIMENTAL \\
\hline \multirow{20}{*}{ Filtek $^{\mathrm{TM}}$ Supreme XT } & \multirow{10}{*}{ A2E } & 0,2 & M1T1E2 \\
\hline & & 0,4 & M1T1E4 \\
\hline & & 0,6 & M1T1E6 \\
\hline & & 0,8 & M1T1E8 \\
\hline & & 1,0 & M1T1E10 \\
\hline & & 1,2 & M1T1E12 \\
\hline & & 1,4 & M1T1E14 \\
\hline & & 1,6 & M1T1E16 \\
\hline & & 1,8 & M1T1E18 \\
\hline & & 2,0 & M1T1E20 \\
\hline & \multirow{10}{*}{ B2E } & 0,2 & M1T2E2 \\
\hline & & 0,4 & M1T2E4 \\
\hline & & 0,6 & M1T2E6 \\
\hline & & 0,8 & M1T2E8 \\
\hline & & 1,0 & M1T2E10 \\
\hline & & 1,2 & M1T2E12 \\
\hline & & 1,4 & M1T2E14 \\
\hline & & 1,6 & M1T2E16 \\
\hline & & 1,8 & M1T2E18 \\
\hline & & 2,0 & M1T2E20 \\
\hline \multirow{20}{*}{4 Seasons $^{\circledR}$} & \multirow{10}{*}{ A2E } & 0,2 & M2T1E2 \\
\hline & & 0,4 & M2T1E4 \\
\hline & & 0,6 & M2T1E6 \\
\hline & & 0,8 & M2T1E8 \\
\hline & & $\begin{array}{l}0,0 \\
1,0\end{array}$ & M2T1E10 \\
\hline & & 1,2 & M2T1E12 \\
\hline & & 1,4 & M2T1E14 \\
\hline & & 1,6 & M2T1E16 \\
\hline & & 1,8 & M2T1E18 \\
\hline & & 2,0 & M2T1E20 \\
\hline & \multirow{10}{*}{ B2E } & 0,2 & M2T22E2 \\
\hline & & 0,4 & M2T2E4 \\
\hline & & 0,6 & M2T2E6 \\
\hline & & 0,8 & M2T2E8 \\
\hline & & 1,0 & M2T2E10 \\
\hline & & 1,2 & M2T2E12 \\
\hline & & 1,4 & M2T2E14 \\
\hline & & 1,6 & M2T2E16 \\
\hline & & 1,8 & M2T2E18 \\
\hline & & 2,0 & M2T2E20 \\
\hline
\end{tabular}


Antes de cada sessão de mensuração e após o término da mensuração dos corpos-de-prova de mesma espessura, o equipamento foi calibrado selecionando na tela do equipamento o modo "verificar restauração" e, em seguida, selecionava-se a tonalidade que seria efetuada a mensuração. A partir daí o equipamento calculava o valor de $\Delta \mathrm{E}$ desta amostra em relação à tonalidade previamente selecionada, que neste estudo foram as tonalidades A2 e B2 para esmalte.

Para padronizar o posicionamento dos corpos-de-prova foi utilizada a mesma haste metálica citada anteriormente, na qual a ponta ativa dos equipamentos de mensuração de cor foi fixa com a finalidade de garantir que a mesma ficasse em contato e no centro dos corpos-de-prova ${ }^{51}$ (FIGURA 18).

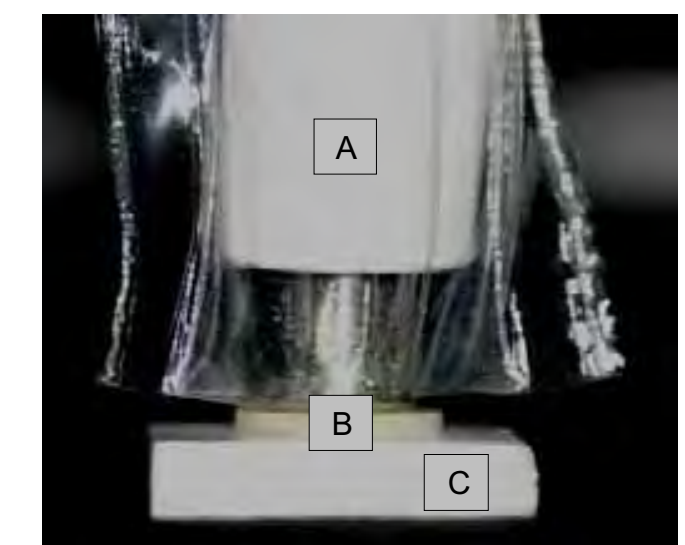

FIGURA 18 - Ponta ativa posicionada no centro do corpo-de-prova.

Sendo: A - Ponta ativa do equipamento; B - Corpo-de-prova; C - Bloco cerâmico.

Em seguida, o corpo-de-prova foi retirado do recipiente plástico e posicionado sobre o fundo branco anteriormente descrito. Depois, foram realizadas 3 mensurações por corpo-de-prova. 
Após a mensuração de todos os corpos-de-prova, esses valores também foram transpostos e organizados em planilhas eletrônicas especialmente elaboradas para este fim com o auxílio do software Microsoft Excel.

\subsection{Análise Estatística}

Para o experimento 1 foi realizada apenas uma análise qualitativa dos dados obtidos.

No experimento 2 foi realizada uma análise quantitativa, em que a diferença de cor das amostras das resinas compostas nas diferentes espessuras foram calculadas a partir da cor de referência das resinas compostas A2E e B2E, no modo "verificar restauração", para se obter os valores de $\Delta \mathrm{E}$ que seriam necessários para a avaliação da correspondência de cor neste estudo.

A avaliação de $\Delta \mathrm{E}$, obtida pelo equipamento, em resinas de diferentes tonalidades de cores, em função da espessura dos corpos-deprova, foi realizada por análise de regressão quadrática. Essas equações foram também empregadas para examinar a correspondência das cores das resinas com três escalas de referência. Adotou-se o nível de significância $5 \%$ para a realização de testes de hipóteses e o nível de confiança de $95 \%$ para a construção de intervalos de confiança para os parâmetros populacionais. 
Resultado 


\section{RESULTADO}

\subsection{Experimento 1 - Correspondência entre as tonalidades de}

diferentes marcas comerciais de escalas de referência de cor segundo o espectrofotômetro Vita Easyshade ${ }^{\circledR}$

Os valores médios de $\Delta \mathrm{E}$ e desvios-padrão de cada uma das tonalidades das escalas de referência: Vita Classical, Vitapan 3D-Master e Chromascop, obtidos pelo equipamento no modo "dente individual", estão apresentados nos Quadros de 4 a 6 e no gráfico 1.

Quadro 4 - Valores médios e desvios-padrão das tonalidades da Escala Vita Classical

\begin{tabular}{|c|c|c|}
\hline $\begin{array}{c}\text { Tonalidades da Escala } \\
\text { Vita Classical }\end{array}$ & Valores Médios de $\Delta \mathrm{E}$ & Desvio-Padrão (DP) \\
\hline A1 & 2,4 & 0,10 \\
\hline A2 & 2,2 & 0,18 \\
\hline A3 & 1,9 & 0,24 \\
\hline A3,5 & 1,3 & 0,25 \\
\hline A4 & 1,4 & 0,05 \\
\hline B1 & 3,2 & 0,19 \\
\hline B2 & 1,5 & 0,13 \\
\hline B3 & 0,2 & 0,21 \\
\hline B4 & 1,6 & 0,24 \\
\hline C1 & 1,0 & 0,00 \\
\hline C2 & 1,7 & 0,20 \\
\hline C3 & 1,3 & 0,10 \\
\hline C4 & 4,9 & 0,36 \\
\hline D2 & 1,6 & 0,05 \\
\hline D3 & 1,8 & 0,00 \\
\hline D4 & 2,7 & 0,08 \\
\hline
\end{tabular}


Quadro 5 - Valores médios e desvios-padrão das tonalidades da Escala Vitapan 3D-Master

\begin{tabular}{|c|c|c|}
\hline $\begin{array}{c}\text { Tonalidades da Escala } \\
\text { Vitapan 3D-Master }\end{array}$ & Valores Médios de $\Delta \mathrm{E}$ & Desvio-Padrão (DP) \\
\hline 1M1 & 3,1 & 0,05 \\
\hline 1M2 & 2,1 & 0,11 \\
\hline $2 \mathrm{~L} 1,5$ & 1,4 & 0,05 \\
\hline $2 \mathrm{~L} 2,5$ & 0,9 & 0,00 \\
\hline 2M1 & 2,4 & 0,05 \\
\hline 2M2 & 2,1 & 0,11 \\
\hline 2M3 & 0,5 & 0,00 \\
\hline 2R1,5 & 3,1 & 0,05 \\
\hline $2 \mathrm{R} 2,5$ & 2,5 & 0,05 \\
\hline 3L1,5 & 3,7 & 0,05 \\
\hline $3 \mathrm{~L} 2,5$ & 0,4 & 0,29 \\
\hline 3M1 & 3,7 & 0,05 \\
\hline 3M2 & 3,1 & 0,17 \\
\hline $3 \mathrm{M} 3$ & 4,4 & 0,25 \\
\hline 3R1,5 & 2,1 & 0,11 \\
\hline 3R2,5 & 2,0 & 0,00 \\
\hline $4 \mathrm{LL1,5}$ & 3,7 & 0,08 \\
\hline $4 \mathrm{LL2,5}$ & 4,2 & 0,25 \\
\hline 4M1 & 4,6 & 0,18 \\
\hline 4M2 & 3,1 & 0,05 \\
\hline 4M3 & 4,8 & 0,19 \\
\hline 4R1,5 & 4,8 & 0,05 \\
\hline 4R2,5 & 3,5 & 0,00 \\
\hline $5 \mathrm{M1}$ & 8,7 & 0,05 \\
\hline $5 \mathrm{M} 2$ & 5,5 & 0,30 \\
\hline $5 \mathrm{M} 3$ & 14,8 & 0,08 \\
\hline
\end{tabular}


Quadro 6 - Valores médios e desvios-padrão das tonalidades da Escala Chromascop

\begin{tabular}{|c|c|c|}
\hline $\begin{array}{c}\text { Tonalidades da Escala } \\
\text { Chromascop }\end{array}$ & Valores Médios de $\Delta \mathrm{E}$ & Desvio-Padrão (DP) \\
\hline $01 / 110$ & 2,7 & 0,10 \\
\hline 1A/120 & 2,9 & 0,10 \\
\hline 2A/130 & 2,5 & 0,10 \\
\hline $1 \mathrm{C} / 140$ & 3,0 & 0,15 \\
\hline $2 \mathrm{~B} / 210$ & 2,7 & 0,36 \\
\hline $1 \mathrm{D} / 220$ & 3,3 & 0,17 \\
\hline $1 E / 230$ & 3,7 & 0,06 \\
\hline $2 \mathrm{C} / 240$ & 6,2 & 0,05 \\
\hline $3 A / 310$ & 4,3 & 0,12 \\
\hline $5 \mathrm{~B} / 320$ & 4,3 & 0,13 \\
\hline $2 \mathrm{E} / 330$ & 5,3 & 0,31 \\
\hline $3 \mathrm{E} / 340$ & 7,2 & 0,30 \\
\hline $4 \mathrm{~A} / 410$ & 2,3 & 0,00 \\
\hline $6 \mathrm{~B} / 420$ & 1,7 & 0,26 \\
\hline $4 \mathrm{~B} / 430$ & 1,2 & 0,11 \\
\hline $6 \mathrm{C} / 440$ & 5,2 & 0,15 \\
\hline $6 \mathrm{D} / 510$ & 5,9 & 0,12 \\
\hline $4 C / 520$ & 4,6 & 0,25 \\
\hline $3 \mathrm{C} / 530$ & 9,3 & 0,21 \\
\hline 4D/540 & 11,2 & 0,22 \\
\hline
\end{tabular}




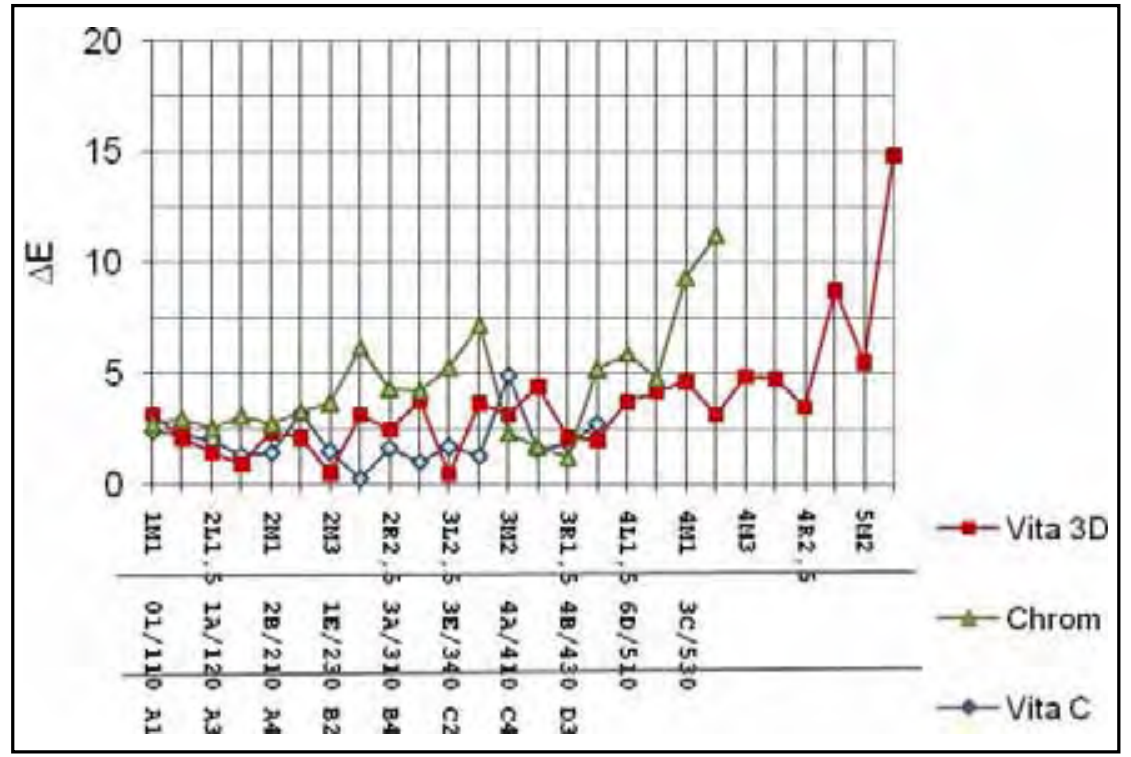

GRÁFICO 1 - Correspondência de cor e distribuição das tonalidades, segundo valores de $\Delta \mathrm{E}$, determinados pelo espectrofotômetro Vita Easyshade ${ }^{\circledR}$.

A correspondência de cor entre as tonalidades das escalas de referência em relação à escala Vita Classical foi calculada por meio de matrizes (Quadros $7-9$ ), a partir dos valores de $\Delta \mathrm{E}$ dispostos nas linhas e nas colunas. Por estes valores pôde-se concluir se as tonalidades foram ou não correspondentes.

Os cálculos de correspondência de cor nas matrizes foram efetuados por meio da função: $f=\Delta E_{m a}-\Delta E_{m e}$

Onde: $\mathbf{m a}=$ maior valor $\mathrm{e} \mathbf{m e}=$ menor valor 
Quadro 7 - Matriz de correspondência de cor entre tonalidades da escala Vita Classical e Vita Classical, segundo dados obtidos com 0 espectrofotômetro Vita Easyshade ${ }^{\circledR}$ e $\Delta E \leq 3,7$

\begin{tabular}{|c|c|c|c|c|c|c|c|c|c|c|c|c|c|c|c|c|c|}
\hline & Af & 31.9 & 37.4 & 37.9 & 43.1 & 45.7 & 36.1 & 36.3 & 40.0 & 40.7 & 39.5 & 43.3 & 44.7 & 46.9 & 38.6 & 39.4 & 43.5 \\
\hline AF & $\begin{array}{l}\text { Escala } \\
\text { vecNC }\end{array}$ & A1 & A2 & A3 & $A 3,5$ & A4 & B1 & B2 & B3 & B4 & C1 & $\mathrm{C2}$ & c3 & C. & v2 & D3 & D4 \\
\hline 31.9 & A1 & 0.0 & 5.5 & 6.0 & 11.2 & 13.8 & 4.2 & 4.4 & 8.1 & 8.8 & 7.6 & 11.4 & 12.8 & 15.0 & 6.7 & 7.5 & 11.6 \\
\hline 37.4 & $A Z$ & 5.5 & 0.0 & 0.4 & 5.6 & 7.9 & 2.3 & 1.1 & 2.6 & 3.2 & 2.1 & 5.8 & 7.3 & 9.4 & 1.2 & 2.0 & 6.0 \\
\hline 37.9 & $\mathbf{A B}^{3}$ & 6.0 & 0.4 & 0.0 & 5.2 & 7.9 & 1.7 & 1.6 & 2.2 & 2.8 & 17 & 5.4 & 6.8 & 9.0 & 0.8 & 1.5 & 5.6 \\
\hline 43.1 & A3,5 & 11.2 & 5.6 & 5.2 & 0.0 & 26 & 6.9 & 6.8 & 5.7 & 24 & 3.6 & 0.2 & 1.6 & 3.8 & 4.5 & 3.7 & 0.4 \\
\hline 45.7 & A4 & 13.8 & 8.3 & 7.9 & 2.6 & 0.0 & 9.6 & 9.4 & 5.7 & 5.0 & 6.2 & 24 & 1.0 & 1.2 & 7.1 & 6.3 & 2.2 \\
\hline 36.1 & B1 & 4.2 & 1.3 & 1.7 & 6.9 & 9.6 & 0.0 & 0.1 & 3.9 & 4.5 & 3.4 & 7.1 & 8.6 & 10.7 & 2.5 & 3.3 & 7.3 \\
\hline 36.3 & B2 & 4.4 & 1.1 & 1.6 & 6.8 & 9.4 & 0.1 & 0.0 & 3.7 & 4.4 & 3.2 & 7.0 & 8.4 & 10.6 & 2.3 & 3.1 & 7.2 \\
\hline 400 & B3 & 8.1 & 2.6 & 2.2 & 3.1 & 5.7 & 3.9 & 3.7 & 0.0 & 0.6 & 0.5 & 3.2 & 4.7 & 6.8 & 1.4 & 0.6 & 3.5 \\
\hline 40.7 & B4 & 8.8 & 3.2 & 2.8 & 2.4 & 5.0 & 4.5 & 4.4 & 0.6 & 0.0 & 1.1 & 2.6 & 4.0 & 6.2 & 2.1 & 1.3 & 2.8 \\
\hline 39.5 & c1 & 7.6 & 2.1 & 1.7 & 3.6 & 6.2 & 3.4 & 3.2 & 3.2 & 1.1 & 0.0 & 3.7 & 5.2 & 7.3 & 0.9 & 0.1 & 4.0 \\
\hline 43.3 & C2 & 11.4 & 5.8 & 5.4 & 0.2 & 2.4 & 7.1 & 7.0 & 3.2 & 2.6 & 3.7 & 0.0 & 1.4 & 3.6 & 4.7 & 3.9 & 0.2 \\
\hline 447 & c3 & 12.8 & 7.3 & 6.8 & 1.6 & 1.0 & 8.6 & 8.4 & 4.7 & 4.0 & 5,2 & 1.4 & 0.0 & 2.2 & G.1 & 5.3 & 1.2 \\
\hline 46.9 & C4 & 15.0 & 9.4 & 9.0 & 3.8 & 1.2 & 10.7 & 10.6 & 6.8 & 6.2 & 7.3 & 3.6 & 2.2 & 0.0 & 8.3 & 7.5 & 3.4 \\
\hline 380 & D2 & 38.6 & 1.2 & 0.8 & 4.5 & 7.1 & 2.5 & 2.3 & 1.4 & 2.1 & 0.9 & 4.7 & 6.1 & 8.3 & 0.0 & 0.8 & 4.9 \\
\hline 39.4 & n3 & 75 & 20 & 15 & 37 & 6.3 & 33 & 31 & 0.6 & 1.3 & 0.1 & 3.9 & 5.3 & 75 & 0.8 & 0.0 & 41 \\
\hline 43.5 & D4 & 11.6 & 6.0 & 5.6 & 0.4 & 2.2 & 7.3 & 7.2 & 3.5 & 2.8 & 4.0 & 0.2 & 1.2 & 3,4 & 4.9 & 4.1 & 0.0 \\
\hline
\end{tabular}

\section{LEGENDA DOS QUADROS 7 - 9:}

Cores correspondentes, segundo $\Delta \mathrm{E} \leq 3,7$.

Cores não correspondentes, segundo $\Delta \mathrm{E} \leq 3,7$. 
Quadro 8 - Matriz de correspondência de cor entre tonalidades da escala Vita Classical e Vitapan 3D-Master, segundo dados obtidos com o espectrofotômetro Vita Easyshade ${ }^{\circledR}$ e $\Delta \mathrm{E} \leq 3,7$

\begin{tabular}{|c|c|c|c|c|c|c|c|c|c|c|c|c|c|c|c|c|c|c|c|c|c|c|c|c|c|c|c|}
\hline & $\Delta$ & 35.4 & & \begin{tabular}{|l|l}
36.1 \\
\end{tabular} & 1 & 35.8 & \begin{tabular}{|l|l}
35.0 \\
\end{tabular} & & 365 & 39.1 & |3900 & 41.4 & 380 & $40:$ & 408 & 40.1 & \begin{tabular}{|l|}
448 \\
\end{tabular} & 420 & 449 & 409 & 43.6 & 46.3 & \begin{tabular}{|l|}
463 \\
\end{tabular} & 453 & 46,4 & 453 & 440 \\
\hline & 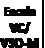 & IIIT) & w & & & $2 \times 1$ & 200 & & & 252.6 & & 3126 & 3 & ane & ans & 3R1.6 & 3 R2, & & 42.5 & $4 M 1$ & 40 & $=$ & & $4 F 2,6$ & sav1 & ane & कМ⿻ \\
\hline 1 & A & & & & & & & & & & & & & & & & 80 & 122 & & & 118 & & & 134 & 4.5 & 34 & 123 \\
\hline & $A$ & & & & & & & & & & & & & & & & 24 & 4.6 & & 35 & 62 & $A$ & 38 & 78 & s & 79 & 5.5 \\
\hline 7. & No & 38 & & & & & & & & 13 & 12 & & & 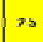 & 30 & 23 & 70 & 43 & 71 & 11 & 58 & 85 & 85 & 74 & 25 & 75 & 52 \\
\hline 13.1 & As & 36 & & & & 72 & & & & 39 & 41 & 15 & 50 & 28 & 22 & 30 & 18 & \begin{tabular}{|l|}
10 \\
\end{tabular} & 18 & 21 & 0.6 & 33 & 33 & 22 & 34 & 22 & 10 \\
\hline 15. & $M$ & , & & & o & gو & & $\mathrm{b}$ & & 68 & 68 & 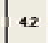 & 6 & b4 & 49 & 35 & os & 37 & $\cos$ & 47 & 30 & of & or & 04 & $\infty x$ & as & 16 \\
\hline 6.1 & घ1 & 3.3 & 30 & 10 & 30 & 03 & 11 & 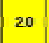 & 14 & 30 & 79 & 3 & 19 & 47 & 41 & 48 & 23 & 59 & $\mathrm{ss}$ & 48 & 75 & 107 & ט & 9 & 103 & 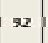 & 23 \\
\hline 8. & B2 & 08 & 37 & 11 & 78 & 184 & 13 & 19 & 183 & 79 & "x & 3) & 18 & 40 & 48 & 38 & 25 & 58 & $\approx 0$ & 40 & 7.4 & 101 & 101 & 90 & 100 & 90 & 78 \\
\hline 10.0 & Bs & 4.6 & 69 & 38 & 0.9 & 42 & 50 & 19 & 35 & os & 10 & 14 & 19 & 03 & 0.3 & 0.1 & 48 & 20 & 45 & es & 36 & 63 & 63 & 53 & s & 53 & 40 \\
\hline 10.7 & Bu & 52 & 75 & 45 & 15 & 48 & & 25 & 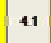 & 15 & 16 & 08 & 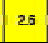 & 0.3 & 02 & 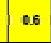 & 4.2 & 14 & 43 & 0.3 & 30 & $s$ & $s$ & $4 b$ & 33 & 4.5 & - \\
\hline 39.5 & c1 & 41 & 64 & as & 04 & 37 & 45 & 14 & 30 & o. & 05 & 9 & 15 & 08 & 13 & 06 & 53 & 25 & 5.4 & 1.4 & 41 & 68 & 68 & 58 & 63 & 58 & 45 \\
\hline 43.3 & C2 & 78 & wi. & 7 & 4 & 74 & 82 & 5 & 67 & 41 & 2 & 18 & 12 & 29 & 24 & 2 & ${ }_{15}$ & 12 & 13 & 23 & a.4 & 31 & 31 & 20 & 32 & 20 & 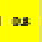 \\
\hline 4.7. & $\boldsymbol{\omega}$ & 82 & 118 & 85 & 56 & 89 & 97 & 65 & 81 & 55 & 57 & $=$ & 86 & 44 & 39 & 6 & 02 & 26 & 03 & ${ }^{3} x$ & 10 & 16 & 13 & 0.5 & 13 & 0.5 & 0.5 \\
\hline 48.9 & a & 114 & 137 & & 7 & 110 & 118 & 07 & 103 & D & 78 & 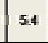 & 83 & 35 & os & 58 & 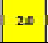 & is & 13 & $5 s$ & 32 & ${ }_{25}$ & 05 & 16 & os & 15 & 23 \\
\hline 38.6 & 02 & 72 & 55 & 2 & & 28 & & & 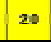 & 05 & a & & 0.5 & 17 & 22 & 1. & 1 & 34 & 63 & 24 & 11 & $x z$ & 78 & 67 & 13 & 5 & 55 \\
\hline 39.4 & Do & 314 & 63 & 32 & & 36 & & & & 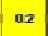 & o & & 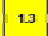 & 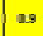 & 1.4 & 8 & 55 & $\infty$ & $\ldots$ & -8 & 43 & 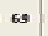 & $\cdots$ & so & 71 & 50 & 4 \\
\hline 43.5 & DA & 80 & $n_{3}$ & 73 & $\mid 14$ & 7 & 85 & 53 & 69 & 13 & 45 & 20 & 54 & & 120 & 34 & Is & 14 & 15 & 25 & 0.2 & $2 s$ & 29 & 18 & $3^{30}$ & 18 & 0.5 \\
\hline
\end{tabular}

Quadro 9 - Matriz de correspondência de cor entre tonalidades da escala Vita Classical e Chromascop, segundo dados obtidos com 0 espectrofotômetro Vita Easyshade ${ }^{\circledR}$ e $\Delta E \leq 3,7$

\begin{tabular}{|c|c|c|c|c|c|c|c|c|c|c|c|c|c|c|c|c|c|c|c|c|c|}
\hline & $\Delta \mathrm{AE}$ & 30.0 & 33.2 & 34.0 & 36.7 & 35.0 & 37.4 & 38.4 & 30.6 & 40.2 & 40.1 & 41.1 & 42.4 & 38.4 & \begin{tabular}{|l|}
38.0 \\
\end{tabular} & 0.1 & 40.3 & 60.0 & 39.5 & 41.4 & \begin{tabular}{|l}
43.6 \\
\end{tabular} \\
\hline$\Delta E$ & & & & & & & & & {$[x+20$} & & & . & & & 0,442 & 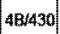 & $6 ., 440]$ & & 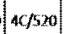 & 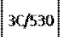 & $40 / 540$ \\
\hline 31.9 & A1 & 0.9 & 1.3 & 21 & 3.9 & 4.1 & 5.6 & 6.6 & 7.7 & 8.4 & 8.3 & 9.3 & 10.5 & 6.6 & 7.1 & 7.3 & 8.4 & 8.2 & 7.6 & 95 & 111.7 \\
\hline 37.4 & A2 & 6.5 & 4.2 & 3.4 & 1.7 & 1.5 & 0.0 & 1.0 & 22 & 2.8 & 2.7 & 3.8 & 5.0 & 1.0 & 1.5 & 1.7 & 29 & 2.6 & 21 & 4.0 & 62 \\
\hline 97.9 & $A_{3}$ & 6.9 & 4.7 & 3.8 & 2.1 & 1.9 & 0.4 & 0.6 & 1.8 & 24 & 2.3 & 3.3 & 4.6 & 0.6 & 1.1 & 13 & 25 & $2 x$ & 1.7 & 3.6 & 5.8 \\
\hline 43.1 & A3.5 & 12.1 & 9.9 & 9.1 & 7.3 & 7.1 & 5.6 & 4.8 & 3.5 & 28 & 28 & 1.9 & 0.7 & 16 & 4.1 & & 27 & 3.0 & 3.6 & 6 & 0.6 \\
\hline 45.7 & AA & 14.7 & 12.5 & 11.7 & 9.9 & 9.8 & 83 & 72 & 6.1 & 5.4 & 5. & 4.5 & 33 & 72 & 6.7 & 6.5 & 5.4 & 5.6 & 32 & 4.3 & 21 \\
\hline 36.1 & B1 & 5.2 & 29 & 21 & 0.4 & 0.2 & 1.3 & 23 & 3.5 & 4.1 & 4.0 & 5.1 & 6.3 & 23 & 28 & 3.0 & 4.2 & 39 & 3.4 & 5.3 & 75 \\
\hline 36.3 & B2 & 5.3 & 3.1 & 23 & os & 0.3 & 1.2 & 2.2 & 3.3 & 40 & 3.5 & 49 & 6.1 & 22 & 27 & 29 & 4.0 & 3.8 & $3 x$ & 5.1 & 73 \\
\hline 40.0 & B3 & 9.1 & 6.8 & 60 & 4.3 & 4.1. & 26 & 1.6 & 0.4 & 0.2 & 0.2 & 12 & 24 & 1.6 & 1.1 & 09 & 0.3 & 0.1 & 05 & 14 & 3.6 \\
\hline 40.7 & BA & 9.7 & is & 6.7 & 49 & 4.7 & 32 & 22 & 10 & 0.4 & o.s & os & 18 & 22 & 17 & 15 & 0.3 & 0.6 & 12 & 0.8 & 3.0 \\
\hline 39.5 & c1 & 8.6 & 6.3 & 5.5 & 3.8 & 3.6 & 21 & 1.1 & 0.1 & 0.7 & 0.7 & 17 & 29 & 11 & 0.6 & 0.4 & 0.8 & 0.6 & 0.0 & 19 & 4.1 \\
\hline 43.3 & c2 & 12 & 10.1 & 93 & 75 & 73 & 5.8 & 4.8 & 3.6 & 30 & 3.1 & 21 & 0.8 & 1.1 & 43 & 4.1 & 29 & 32 & 38 & 1.8 & 0.4 \\
\hline 44.7 & C3 & 13.7 & 11.5 & 10.7 & 8.9 & 8.7 & 7.2 & 6.2 & 5.1 & 4.4 & 4.5 & 3.5 & 23 & 62 & 5.7 & 5.5 & 4.4 & 4.6 & 5.2 & 3.3 & 1.1 \\
\hline 46.9 & $\mathrm{c}_{4}$ & 159 & 137 & 129 & 1111 & 109 & 9.4 & 8.4 & 72 & 6.6 & 6.7 & 5.7 & 4.4 & 84 & 79 & 7.7 & 6.5 & 6.8 & 74 & 5,4 & 32 \\
\hline 38.6 & D2 & 7.6 & 3.4 & 4.6 & 28 & 27 & 1.1 & 0.1 & 10 & 1.7 & 16 & 200 & 3.8 & 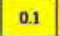 & 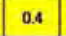 & 6 & 1.7 & 15 & . & 28 & 5.0 \\
\hline 39.4 & D3 & 8.4 & 6.2 & 5.4 & 3.6 & 35 & 19 & 0.9 & 0.2 & os & 0.8 & 1.8 & 3.0 & 0.9 & 0.4 & $0 x$ & 0.9 & 0.7 & 0.1 & 20 & 4.2 \\
\hline 43.5 & D4 & 12.5 & 10.3 & 9.5 & 7.7 & 7.5 & 6.0 & 5.0 & 3.9 & 32 & 3.3 & 23 & 1.1 & 5.0 & 4.5 & 4.3 & 3.1 & 3.4 & 4.0 & 2.1 & 0.2 \\
\hline
\end{tabular}




\subsection{Experimento 2 - Correspondência de cor entre resinas compostas} e escalas de referência de cor em função de: tonalidade, composição e espessura

$\mathrm{Na}$ determinação da correspondência de cor $(\Delta \mathrm{E})$ de duas resinas comerciais (Filtek ${ }^{\mathrm{TM}}$ Supreme $\mathrm{XT}$ e 4 Seasons $^{\circledR}$ ), em duas tonalidades (A2E e B2E) formaram-se quatro grupos experimentais, com cinco corpos-de-prova em cada uma de dez espessuras: $0,2 \mathrm{~mm} ; 0,4 \mathrm{~mm} ; \ldots 2,0$ $\mathrm{mm}$. Foi empregado para o cálculo de $\Delta \mathrm{E}$ o método instrumental Vita Easyshade $^{\circledR}$, com os resultados apresentados a seguir (Tabelas 1 e 2, FIGURA 19).

Ajustaram-se equações de regressão polinomiais quadráticas aos valores de $\Delta \mathrm{E}$ obtidos pelo espectrofotômetro Vita Easyshade ${ }^{\circledR}$, em função da espessura dos corpos-de-prova, para os quatro grupos experimentais em estudo. Na Tabela 1 são dados os coeficientes das equações de regressão quadrática ajustadas aos $\Delta \mathrm{E}$, os erros padrão desses coeficientes, o erro padrão residual da regressão e o coeficiente de determinação $R^{2}$. Esses coeficientes indicam que, no mínimo, 94,7\% da variação de $\Delta \mathrm{E}$ é explicada pelas regressões.

Os coeficientes de regressão são todos significativamente diferentes de zero, de acordo com o teste $t$ apropriado $(p<0,001)$. Observando-se os intervalos de confiança de 95\% para os parâmetros, dados por: coeficiente de regressão $\pm 2,0$ x erro padrão do coeficiente, vêse que $c_{0}$ e $c_{2}$ apresentaram variação, para mais ou para menos, menor 
do 0,6 unidades e $c_{1}$ variação entre 0,8 e 1,2 unidades em relação aos valores estimados pelas equações.

Os pares de coeficientes $c_{1}$ das equações da tonalidade $A 2 E$ não são significativamente diferentes de acordo com o teste $t$ de Student $(p>0,05)$. O mesmo resultado foi observado para os pares de coeficientes $\mathrm{C}_{2}$. Por outro lado, para esta tonalidade, a diferença entre os coeficientes $\mathrm{C}_{0}$ de 4 Seasons $^{\circledR}$ e Filtek $^{\mathrm{TM}}$ Supreme XT, nesta ordem, é -1,17 $(=12,98$ 14,15). Esse valor é estatisticamente significativo e representa uma diferença média de $\Delta \mathrm{E}$ entre as duas resinas na tonalidade $\mathrm{A} 2 \mathrm{E}$, em qualquer espessura considerada. Um paralelismo desse tipo não foi encontrado para a tonalidade B2E, com as duas resinas apresentando diferenças entre médias de $\Delta \mathrm{E}$ variando conforme a espessura.

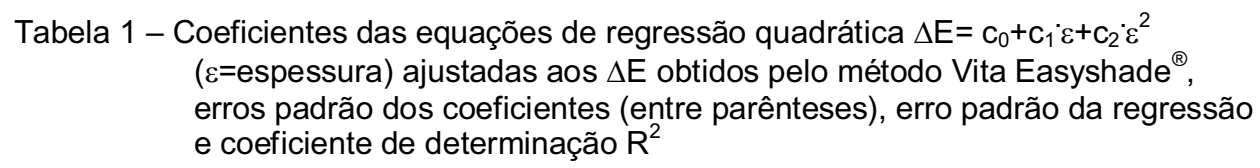
( $\varepsilon=$ espessura) ajustadas aos $\Delta \mathrm{E}$ obtidos pelo método Vita Easyshade ${ }^{\circledR}$ erros padrão dos coeficientes (entre parênteses), erro padrão da regressão e coeficiente de determinação $R^{2}$

\begin{tabular}{|c|c|c|c|c|c|c|}
\hline \multirow[t]{2}{*}{ Resina } & \multirow[t]{2}{*}{ Tonalidade } & \multicolumn{3}{|c|}{ Coeficiente de regressão } & \multirow{2}{*}{$\begin{array}{r}\text { Erro } \\
\text { padrão }\end{array}$} & \multirow[t]{2}{*}{$\mathrm{R}^{2}$} \\
\hline & & $\mathrm{C}_{0}$ & $\mathrm{c}_{1}$ & $\mathrm{C}_{2}$ & & \\
\hline \multirow[t]{4}{*}{4 Seasons } & A2E & 12,98 & $-15,01$ & 5,49 & & 0,969 \\
\hline & & $(0,22)$ & $(0,47)$ & $(0,21)$ & 0,425 & \\
\hline & $\mathrm{B} 2 \mathrm{E}$ & 9,84 & $-7,36$ & 2,19 & & 0,947 \\
\hline & & $(0,21)$ & $(0,43)$ & $(0,19)$ & 0,391 & \\
\hline \multirow[t]{4}{*}{ Filtek Supreme XT } & A2E & 14,15 & $-16,40$ & 5,64 & & 0,962 \\
\hline & & $(0,30)$ & $(0,63)$ & $(0,28)$ & 0,574 & \\
\hline & $\mathrm{B} 2 \mathrm{E}$ & 14,61 & $-14,67$ & 4,28 & & 0,977 \\
\hline & & $(0,27)$ & $(0,57)$ & $(0,25)$ & 0,521 & \\
\hline
\end{tabular}

$\mathrm{Na}$ Tabela 2 são dadas as médias e desvios padrão dos $\Delta \mathrm{E}$ obtidos pelo método Vita Easyshade ${ }^{\circledR}$ e os valores previstos pelas equações de 
regressão quadráticas. Na FIGURA 19 estão representadas as médias de $\Delta \mathrm{E}$ e as curvas de regressão quadrática.

Tabela 2 - Médias e desvios padrão (DP) de $\Delta \mathrm{E}$ obtido pelo método Vita Easyshade ${ }^{\circledR}$ e valores previstos pelas equações de regressão quadráticas

\begin{tabular}{|c|c|c|c|c|c|c|c|c|c|c|c|}
\hline \multirow[t]{2}{*}{ Resina } & \multirow[t]{2}{*}{ Tonalidade } & & \multicolumn{9}{|c|}{ Espessura $(\mathrm{mm})$} \\
\hline & & & 0,2 & 0,4 & 0,6 & $0,8 \quad 1,0$ & 1,2 & 1,4 & 1,6 & 1,8 & 2,0 \\
\hline \multirow[t]{6}{*}{4 Seasons } & $\mathrm{A} 2 \mathrm{E}$ & Média & 10,0 & 7,9 & 6,2 & $4,7 \quad 3,5$ & 2,5 & 2,4 & 3,3 & 3,9 & 4,9 \\
\hline & & DP & 0,2 & 0,6 & 0,4 & $0,6 \quad 0,2$ & 0,4 & 0,2 & 0,2 & 0,2 & 0,5 \\
\hline & & Previsto & 10,2 & 7,9 & 6,0 & $4,5 \quad 3,5$ & 2,9 & 2,7 & 3,0 & 3,8 & 4,9 \\
\hline & B2E & Média & 9,0 & 6,7 & 5,9 & $5,1 \quad 5,0$ & 4,4 & 3,9 & 3,8 & 3,8 & 3,6 \\
\hline & & $\mathrm{DP}$ & 0,3 & 0,1 & 0,2 & $0,4 \quad 0,2$ & 0,1 & 0,1 & 0,1 & 0,2 & 0,3 \\
\hline & & Previsto & 8,5 & 7,2 & 6,2 & $5,4 \quad 4,7$ & 4,2 & 3,8 & 3,7 & 3,7 & 3,9 \\
\hline \multirow[t]{6}{*}{ Filtek Supreme XT } & $\mathrm{A} 2 \mathrm{E}$ & Média & 10,4 & 8,9 & 7,1 & $4,6 \quad 3,4$ & 2,1 & 2,0 & 2,2 & 3,4 & 3,9 \\
\hline & & DP & 0,9 & 0,3 & 0,4 & $0,5 \quad 0,3$ & 0,1 & 0,1 & 0,2 & 0,2 & 0,3 \\
\hline & & Previsto & 11,1 & 8,5 & 6,3 & $4,6 \quad 3,4$ & 2,6 & 2,2 & 2,4 & 2,9 & 3,9 \\
\hline & $\mathrm{B} 2 \mathrm{E}$ & Média & 11,4 & 9,4 & 7,9 & $6,1 \quad 4,4$ & 2,9 & 1,8 & 1,6 & 2,3 & 2,7 \\
\hline & & DP & 0,3 & 0,3 & 0,6 & $0,4 \quad 0,5$ & 0,2 & 0,2 & 0,1 & 0,1 & 0,2 \\
\hline & & Previsto & 11,8 & 9,4 & 7,3 & $5,6 \quad 4,2$ & 3,2 & 2,5 & 2,1 & 2,1 & 2,4 \\
\hline
\end{tabular}

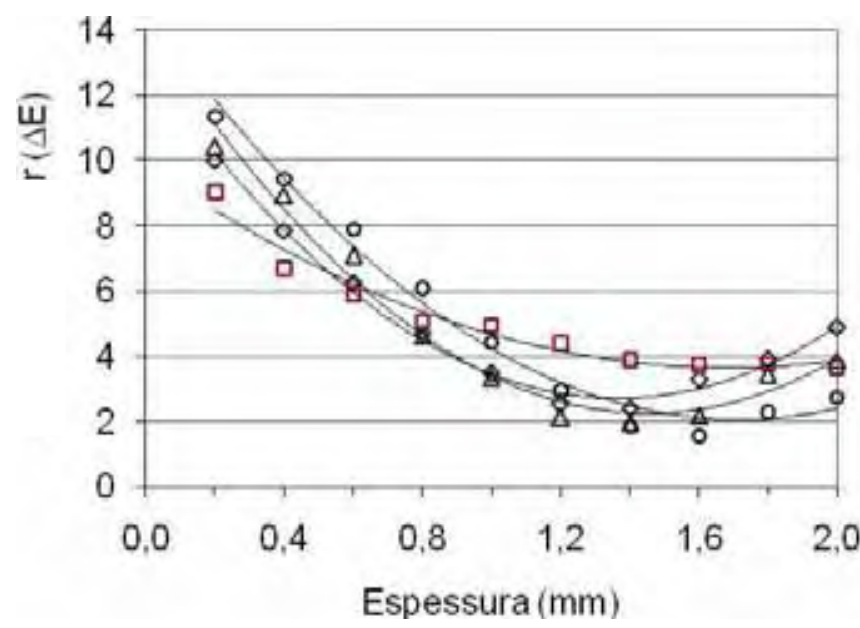

- 4 seasons A2

口 4 seasons B2

$\triangle$ Filtek A2

o Filtek B2

FIGURA 19 - Médias de correspondência de cor $(\Delta \mathrm{E})$ obtidas pelo método Vita Easyshade $^{\circledR}$ e curvas de regressão quadrática.

Verifica-se nesta figura que os valores de $\Delta \mathrm{E}$ foram diminuindo da espessura de $0,2 \mathrm{~mm}$ até a espessura de 1,4 ou 1,6 $\mathrm{mm}$, porque pelo método de cálculo de diferença de cor deste equipamento, que foi 
calculada a partir das tonalidades A2E ou B2E, as espessuras de 1,4 ou 1,6 mm são as que geralmente apresentaram correspondência de cor mais próxima do A2E ou B2E e para as espessuras de 1,8 mm e 2,0 mm geralmente existiu um aumento nos valores de $\Delta \mathrm{E}$, demonstrando que a partir dessas espessuras recomeçou uma diferença em relação às tonalidades A2E e B2E.

Os $\Delta \mathrm{E}$ foram obtidos pelo método Vita Easyshade ${ }^{\circledR}$ nas três escalas de referência: Vita Classical; Vitapan 3D-Master e Chromascop. A média de cinco (5) determinações em um mesmo dente artificial da escala foi adotada para representar $\mathrm{o} \Delta \mathrm{E}$ do dente. Os valores obtidos foram confrontados com intervalos de confiança de $95 \%$ construídos para os $\Delta \mathrm{E}$ das resinas compostas, em cada espessura. Os resultados estão apresentados nas Tabelas 3 a 5, uma para cada escala de referência. 
Tabela 3 - Espessuras das resinas compostas 4 Seasons $^{\circledR}$ e Filtek ${ }^{\mathrm{TM}}$ Supreme $\mathrm{XT}$ nas tonalidades $\mathrm{A} 2 \mathrm{E}$ e B2E cujos $\Delta \mathrm{E}$ demonstraram correspondência de cor com os $\Delta E$ das tonalidades $A 2$ e $B 2$ da escala de referência Vita Classical

\begin{tabular}{|c|c|c|c|c|c|}
\hline \multirow[t]{2}{*}{ Escala } & \multirow[t]{2}{*}{$\Delta \mathrm{E}$} & \multicolumn{4}{|c|}{ Espessura (mm) } \\
\hline & & $4 \mathrm{~s} \mathrm{A2E}$ & 4 s B2E & F A2E & $\mathrm{F} \mathrm{B2E}$ \\
\hline A1 & 2,4 & $1,2-1,6$ & & $1,0-1,8$ & $1,2-2,0$ \\
\hline A2 & 2,2 & 1,$2 ; 1,4 ; 1,6$ & & 1,$0 ; 1,2 ; 1,4 ; 1,6 ; 1,8$ & $1,2-2,0$ \\
\hline A3 & 1,9 & $1,2-1,6$ & & $1,2-1,8$ & $1,4-2,0$ \\
\hline $\mathrm{A} 3,5$ & 1,3 & & & $1,4-1,6$ & $1,6-2,0$ \\
\hline A4 & 1,4 & & & $1,2-1,6$ & $1,4-2,0$ \\
\hline B1 & 3,2 & $1,0-1,8$ & $1,4-2,0$ & $1,0-2,0$ & $1,0-2,0$ \\
\hline B2 & 1,5 & & & $1,2-1,6$ & 1,$4 ; 1,6 ; 1,8 ; 2,0$ \\
\hline B3 & 0,2 & & & & \\
\hline B4 & 1,6 & & & $1,2-1,6$ & $1,4-2,0$ \\
\hline C1 & 1,0 & & & & $1,6-1,8$ \\
\hline C2 & 1,7 & & & $1,2-1,6$ & $1,4-2,0$ \\
\hline C3 & 1,3 & & & $1,4-1,6$ & $1,6-2,0$ \\
\hline C4 & 4,9 & 2,0 & $0,8-1,2$ & 0,8 ou 2,0 & $0,8-1,0$ \\
\hline $\mathrm{D} 2$ & 1,6 & & & $1,2-1,6$ & $1,4-2,0$ \\
\hline D3 & 1,8 & & & $1,2-1,8$ & $1,4-2,0$ \\
\hline D4 & 2,7 & $1,0-1,6$ & & $1,0-1,8$ & $1,2-2,0$ \\
\hline
\end{tabular}

\section{LEGENDA:}

Espessuras das resinas compostas 4 Seasons $^{\circledR}$ e Filtek $^{\text {TM }}$ Supreme $\mathrm{XT}$ que foram correspondentes à tonalidade $\mathrm{A} 2 \mathrm{E}$ da escala Vita Classical.

Espessuras das resinas compostas 4 Seasons $^{\circledR}$ e Filtek $^{T M}$ Supreme $\mathrm{XT}$ que foram correspondentes à tonalidade B2E da escala Vita Classical. 
Tabela 4 - Espessuras das resinas compostas 4 Seasons $^{\circledR}$ e Filtek ${ }^{\mathrm{TM}}$ Supreme $\mathrm{XT}$ nas tonalidades $\mathrm{A} 2 \mathrm{E}$ e B2E cujos $\triangle \mathrm{E}$ apresentaram maior correspondência de cor com os $\triangle \mathrm{E}$ das tonalidades A2E e B2E da escala Vita Classical

\begin{tabular}{|c|c|c|c|c|c|}
\hline \multirow[t]{2}{*}{ Escala } & \multirow[t]{2}{*}{$\Delta \mathrm{E}$} & \multicolumn{4}{|c|}{ Espessura (mm) } \\
\hline & & $4 \mathrm{~s} \mathrm{A2E}$ & 4s B2E & F A2E & F B2E \\
\hline $1 \mathrm{M} 1$ & 3,1 & $1,0-1,8$ & $1,4-2,0$ & $1,0-2,0$ & $1,2-2,0$ \\
\hline $1 \mathrm{M} 2$ & 2,1 & 1,$2 ; 1,4$ & & 1,$2 ; 1,4 ; 1,6 ; 1,8$ & $1,2-2,0$ \\
\hline 2L1,5 & 1,4 & & & $1,2-1,6$ & 1,$4 ; 1,6 ; 1,8 ; 2,0$ \\
\hline $2 \mathrm{~L} 2,5$ & 0,9 & & & & \\
\hline 2M1 & 2,4 & $1,2-1,6$ & & $1,0-1,8$ & $1,2-2,0$ \\
\hline 2M2 & 2,1 & 1,$2 ; 1,4$ & & 1,$2 ; 1,4 ; 1,6 ; 1,8$ & $1,2-2,0$ \\
\hline $2 \mathrm{M} 3$ & 0,5 & & & & \\
\hline $2 \mathrm{R} 1,5$ & 3,1 & $1,0-1,8$ & $1,4-2,0$ & $1,0-2,0$ & $1,2-2,0$ \\
\hline $2 \mathrm{R} 2,5$ & 2,5 & $1,2-1,6$ & & $1,0-1,8$ & $1,2-2,0$ \\
\hline $3 \mathrm{~L} 1,5$ & 3,7 & $0,8-1,8$ & $1,2-2,0$ & $0,8-1,2$ ou $1,8-2,0$ & $1,0-1,2$ \\
\hline $3 \mathrm{~L} 2,5$ & 0,4 & & & & \\
\hline 3M1 & 3,7 & $0,8-1,8$ & $1,2-2,0$ & $0,8-1,2$ ou $1,8-2,0$ & $1,0-1,2$ \\
\hline $3 \mathrm{M} 2$ & 3,1 & $1,0-1,8$ & $1,4-2,0$ & $1,0-2,0$ & $1,2-2,0$ \\
\hline $3 \mathrm{M} 3$ & 4,4 & 0,8 ou $1,8-2,0$ & $1,0-2,0$ & $0,8-1,0$ ou 2,0 & 1,0 \\
\hline $3 R 1,5$ & 2,1 & 1,$2 ; 1,4$ & & 1,$2 ; 1,4 ; 1,6 ; 1,8$ & $1,2-2,0$ \\
\hline $3 R 2,5$ & 2,0 & $1,2-1,4$ & & $1,2-1,8$ & $1,4-2,0$ \\
\hline 4L1,5 & 3,7 & $0,8-1,8$ & $1,2-2,0$ & $0,8-1,2$ ou $1,8-2,0$ & $1,0-1,2$ \\
\hline $4 \mathrm{~L} 2,5$ & 4,2 & $0,8-1,0$ ou $1,8-2,0$ & $1,0-2,0$ & $0,8-1,0$ ou 2,0 & $1,0-1,2$ \\
\hline 4M1 & 4,6 & 0,8 ou $1,8-2,0$ & $0,8-2,0$ & 0,8 ou 2,0 & $0,8-1,0$ \\
\hline $4 \mathrm{M} 2$ & 3,1 & $1,0-1,8$ & $1,4-2,0$ & $1,0-2,0$ & $1,2-2,0$ \\
\hline $4 \mathrm{M} 3$ & 4,8 & 0,8 ou 2,0 & $0,8-1,2$ & 0,8 ou 2,0 & $0,8-1,0$ \\
\hline 4R1,5 & 4,8 & 0,8 ou 2,0 & $0,8-1,2$ & 0,8 ou 2,0 & $0,8-1,0$ \\
\hline $4 \mathrm{R} 2,5$ & 3,5 & $1,0-1,8$ & $1,2-2,0$ & $0,8-2,0$ & $1,0-1,4$ \\
\hline 5M1 & 8,7 & 0,4 & 0,2 & 0,4 & 0,4 \\
\hline $5 \mathrm{M} 2$ & 5,5 & 0,6 ou 2,0 & $0,6-1,2$ & $0,6-0,8$ & 0,8 \\
\hline $5 \mathrm{M} 3$ & 14,8 & & & & \\
\hline
\end{tabular}

\section{LEGENDA:}

Tonalidades das referências de cor da escala Vitapan 3D-Master cujos $\Delta \mathrm{E}$ apresentaram maior correspondência de cor em relação ao $\Delta \mathrm{E}$ da tonalidade $\mathrm{A} 2 \mathrm{E}$ da escala Vita Classical, e as respectivas espessuras das resinas compostas 4 Seasons ${ }^{\circledR} \mathrm{e}$ Filtek $^{\mathrm{TM}}$ Supreme $\mathrm{XT}$ cujos $\Delta \mathrm{E}$ foram correspondentes à essa tonalidade.

Tonalidades das referências de cor da escala Vitapan 3D-Master cujos $\Delta \mathrm{E}$ apresentaram maior correspondência de cor em relação ao $\Delta \mathrm{E}$ da tonalidade $\mathrm{B} 2 \mathrm{E}$ da escala Vita Classical, e as respectivas espessuras das resinas compostas 4 Seasons ${ }^{\circledR} \mathrm{e}$ Filtek $^{\mathrm{TM}}$ Supreme $\mathrm{XT}$ cujos $\Delta \mathrm{E}$ foram correspondentes à essa tonalidade.

${ }^{*}$ Células em branco demonstram que não houve espessuras de resinas compostas que tenham apresentado $\Delta \mathrm{E}$ correspondentes aos $\Delta \mathrm{E}$ das referências de cor da escala Vitapan 3D-Master. 
Tabela 5 - Espessuras das resinas compostas 4 Seasons $^{\circledR}$ e Filtek $^{\mathrm{TM}}$ Supreme $\mathrm{XT}$ nas tonalidades $\mathrm{A} 2 \mathrm{E}$ e B2E cujos $\triangle \mathrm{E}$ apresentaram maior correspondência de cor com os $\Delta E$ das tonalidades $A 2 E$ e B2E da escala Vita Classical

\begin{tabular}{|c|c|c|c|c|c|}
\hline \multirow[t]{2}{*}{ Escala } & \multirow[t]{2}{*}{$\Delta \mathrm{E}$} & \multicolumn{4}{|c|}{ Espessura (mm) } \\
\hline & & 4s A2E & 4s B2E & F A2E & F B2E \\
\hline $01 / 110$ & 2,7 & $1,0-1,6$ & & $1,0-1,8$ & $1,2-2,0$ \\
\hline $1 \mathrm{C} / 140$ & 2,9 & $1,0-1,8$ & $1,6-1,8$ & $1,0-2,0$ & $1,2-2,0$ \\
\hline $1 \mathrm{~A} / 120$ & 2,5 & $1,2-1,6$ & & $1,0-1,8$ & $1,2-2,0$ \\
\hline $2 \mathrm{~A} / 130$ & 3,0 & $1,0-1,8$ & $1,4-1,8$ & $1,0-2,0$ & $1,2-2,0$ \\
\hline $2 \mathrm{~B} / 210$ & 2,7 & $1,0-1,6$ & & $1,0-1,8$ & $1,2-2,0$ \\
\hline $1 \mathrm{D} / 220$ & 3,3 & $1,0-1,8$ & $1,4-2,0$ & $1,0-2,0$ & $1,0-1,4$ ou 2,0 \\
\hline $1 \mathrm{E} / 230$ & 3,7 & $0,8-1,8$ & $1,2-2,0$ & $0,8-1,2$ ou $1,8-2,0$ & $1,0-1,2$ \\
\hline $2 C / 240$ & 6,2 & 0,6 & 0,6 & 0,6 & 0,8 \\
\hline $3 A / 310$ & 4,3 & $0,8-1,0$ ou $1,8-2,0$ & $1,0-2,0$ & $0,8-1,0$ ou 2,0 & 1,0 \\
\hline $5 B / 320$ & 4,3 & $0,8-1,0$ ou $1,8-2,0$ & $1,0-2,0$ & $0,8-1,0$ ou 2,0 & 1,0 \\
\hline $3 E / 340$ & 5,3 & $0,6-0,8$ ou 2,0 & $0,8-1,0$ & $0,6-0,8$ & $0,8-1,0$ \\
\hline $2 \mathrm{E} / 330$ & 7,2 & 0,4 & 0,4 & 0,6 & 0,6 \\
\hline $4 \mathrm{~A} / 410$ & 2,3 & 1,$2 ; 1,4 ; 1,6$ & & 1,$0 ; 1,2 ; 1,4 ; 1,6 ; 1,8$ & $1,2-2,0$ \\
\hline $6 \mathrm{~B} / 420$ & 1,7 & & & $1,2-1,6$ & 1,$4 ; 1,6 ; 1,8 ; 2,0$ \\
\hline $4 \mathrm{~B} / 430$ & 1,2 & & & $1,4-1,6$ & $1,6-1,8$ \\
\hline $6 \mathrm{C} / 440$ & 5,2 & $0,6-0,8$ ou 2,0 & $0,8-1,0$ & $0,6-0,8$ & $0,8-1,0$ \\
\hline $6 \mathrm{D} / 510$ & 5,9 & 0,6 & $0,6-0,8$ & 0,6 & 0,8 \\
\hline $4 C / 520$ & 4,8 & 0,8 ou 2,0 & $0,8-1,2$ & 0,8 ou 2,0 & $0,8-1,0$ \\
\hline $3 C / 530$ & 9,3 & 0,2 & 0,2 & 0,4 & 0,4 \\
\hline 4D/540 & 11,2 & 0,2 & & 0,2 & 0,2 \\
\hline
\end{tabular}

\section{LEGENDA:}

Tonalidades das referências de cor da escala Chromascop cujos $\Delta \mathrm{E}$ foram correspondentes à tonalidade $\mathrm{A} 2 \mathrm{E}$ da escala Vita Classical, e as respectivas espessuras das resinas compostas 4 Seasons $^{\circledR}$ e Filtek $^{\mathrm{TM}}$ Supreme XT cujos $\Delta \mathrm{E}$ foram correspondentes à essa tonalidade.

Tonalidades das referências de cor da escala Chromascop cujos $\Delta \mathrm{E}$ foram correspondentes à tonalidade B2E da escala Vita Classical, e as respectivas espessuras das resinas compostas 4 Seasons $^{\circledR}$ e Filtek $^{\text {TM }}$ Supreme XT cujos $\Delta \mathrm{E}$ foram correspondentes à essa tonalidade.

* Células em branco demonstram que não houve espessuras de resinas compostas que tenham apresentado $\Delta \mathrm{E}$ correspondentes aos $\Delta \mathrm{E}$ das referências de cor da escala Chromascop. 
Discussão 


\section{DISCUSSÃO}

A seleção da cor é um desafio na odontologia ${ }^{14,26,31}$ e alcançar uma correspondência de cor entre os materiais restauradores e os dentes naturais tem sido o objetivo de cirurgiões-dentistas, protesistas e pesquisadores $^{60,77}$. O procedimento clínico padrão para selecionar e reproduzir a cor do dente natural com restaurações cerâmicas e de resina composta é a comparação visual usando uma escala odontológica, porém este método tem caráter subjetivo ${ }^{13,49}$.

A escala Vita Lumin Vacuum (Vita) foi introduzida em 1956, e representou um marco no desenvolvimento de um padrão universal para referência de cor, e ainda é a escala mais utilizada. Em 1998, foi desenvolvida a escala Vitapan 3D-Master (Vita), referenciada pelo sistema Lab* estabelecido em 1976 pela Comissão Internacional em lluminação (CIE), que produziu um padrão científico internacional para a mensuração da cor. Esta escala apresenta uma distribuição científica da cor, possuindo uma cobertura sistemática do espaço de cor do dente natural de acordo com o princípio de ordem colorimétrica CIELab ${ }^{28}$.

Uma outra opção de escala de referência foi desenvolvida pela Ivoclar/Vivadent. A escala Chromascop é dividida em 5 grupos referenciados por números $(100,200,300,400$ e 500). O grupo representado pelo número 100 corresponde ao branco, o grupo 200 ao amarelo, o grupo 400 ao cinza e 500 ao marrom escuro. Dentro de cada um destes, há subdivisões em que o croma aumenta e o valor diminui ${ }^{61}$. 
A escala Vitapan 3D-Master é uma escala desenvolvida pelo mesmo fabricante da escala Vita Classical, mas apresenta uma gama maior de cores em relação a esta, ela é tida como a escala que apresenta uma abrangência de cores mais completa e bem distribuída quando comparadas com outras escalas disponíveis ${ }^{8,13,28}$.

Por outro lado, a escala Chromascop é uma escala independente desenvolvida pela empresa Ivolclar/Vivadent para a seleção de cores dos seus produtos. Considerando que no presente estudo uma das resinas selecionadas é pertencente a este fabricante foi incluída esta escala como mais de uma das referências a serem analisadas.

Foi utilizada para a presente investigação apenas uma escala de referência de cada marca comercial, que foram escolhidas aleatoriamente, apesar de Portero et al. ${ }^{65}(2008)$, terem constatado diferenças de cor $(\Delta \mathrm{E})$ estatisticamente significativas entre cinco escalas de referências de mesma marca comercial e fabricante.

A primeira hipótese testada nesse estudo, realizada através da comparação de tonalidades entre as escalas de referência Vita Classical, Vitapan 3D-Master e Chromascop (experimento 1) não foi comprovada (gráfico 1), uma vez que as escalas apresentaram pouca correspondência entre as suas tonalidades.

A escala Vita Classical foi selecionada como referência padrão por ser a mais universalmente utilizada pelos cirurgiões-dentistas e porque a maioria das resinas compostas tem suas tonalidades referenciadas em 
sua codificação de grupos A, B, C e D. Foram selecionadas também as escalas Vitapan 3D-Master e a Chromascop.

Apesar da proposta do fabricante da escala Vitapan 3D-Master ser uma distribuição uniforme no espaço de $\operatorname{cor}^{71}$, foi observado por meio do gráfico 1, que a organização dessa escala, assim como das escalas Vita Classical e Chromascop apresentou uma distribuição irregular no espaço de cor, não havendo uma sequência lógica na ordenação das referências de cor através da escala.

Como comprovação da distribuição irregular das tonalidades em todas as escalas, pode-se destacar alguns exemplos: Para a escala Vita Classical o valor $\Delta E$ obtido entre as tonalidades $B 1$ e $B 2$ é de 1,7 unidades, e entre as tonalidades B2 e B3 é de 1,3 unidades, e entre esta tonalidade e a tonalidade B4 é de 1,4. Foi observado para a escala Vitapan 3D-Master que o valor de $\Delta \mathrm{E}$ entre as tonalidades $4 \mathrm{R} 2,5$ e $5 \mathrm{M} 1$ é de 5,2 unidades, e entre esta tonalidade com a tonalidade $5 \mathrm{M} 2$ o $\Delta \mathrm{E}$ é de 3,2 unidades e desta para com a tonalidade $5 \mathrm{M} 3$ o $\Delta \mathrm{E}$ é de 9,3 unidades. Estes dados corroboram com os verificados em outros estudos de Hassel $^{30}$ et al., 2005 e Paravina ${ }^{59}$ et al., 2001. Quando se analisa as tonalidades da escala Chromascop verifica-se que o valor de $\Delta \mathrm{E}$ entre a tonalidade $6 \mathrm{D} / 510$ e a tonalidade $4 \mathrm{C} / 520$ é de 1,3 unidades, entre a tonalidade $4 \mathrm{C} / 520$ e a tonalidade $3 C / 530$ é de 4,7 unidades, e para entre esta tonalidade e a tonalidade $4 \mathrm{D} / 540$ o valor de $\Delta \mathrm{E}$ é de 1,9 unidades. Os resultados obtidos corroboram com os obtidos por Park et al. ${ }^{61}$, em 
2006, onde determinaram a distribuição de cor nas escalas de referência Vita Classical e Chromascop e verificaram que a distribuição de cor dessas escalas pelo valor e pelo croma não é equilibrada e equidistantemente distribuída.

Os dados aqui abordados e explicitados no gráfico 1 demonstraram que as escalas apresentam pouca correspondência entre suas tonalidades.

Esses resultados estão em desacordo com o que se acreditava sobre essas escalas. Pressupunha-se que como a escala Vita Classical é uma escala considerada "padrão ouro", e que uma escala de cores é uma amostra que representa as cores mais frequentemente encontradas na dentição humana, a escala Vitapan 3D-Master apresentaria alta correspondência com a maioria das cores da Vita Classical, uma vez que esta, assim como a Chromascop são mais abrangentes, 26 e 20 cores respectivamente, do que a escala padrão Vita Classical que possuem apenas 16 tonalidades.

Antes da abordagem sobre os dados relacionados às mensurações de cor, é importante destacar que não existe um consenso no limite para diferença de cor que pode ser visualmente perceptível ou clinicamente aceitável ${ }^{19,20,45,69}$. As diferenças de cor têm uma unidade de medida denominada $\Delta \mathrm{E}$. Existem divergências na literatura com relação aos valores de $\Delta \mathrm{E}$ que representam correspondências de cor clinicamente perceptíveis. Um limite de perceptibilidade de 3,3 unidades de $\Delta \mathrm{E}$ foi 
considerado como aceitável para amostras em resina composta por Russel et al. ${ }^{68}$, em 2000. Por outro lado, Douglas et al. ${ }^{19}$, em 1998, consideraram o limite de perceptibilidade para coroas de porcelana de 1,7 unidades $\Delta \mathrm{E}$. Clinicamente, o limite de 3,7 unidades de $\Delta \mathrm{E}$ foi julgado como um critério de avaliação da adequada correspondência de cor e qualidade das restaurações estéticas pelo Serviço de Saúde Pública dos Estados Unidos (USPHS) ${ }^{36}$.

Pesquisas sugerem que a tolerância para a perceptibilidade e para a aceitabilidade da correspondência de cor determinada sob condições clínicas é mais alta que aquela determinada in vitro ${ }^{20-21}$. Portanto, o valor de correspondência de cor de 3,7 unidades de $\Delta \mathrm{E}$ foi considerado como diferença perceptível nesse estudo e foi usado para descrever se houve correspondência de cor entre as tonalidades das diferentes escalas de referência e entre amostras de resinas compostas, e destas com as escalas de referência de cores utilizadas.

Ainda em relação à correspondência de cor entre as escalas de referência, foram utilizadas matrizes para calcular a correspondência de cor entre as escalas Vitapan 3D-Master e Chromascop com a escala padrão Vita Classical (experimento 1). As matrizes são uma forma de apresentação de dados dispostos em linhas e colunas e permitem calcular por meio dos valores de $\Delta \mathrm{E}$ fornecidos pelo equipamento Vita Easyshade $^{\circledR}$, se as tonalidades das escalas foram correspondentes $(\Delta \mathrm{E} \leq 3,7)$. Verificou-se neste estudo (Quadro 7) que não houve 
correspondência de cor para a tonalidade A1 na escala Vita Classical. Além disso, para esta escala a tonalidade A2 apresentou correspondência de cor com as tonalidades: A3, B1, B2, B3, B4, C1, D2 e D3; por outro lado, a tonalidade A3 apresentou correspondência para essa escala com as tonalidades: A2, B1, B2, B3, B4, C1, D2 e D3; para a tonalidade A3,5 as tonalidades A4, B4, C1, D2 e D3 e para a tonalidade B2 as seguintes tonalidades apresentaram correspondência de cor: A2, A3, B1, B2, B3, C1, D2 e D3.

Considerando a correspondência de cor entre as tonalidades das escalas Vita Classical e Vitapan 3D-Master (Quadro 8) verificou-se que a tonalidade A1 apresentou correspondência de cor com as tonalidades 1M1, $1 \mathrm{M} 2$ e 2M2; por outro lado, a tonalidade A2 apresentou correspondência de cor com as tonalidades 2L2,5, 2L2,5, 2M1, 2M2, 2M3, $2 \mathrm{R} 1,5,2 \mathrm{R} 2,5,3 \mathrm{~L} 1,5,3 \mathrm{M} 1,3 \mathrm{M} 2,3 \mathrm{M} 3,3 \mathrm{R} 1,5$ e para a tonalidade $\mathrm{B} 2$ as seguintes tonalidades escala Vitapan 3D-Master foram correspondentes: 1M1, 1M2, 2L1,5, 2L2,5, 2L2,5, 2M2, 2M3, 2R1,5, 2R2,5, 3L1,5 e 3M1. Já com relação à correspondência de cor entre as escalas de referência Vita Classical e Chromascop (Quadro 9), verificou-se que a tonalidade A1 da escala Vita Classical apresentou correspondência de cor com as tonalidades: $01 / 110,1 \mathrm{~A} / 120$ e 2A/130 da escala Chromascop; para a tonalidade $\mathrm{A} 2$ as tonalidades: $2 \mathrm{~A} / 130,1 \mathrm{C} / 140,2 \mathrm{~B} / 210,1 \mathrm{D} / 220$, 1E/230, 2C/240, 3A/310, 5B/320, 4A/410, 6B/420, 4B/430, 6C/440, $6 \mathrm{D} / 510$ e $4 \mathrm{C} / 520$ e para a tonalidade $B 2$ as seguintes tonalidades da 
escala Chromascop foram correspondentes: 1A/120, 2A/130, 1C/140, 2B/210, 1D/220, 1E/230, 2C/240, 4A/410, 6B/420, 4B/430 e 4C/520.

Esta análise da correspondência de cor entre as escalas de referência foi realizada porque estabelecer uma correspondência entre escalas permitiria uma melhor comunicação entre profissionais e protéticos. Além disso, como a escala Vita Classical é de melhor compreensão para o clínico, estabelecer a correspondência desta escala com as escalas Vitapan 3D-Master e com a Chromascop facilitaria a prática clínica.

Esses resultados demonstraram que a tonalidade $\mathrm{A} 1$ foi a que apresentou a menor correspondência de cor entre as escalas de referência, reforçando a dificuldade existente em se obter uma correspondência de cor de materiais restauradores estéticos em dentes mais claros.

Observou-se também de acordo com esses resultados, que tonalidades como o A2 (Vita Classical) apresentou uma correspondência com várias tonalidades das escalas Vitapan 3D-Master e Chromascop, indicando serem tonalidades que possuem maiores possibilidades de se obter uma cor final correspondente com o dente a ser restaurado. Estes resultados podem indicar também que o espectrofotômetro Vita Easyshade $^{\circledR}$ não é um equipamento confiável para a seleção precisa da cor. Tais resultados podem indicar ainda, que o valor de $\Delta \mathrm{E} \leq 3,7$ adotado para este estudo como limite clinicamente aceitável, talvez seja um valor 
elevado para a perceptibilidade humana da cor do dente, uma vez que, visualmente, muitas das correspondências encontradas podem ser contestadas.

Analisando estes achados, é possível relacioná-los ainda aos obtidos e discutidos por meio do gráfico 1, na qual foi verificada pouca correspondência de cor entre as escalas Vita Classical e Vitapan 3DMaster. De acordo com os dados explicitados pelo Quadro 8, observou-se que nenhum dos valores de $\Delta \mathrm{E}$ foi zero, ou seja, as tonalidades entre as escalas Vita Classical e Vitapan 3D-Master podem ser consideradas próximas ou similares mas não correspondentes. Estes achados corroboram com aqueles obtidos por meio da FIGURA 19, a qual permitiu observar que a escala Vitapan 3D-Master não apresenta nem a mesma ordenação nem as tonalidades representadas na escala Vita Classical.

Com o objetivo de minimizar o erro na seleção de cor devido à análise visual (escala de cores), espectrofotômetros clínicos visuais têm sido desenvolvidos e fabricados. Diversos estudos também têm sido conduzidos utilizando os espectrofotômetros, espectroradiômetros e

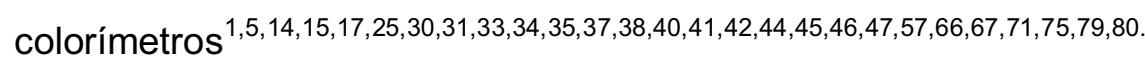

Outra razão que justifica os achados desta pesquisa e que coincidem com a opinião de Van der Burgt et al. $^{79}(1990)$, é que os resultados de um equipamento colorimétrico para uso odontológico podem ser alterados porque a luz padronizada emitida pelo equipamento 
pode ser dispersada, absorvida, transmitida, refletida, e até mesmo deslocada lateralmente como resultado das propriedades ópticas dos dentes, resinas compostas e porcelanas odontológicas, ocasionando erros de leitura e consequentemente, de classificação de cores e correspondências. Muito embora o uso de tais equipamentos seja considerado como cientificamente correto e seguro, é preciso considerar as limitações de tais dispositivos em situações clínicas.

Para que estes equipamentos possam realizar registros de cor de forma precisa é necessário que a superfície a ser analisada seja plana e sem irregularidades e que o objeto tenha cor opaca, uniforme e preferencialmente não emita fluorescência, condições que os dentes naturais, amostras das escalas e materiais restauradores, devido a sua constituição, forma e propriedades ópticas não atendem.

Além da análise da correspondência de cor entre as tonalidades das escalas por meio de matrizes e sua disposição (gráfico 1), o presente estudo também investigou a correspondência de cor entre as escalas de referências com o espectrofotômetro Vita Easyshade ${ }^{\circledR}$ regulado no modo "dente individual".

Os resultados encontrados e apresentados nas tabelas 3, 4 e 5, demonstraram que a maior correspondência de cor entre as escalas de referências na tonalidade A2 da escala Vita Classical ocorreu para as tonalidades 1M2, 2M2 e 3R1,5 da escala Vitapan 3D-Master e para a tonalidade $4 \mathrm{~A} / 410$ da escala Chromascop. No entanto, para a tonalidade 
B2 da escala Vita Classical a maior correspondência de cor ocorreu com a tonalidade $2 \mathrm{~L} 1,5$ da escala Vitapan 3D-Master e para a tonalidade 6B/420 da escala Chromascop. Estes dados possibilitaram saber quais tonalidades poderiam ser utilizadas em correspondência ao A2E e B2E da escala Vita Classical, caso a tonalidade dos materiais restauradores estivesse denominada segundo as escalas Vitapan 3D-Master ou Chromascop, como acontece com as cerâmicas da Ivoclar/Vivadent.

A segunda hipótese testada neste estudo referiu-se à existência de correspondência entre as tonalidades das resinas compostas (experimento 2). Essa hipótese foi testada, pois estabelecer a correspondência entre resinas permite a utilização alternativa de uma ou outra marca comercial com previsibilidade de resultados. Foram selecionadas para esta análise a resina composta FilteK ${ }^{\mathrm{TM}}$ Supreme $\mathrm{XT}$ que é uma resina nano-aglomerada e a resina 4 Seasons ${ }^{\circledR}$ que é uma resina composta híbrida, afinal estas categorias de materiais são atualmente as mais empregadas por serem de uso universal.

Esta avaliação foi realizada por meio da análise dos valores de $\Delta \mathrm{E}$, os quais estão apresentados na FIGURA 19. Quando se avaliou a correspondência de cor entre essas resinas FilteK $^{\mathrm{TM}}$ Supreme XT e 4 Seasons $^{\circledR}$ nas tonalidades A2E e B2E. Verificou-se valores estatisticamente diferentes, ou seja, as tonalidades A2E das 2 resinas compostas avaliadas, assim como as tonalidades B2E, não apresentaram correspondência de cor. Desta forma, a partir destes resultados, verifica- 
se que essa hipótese não foi comprovada e que apesar destas resinas apresentarem as mesmas tonalidades, apresentaram comportamentos ópticos distintos quando da interação com a luz do equipamento Vita Easyshade $^{\circledR}$.

Estes achados concordaram parcialmente com estudos de Kim, Lee $^{42}$ (2009) em que avaliaram a diferença de cor e das coordenadas de cor por meio do espectrofotômetro clínico Color-Eye 7000A. Os autores desta pesquisa verificaram que todos os valores de $\Delta \mathrm{E}$ de 8 marcas comerciais de resinas compostas, exceto para a tonalidade $\mathrm{A} 2$, foram maiores que o clinicamente perceptível $(\Delta E>3,7)$, e que os valores médios de $\Delta \mathrm{E}$ das resinas na tonalidade $\mathrm{A} 2$ foram os menores $(\Delta \mathrm{E}=3,4)$, apresentando a melhor correspondência de cor entre as diferentes marcas. Quanto a estes resultados vale destacar que estes autores encontraram resultados semelhantes para a tonalidade $\mathrm{B} 2$, enquanto para a tonalidade $\mathrm{A} 2$ os resultados foram divergentes, pois nesta pesquisa as duas resinas testadas na tonalidade A2 não foram correspondentes. É valido destacar também que esses autores utilizaram resinas nas tonalidades A2 e B2 de dentina e de corpo, e em nosso estudo utilizamos resinas para esmalte.

A terceira hipótese deste estudo foi que a composição da resina composta não afeta a correspondência de cor entre as mesmas e nem com as escalas de referência (experimento 2). Como visto, foram selecionadas duas categorias de resina composta: nano-aglomerada e 
híbrida. O que difere entre estes materiais e permite que sejam divididos em diferentes categorias é principalmente o tamanho e a distribuição de partículas inorgânicas, como descrito na introdução. Estas diferenças na porção inorgânica têm influência direta nas propriedades ópticas destes materiais ${ }^{55}$.

Esta investigação revelou que a resina composta nanoaglomerada (Filtek ${ }^{\mathrm{TM}}$ Supreme $\mathrm{XT}$ ) apresentou maior correspondência de cor com as escalas de cores testadas quando comparada à resina composta híbrida (4 Seasons ${ }^{\circledR}$ ), ou seja, a terceira hipótese também não foi comprovada, concordando com Yu, Lee ${ }^{85}$, em 2008. Estes autores verificaram que as propriedades ópticas das resinas compostas fluidas e universais foram significativamente diferentes, e que houve diferenças na cor, translucidez e fluorescência entre resinas de mesma tonalidade, porém de composições diferentes. Concluíram que a composição das resinas compostas deveria ser considerada para uma seleção de cor clinicamente aceitável.

Ainda em relação à composição das resinas compostas, Masotti et al. $^{53}$ (2007) avaliaram a transmitância das resinas compostas microhíbridas e nanoparticuladas nas cores de dentina e translúcidas e verificaram que a transmitância não está diretamente relacionada com a cor da resina composta, já a composição da resina composta está diretamente relacionada à cor. 
Os resultados desta pesquisa podem ser explicados, como visto anteriormente, pelo fato da resina nano-aglomerada apresentar propriedades ópticas semelhantes àquelas apresentadas pelas referências das escalas de referências de cores estudadas. Como a resina nano-aglomerada possui superfície mais lisa e regular que a resina híbrida ${ }^{55}$, esta característica provavelmente possibilitou maior índice de reflexão da luz do equipamento durante a aferição da cor. Tal reflexão de luz foi mais semelhante à das referências das escalas que possuem brilho elevado devido à camada de glaze aplicada sobre sua superfície, possibilitando maiores correspondências de cor entre esse material e as escalas analisadas. Essa influência da camada de glaze nos parâmetros de cor nas escalas foi verificada por Kim et al. ${ }^{43}(2008)$. Estes autores verificaram alterações na cor quando esta camada superficial foi removida.

Outra provável explicação para estes achados pode estar associada à quantidade de monômero BisGMA ou ao tipo de pigmento presentes na resina composta. Esta explicação de deve ao fato de Azzopard $^{4}$ et al., em 2009, terem investigado o efeito da composição da matriz resinosa na translucidez de resinas compostas experimentais à base de BisGMA, UDMA e TEGDMA. Estes autores concluíram que a quantidade de BisGMA adicionada à matriz resinosa ocasiona um efeito significativo na translucidez das resinas compostas contendo partículas de sílica. 
Considerando o pigmento, Lim et. al. ${ }^{51}$, em 2008, determinaram a influência da quantidade de partículas nos parâmetros ópticos de resinas compostas. Neste estudo observaram uma correlação entre a quantidade de partículas de carga e os parâmetros ópticos, e que o pigmento é outro fator que interfere nas propriedades ópticas das resinas compostas.

No presente estudo, de acordo com os fabricantes, as duas resinas apresentam partículas de sílica em sua composição (Quadro 2), porém, dados referentes à quantidade do monômero BisGMA, ou ao tipo e quantidade de pigmento não são fornecidos, o que dificulta a correlação dos nossos resultados aos achados destes autores.

A quarta hipótese testada foi que a espessura da resina composta não afeta a correspondência de cor com as escalas de referência (experimento 2). Esta investigação foi realizada porque existem poucos dados na literatura ${ }^{35,70,74,81}$ referentes à influência da espessura de resina composta para esmalte na cor final de uma restauração. Essa questão é de suma importância, pois o esmalte dental desempenha fundamental papel na percepção da $\operatorname{cor}^{25}$.

Os dados obtidos para a resina 4 Seasons $^{\circledR}$ na tonalidade $A 2$, demonstraram que a espessura que apresentou maior correspondência com a tonalidade $\mathrm{A} 2$ da escala Vita Classical foi a espessura de 1,4 mm, mas as espessuras de 1,2, e 1,6 mm, não apresentaram diferenças estatisticamente significativas entre si. Estes resultados indicaram que as espessuras de 1,2, 1,4 e 1,6 mm apresentaram correspondência de cor 
com a tonalidade A2E da escala Vita Classical. Por outro lado, nenhuma das espessuras dessa resina composta na tonalidade B2E apresentou correspondência de cor com a tonalidade B2E da escala Vita Classical.

Além disso, observou-se que para a tonalidade $\mathrm{A} 2 \mathrm{E}$ da resina composta Filtek $^{\mathrm{TM}}$ Supreme $\mathrm{XT}$, a espessura de $1,4 \mathrm{~mm}$ foi a que apresentou maior correspondência de cor com a tonalidade A2E da mesma escala. Entretanto, as espessuras de 1,0, 1,2, 1,6 e 1,8 mm também apresentaram correspondência com esta tonalidade da escala, visto que, não apresentaram diferenças estatisticamente significativas entre si.

Em relação à tonalidade $\mathrm{B} 2 \mathrm{E}$ dessa resina, a espessura que apresentou maior correspondência de cor com a tonalidade B2E da escala Vita Classical foi a espessura de 1,6 mm e as espessuras de 1,4, 1,8 e 2,0 mm não foram estatisticamente diferentes entre si, apresentando também correspondência de cor com essa tonalidade da escala Vita Classical.

Foi observado que, apesar de algumas variações na correspondência de cor das espessuras das tonalidades das resinas compostas com a escala, essas foram pequenas. Espessuras de resina composta de 1,0 a 2,0 $\mathrm{mm}$ foram as que apresentaram correspondência de cor com as referências das escalas.

Uma provável explicação para estes resultados seria que como as referências de cor das escalas apresentam espessuras de 4,5 mm para a 
escala Vita Classical, 4,1 $\mathrm{mm}$ para a escala Vitapan 3D-Master e 5,0 $\mathrm{mm}$ para a escala Chromascop, as maiores espessuras de resina composta correspondem às tonalidades das escalas estudadas. Estas observações indicam que a cor da resina composta está diretamente correlacionada com a sua espessura e que estabelecer a correspondência de cor em função da espessura do material restaurador permite ajustes previsíveis em situações clínicas.

Além disso, os dados encontrados sugerem que espessuras inferiores a 1,0 $\mathrm{mm}$ podem não representar a cor inicialmente selecionada, uma vez que a percepção dessa tonalidade será diferente, sendo de suma importância que se considere tal fato durante a seleção de cor para a confecção de restaurações em resina composta.

De acordo ainda com esses resultados (FIGURA 19), as espessuras de 1,4 ou $1,6 \mathrm{~mm}$ foram as que geralmente apresentaram correspondência de cor mais próxima da tonalidade A2 e B2 das três escalas de referência. Foi observado também que para as espessuras de $1,8 \mathrm{~mm}$ e $2,0 \mathrm{~mm}$ geralmente existiu um aumento dos valores de $\Delta \mathrm{E}$, evidenciando que a partir dessas espessuras a correspondência de cor vai diminuindo em relação às tonalidades $A 2 E$ e B2E.

Em concordância com os achados deste estudo, Vichi et al. ${ }^{81}$, 2007, avaliaram a influência da espessura da camada na cor final de combinações de resinas de diferentes opacidades e tonalidades em laboratório, simulando a técnica de estratificação de duas camadas; e 
concluíram que a espessura da camada e a proporção das resinas translúcida e de dentina desempenham um papel significante na percepção da cor em restaurações de múltiplas camadas.

De acordo com estes dados verificou-se que a quarta hipótese testada neste estudo também não foi comprovada.

É válido destacar as limitações e dificuldades durante a realização deste experimento, dentre elas, especialmente, a dificuldade de manter a ponta ativa do equipamento na mesma posição para todas as referências das três escalas, pois elas são diferentes. Para isso, foi necessária a realização de muitas mensurações para a calibração prévia e para a fixação da sonda de leitura do espectrofotômetro Vita EasyShade ${ }^{\circledR}$ a um dispositivo metálico. Esta dificuldade reflete uma limitação da utilização de tais equipamentos em situações clínicas, o que provavelmente resultará em inúmeros erros de leitura. Apesar do nome, a utilização clínica diária desse espectrofotômetro deve ser feito de forma criteriosa, pois em muitas situações seus resultados simplesmente não poderão ser considerados devido às limitações do caso (superfícies não planas, rugosas, muito translúcidas, etc).

Considerando esta dificuldade relativa ao posicionamento da ponta ativa do espectrofotômetro Vita Easyshade ${ }^{\circledR}$ durante o procedimento de mensuração da cor, Douglas ${ }^{18}$ (1997), verificou que o colorímetro testado quando associado a um posicionador apresentou uma precisão aceitável para mensuração intra-oral da cor dental. 
Esta investigação, apesar de ter sido realizado in vitro e sob condições controladas, forneceu condições de orientar os cirurgiõesdentistas, estudantes de odontologia e protéticos sobre a importância da espessura da resina composta na cor final de uma restauração, sobre a influência da sua composição na cor, sobre a necessidade de se ter cautela quando da utilização de escalas para seleção da cor, visto que não há padronização destas escalas. É importante o treinamento e o conhecimento dos materiais e dos equipamentos utilizados para a obtenção de sucesso na correspondência de cor entre os materiais e a estrutura dental, pois ainda não existem ferramentas confiáveis para a seleção de cores.

Esta pesquisa forneceu também, dados importantes sobre qual dos materiais utilizados responde mais satisfatoriamente em termos de correspondência de cor quando da sua utilização, reduzindo as dificuldades durante a seleção de cores para restaurações dos dentes naturais. E permitiu ainda, que se realizem reflexões sobre o valor limite de $\Delta \mathrm{E}$ utilizado para determinar que nível de diferença seria visualmente perceptível e clinicamente aceitável.

Sugere-se a realização de novos estudos in vivo, que envolvam o maior número de fatores relacionados à etapa de seleção de cor.

Além disso, apesar de ser considerado o método padrão para estabelecer correspondência e diferença de cores, o cálculo do $\Delta \mathrm{E}$, por ser uma simplificação de três coordenadas espaciais em um único 
numero, o qual representa a quantidade da diferença entre duas cores, muitas vezes resulta em dados contraditórios, conflitantes e de difícil entendimento. Um exemplo disso seria a comparação de duas cores que têm a mesma luminosidade, o mesmo valor no eixo $a^{*}$ e valores opostos no eixo $b^{*}$ (positivo e negativo). Apesar de serem visível e fisicamente diferentes, quando comparadas pelo método proposto pelo ClELab, seu valor de $\Delta E$ resultaria em zero, ou seja, azul e amarelo seriam considerados iguais.

Outros métodos de avaliação de cores e sua correspondência, que considerem as características da multidimensionalidade da cor e suas interações precisam ser desenvolvidos e testados a fim de contribuir para uma melhor compreensão da cor e dos fatores que interferem com a correspondência entre as tonalidades dos materiais restauradores e a estrutura dental, objetivando garantir a previsibilidade de resultados e a simplificação de tais procedimentos. 


\section{Conclusão}




\section{CONCLUSÃO}

De acordo com a metodologia utilizada e com os resultados obtidos, concluiu-se que:

1) As escalas de cor Vita Classical, Vitapan 3D-Master e Chromascop não apresentam correspondência entre suas tonalidades, demonstrando apenas semelhança variada entre si;

2) Composição e propriedades ópticas interferem na correspondência de cor entre as resinas compostas 4 Seasons ${ }^{\circledR}$ e Filtek ${ }^{\mathrm{TM}}$ Supreme XT;

3) A resina nano-aglomerada Filtek ${ }^{T M}$ Supreme $X T$ apresentou maior correspondência de cor com as tonalidades A2E e B2E adotadas como referência para avaliação;

4) As espessuras de 1,2; 1,4; e 1,6 mm apresentaram maior correspondência de cor com as tonalidades A2E da escala de referência Vita Classical para ambos os materiais testados;

5) Nenhuma das espessuras dos corpos-de-prova da resina híbrida 4 Seasons ${ }^{\circledR}$ na tonalidade B2E apresentou correspondência com a escala Vita Classical;

6) $\mathrm{O}$ método empregado $(\Delta \mathrm{E})$ mostrou limitações para determinação da correspondência de cor em odontologia. 
Referências 


\section{REFERÊNCIAS *}

1. Anusavice KJ. In: Resinas para restauração. Phillips: Materiais dentários. 11.ed. Rio de Janeiro: Gunanabara Koogan; 1998. p.161-77.

2. Araujo EM. Fechamento de diastemas por meio de restaurações diretas de resina composta. Clínica - Int J Braz Dent. 2005; 1: 33958.

3. Ardu S, Feilzer AJ, Devigus A, Krejci I. Quantitative clinical evaluation of esthetic properties of incisors. Dent Mater. 2008; 24 : 333-40.

4. Azzopard N, Moharamzadeh K, Wood DJ, Martin N, Van Noort R. Effect of resin matrix composition on the translucency of experimental dental composite resins. Dent Mater. 2009; 25: 15648.

5. Barna GJ, Taylor JW, King GE, Pellue GB Jr. The influence of selected light intensities on color perception within the color range of natural teeth. J Prosthet Dent.1981; 46: 450-3.

6. Billmeyer FW, Saltzman M. Principles of color technology. New York: John Wiley \& Sons; 1981.

7. Buchala W, Attin T, Hilgers RD, Hellwig E. The effect of water storage and light exposure on the color and translucency of a hybrid and a mycrofilled composite. J Prosthet Dent. 2002; 87: 26470.

8. Cal E, Guneri P, Kose T. Comparison of digital and spectrofotmetric measurements of colour shade guides. J Oral Rehabil. 2006; 33: 221-8.

9. Chu SJ, Devigus A, Mieleszco A. Fundamentals of color - shade matching and communication in esthetic dentistry. New York: Quintessence; 2004.

10. Clarke FJJ. Measurement of the color of the human teeth. In: Dental ceramics: proceedings of the first international symposium on ceramics. New York: Quintessence; 1983. p.441-89.

\footnotetext{
* De acordo com o estilo Vancouver. Disponível no site: http:// www.nlm.nih.gov/bsd/uniform requirements.html
} 
11. Commission Internationale de l'Eclairage (CIE). Colorimetry technical report. 3rd ed. Vienna: Bureau Central de La CIE; 2004.

CIE Pub. no.15.

12. Corciolani G, Vichi A. Repeatability of colour reading with a clinical and a laboratory spectrophotometer. Int Dent South Afr. 2006; 8: 62-70.

13. Corciolani G, Vichi A, Goracci C, Ferrari M. Colour correspondence of a ceramic system in two different shade guides. J Dent. 2009; 37: 98-101.

14. Culpepper WD. A comparative study of shade-matching procedures. J Prosthet Dent. 1970; 24: 166-74.

15. Dahl JE, Pallesen U. Tooth bleaching - a critical review of the biological aspects. Crit Rev Oral Biol Med. 2003; 14: 292-304.

16. Dancy WK, Yaman P, Dennison JB, O'Brien WJ, Razzoog ME. Color measurements as quality criteria for clinical shade matching of porcelain crowns. J Esthet Restor Dent. 2003; 15: 114-21.

17. Della Bona A, Barret AA, Rosa V, Pinzetta C. Visual and instrumental agreement in dental shade matching protocols. Dent Mater. 2009; 25: 276-81.

18. Douglas RD. Precision of in vivo colorimetric assessment of teeth. $J$ Prosthet Dent. 1997; 77: 464-70.

19. Douglas RD, Brewer JD. Acceptability of shade differences in metal ceramic crows. J Prosthet Dent. 1998; 79: 254-60.

20. Douglas RD, Steinhauer TJ, Wee AG. Intraoral determination of the tolerance of dentists for perceptibility and acceptability of shade mismatch. J Prosthet Dent. 2007; 97: 200-8.

21. Dozic' A, Kleverlaan CJ, Meegdes M, Zel JVD, Feilzer AJ. The influence of porcelain layer thickness on the final shade of ceramic restorations. J Prosthet Dent. 2003; 90: 563-70.

22. Dozic' A, Kleverlaan CJ, El-Zohairy A, Feilzer AJ, Khashayar G. Performance of Five commercial available tooth color-measuring devices. J Prosthodont. 2007; 16: 93-100. 
23. Ferracane JL, Moser JB, Greener EH. Ultraviolet light-induced yellowing of dental restorative resins. J Prosthet Dent. 1985; 54: 483-7.

24. Ferreira D, Monard LA. Measurement of spectral reflectance and colorimetric properties of vita shade guides. J Dent Assoc South Afr. 1991; 46: 63-5.

25. Foldriest J. Shade matching in restorative dentistry: the science and strategies. Int J Periodont Restor Dent. 2003; 23: 467-79.

26. Glary JL, Kinirons MJ. Use of a commom shade guide to test the perception of differences in the shades and value by members of the dental team. Prim Dent Care. 1999; 6: 107-10.

27. Haas NAT, Silveira JLGC. A evolução dos sistemas de acabamento e polimento em resinas compostas. JBC 2002; 6: 504-6.

28. Hammad IA. Intrarater repeatability of shade selections with two shade guides. J Prosthet Dent. 2003; 89: 50-3.

29. Hasegawa A, Ikeda I, Kawaguchi S. Color and translucency of in vivo natural central incisors. J Prosthet Dent. 2000; 83: 418-23.

30. Hassel AJ, Koke U, Schimitter M, Beck J, Rammelsberg P. Clinical effect of different shade guide systems on the tooth shades of ceramic-veneered restorations. Int J Prosthodont. 2005; 18: 422-6.

31. Horn DJ, Bulan-Brady J, Hicks ML. Sphere spectrophotometer versus human evaluation oh tooth shade. J Endod. 1998; 24: 78690.

32. Hunter RS. The measurement of appearance. New York: John \& Sons; 1975. p.3-74.

33. Ishigawa-Nagai S, Ishibashi K, Tsuruta O, Weber HP. Reproducibility of tooth color gradation using a computer colormatching technique applied to ceramic restorations. J Prosthet Dent. 2005; 93: 129-37.

34. Jarad FD, Moss BW, Youngson CC, Russel MD. The effect of enamel porcelain thickness on color and the ability of a shade guide to prescribe chroma. Dent Mater. 2007; 23: 454-60. 
35. Jarad FD, Griffiths CE, Jaffri M, Adeyemi AA, Youngson CC. The effect of bleaching, varying the shade or thickness of composite veneers on final colour: an in vitro study. J Dent. 2008; 36: 554-9.

36. Johnston WM, Kao EC. Assessment of appearance match by visual observation and clinical colorimetry. J Dent Res. 1989; 68: 819-22.

37. Joiner A. Tooth colour: a review of the literature. J Dent. 2004; 32 (Suppl 1): 3-12.

38. Joiner A. The bleaching of teeth: a review of the literature. J Dent. 2006; 34: 412-9.

39. Karamouzos A, Papadopoulus MA, Kolokitha SG, Athanasiou AE. Precision of in vivo spectrophotometric colour evaluation of natural teeth. J Oral Rehabil. 2007; 34: 613-21.

40. Kim S, Lee Y. Changes in color coordinates of an indirect resin composite during curing cycle. J Dent. 2008; 36: 337-42.

41. Kim-Pulsateri S, Brewer JD, Dunford RG, Wee AG. In vitro model to evaluate reliability and accuracy of a dental shade-matching instrument. J Prosthet Dent. 2007; 98: 353-8.

42. Kim B, Lee $Y$. Influence of the shade designation on the color difference between the same shade-designated resin composites by the brand. Dent Mater. 2009; 25: 1148-54.

43. Kim B, Yu B, Lee Y. Influence of surface layer removal of shade guide tabs on the measured color by spectrophotometer and spectroradiometer. J Dent. 2008; 36:1061-7.

44. Klemetti E, Matela AM, Haag P, Kononen M. Shade selection performed by novice dental professionals and colorimeter. J Oral Rehabil. 2006; 33: 31-5.

45. Lagouvardos PE, Diamanti $H$, Polyzois G. Effect of individual shades on reliability and validity of observers in color matching. Euro J Prosthodont Restor Dent. 2004; 12: 51-6.

46. Lagouvardos PE, Fougia AG, Diamantopoulou AS, Polyzois GL. Repeatibility and intervice reliability of two portable color selection devices in matching and measuring tooth color. J Prosthet Dent. 2009; 101: 40-5. 
47. Lee $\mathrm{Y}$. Influence of scattering/absorption characteristics on the color of resin composites. Dent Mater. 2007; 23: 124-31.

48. Lee Y, Lim BS, Kim CW. Difference in the color and color change of dental resin composites by the background. J Oral Rehabil. 2005; 32: 227-33.

49. Li Q, Wang YN. Comparison of shade matching by visual observation and an intraoral dental colorimeter. J Oral Rehabil. 2007; 34: 848-54.

50. Li Q, Yu H, Wang YN. Spectrophotometric evaluation of the optical influence of core build-up composites on all-ceramic materials. Dent Mater. 2009; 25:158-65.

51. Lim Y, Lee $Y$, Lim B, Rhee S, Yang H. Influence of filler distribution on the color parameters of experimental resin composites. Dent Mater. 2008; 24: 67-73.

52. Manual de Instrução do espectrofotômetro Vita Easyshade ${ }^{\circledR}$ Disponível em: HTTP://www.vita-zahnfabrik.com [citado 2009 mar 9].

53. Masotti AS, Onófrio AB, Conceição EN, Spohr AM. UV-vis spectrophotometric direct transmittance analysis of composite resins. Dent Mater. 2007; 23: 724-30.

54. Meireles SS, Demarco FF, Santos IS, Dumith SC, Della Bona A. Validation and reliability of visual assessment with a shade guide for tooth-color classification. Oper Dent. 2008; 33: 121-6.

55. Mitra SB, Wu D, Holmes BN. Uma aplicação da nanotecnologia no avanço dos materiais odontológicos. JADA-Brasil. 2003; 6: 351-8.

56. Monsenego G, Burdairon G. Fluorescence of dental porcelain. Prosthet Dent. 1993; 69(1): 106-13.

57. O'Brien WJ, Boenke KM, Groh CL. Coverage errors of two shade guides. Int J Prosthodont. 1991; 4: 45-50.

58. Okubo S.R, Kanawati A, Richards MW, Childress S. Evaluation of visual and instrument shade matching. J Prosthet Dent. 1998; 80: 642-8.

59. Paravina RD, Powers JM, Fay RM. Dental color standarts: shade tab arrangement. J Esthet Restor Dent. 2001; 13: 254-63. 
60. Paravina R, Stankovic' D, Aleksov L, Mladenovic' D, Ristic' K. Problems in standard shade matching and reproduction procedure in dentistry: a review of the state of the art. Facta Universitatis. 1997; 4: 12-6.

61. Park J, Lee Y, Lim B. Influence of illuminants on the color distribution of shade guides. J Prosthet Dent. 2006; 96: 402-11.

62. Paul SJ, Peter A, Pietrobon N, Hammerle CH. Visual and spectrophotometric shade analysis of human teeth. J Dent Res. 2002; 81: 578-82.

63. Paul SJ, Peter A, Rodoni L, Pietrobon N. Conventional visual VS spectrophotometric shade taking for porcelain-fused-to-metal crowns: a clinical comparison. Int J Periodont Restor Dent. 2004; 24: 222-31.

64. Pedrini D, Jardim OS, Poi WR. Transformação de dente conóide e fechamento de diastema em clínica geral. Rev FOL 2000; 12: 52-6.

65. Portero PP, Florez FLE, Fagundes TC, Ditterich RG, Oliveira-Júnior OB. Avaliação de escalas de cores por meio de espectroscopia de reflectância. In: Anais da 25a. Reunião da Sociedade Brasileira de Pesquisa Odontológica - SBPqO; ago. 2008; Águas de Lindóia (SP). São Paulo: SBPqO; 2008. p. 224.

66. Powers JM, Dennison JB, Lepeak PJ. Parameters that affect the color of direct restorative resins. J Dent Res. 1978; 57: 876-80.

67. Preston JD. Current status of shade selection and color matching. Quintessence Int. 1985; 16: 47-58.

68. Russel MD, Gulfraz M, Moss BW. In vivo measurement of colour changes in natural teeth. J Oral Rehabil. 2000; 27: 786-92.

69. Ruyter IE, Nilner K, Moller B. Color stability of dental composite resin materials for crown and bridge veneers. Dent Mater. 1987; 3 : 246-51.

70. Santos GB, Monte Alto RV, Sampaio Filho HR, da Silva EM, Fellows CE. Light transmission on dental resin composites. Dent Mater. 2008; 24: 571-6. 
71. Schwabacher WB, Goodkind RJ. Three-dimensional color coordinates of natural teeth compared with three shade guides. J Prosthet Dent. 1990; 64: 425-34.

72. Shidhu SK, Ikeda T, Omata Y, Fujita M, Sano H. Change of color and translucency by light curing in resin composites. Oper Dent. 2006; 31: 598-603.

73. Shintani H, Satou J, Satou N, Hayashihara H, Inoue T. Effects of various finishing methods on staining and accumulation of Streptococcus mutans H.S-6 on composite resins. Dent Mater. 1985; 1: 225-7.

74. Shokry TA, Shen C, Elhosary MM, Elkhodary AM. Effect of core and veneer thickness on the color parameters of two all-ceramic systems. J Prosthet Dent. 2006; 95: 124-9.

75. Silva JD, Park SE, Weber H, Ishikawa-Nagai S. Clinical performance of a newly developed spectrophotometric system on tooth color reproduction. J Prosthet Dent. 2008; 99: 361-8.

76. Silva RCSP, Araújo MAM. Avaliação da rugosidade superficial de restaurações estéticas e do esmalte adjacente após o uso de diferentes instrumentos rotatórios de acabamento e polimento. Rev. Odontol. UNESP 1998; 27: 131-49.

77. Sproull RC. Color matching in dentistry. Part I. The threedimensional nature of color. J Prosthet Dent. 2001; 86: 453-7.

78. Tung FF, Goldstein GR, Jang S, Hittelman E. The repeatability of an intraoral dental colorimeter. J Prosthet Dent. 2002; 88: 585-90.

79. Van der Burgt, Bosh JJ, Borsboom PC, Kortsmit WJ. A comparison of new and conventional methods for qualification of tooth color. $J$ Prosthet Dent. 1990; 63: 155-62.

80. Vichi A, Ferrari M, Davidson CL. Influence of ceramic and cement thickness on the masking of various types of opaque posts. J Prosthet Dent. 2000; 83: 412-7.

81. Vichi A, Fraioli A, Davidson CL, Ferrari M. Influence of thickness on color in multi-layering technique. Dent Mater. 2007; 23: 1584-9.

82. Walsh TF, Rawlinson A, Wildgoose D, Marlow I, Haywood J, Ward JM. Clinical evaluation of the stain removing ability of a whitening dentifrice and stain controlling system. J Dent. 2005; 33: 413-8. 
83. Watts A, Addy M. Tooth discolouration and stainning: a review of the literature. Br Dent J. 2001; 190: 309-16.

84. Yuan JC, Brewer JD, Monaco EA, Davis EL. Defining a natural tooth color space based on a 3-dimensional shade system. J Prosthet Dent. 2007; 98: 110-9.

85. Yu B, Lee Y. Differences in color, translucency and fluorescence between flowable and universal resin composites. J Dent. 2008; 36: 840-6. 
Autorizo a reprodução deste trabalho.

(Direitos de publicação reservado ao autor)

Araraquara, 26 de abril de 2010.

Priscila Paiva Portero 